Cochrane Database of Systematic Reviews

\title{
Vena caval filters for the prevention of pulmonary embolism
} (Review)

Young T, Sriram KB

Young T, Sriram KB.

Vena caval filters for the prevention of pulmonary embolism.

Cochrane Database of Systematic Reviews 2020, Issue 10. Art. No.: CD006212.

DOI: 10.1002/14651858.CD006212.pub5.

www.cochranelibrary.com 
TABLE OF CONTENTS

HEADER 1

ABSTRACT

PLAIN LANGUAGE SUMMARY

SUMMARY OF FINDINGS

BACKGROUND

OBJECTIVES

METHODS

RESULTS

Figure 1.

Figure 2.

Figure 3.

Figure 4.

Figure 5.

DISCUSSION

AUTHORS' CONCLUSIONS

ACKNOWLEDGEMENTS

REFERENCES

CHARACTERISTICS OF STUDIES

DATA AND ANALYSES

Analysis 1.1. Comparison 1: Anticoagulation +/-VCF in people at high risk of recurrent PE, Outcome 1: PE

Analysis 1.2. Comparison 1: Anticoagulation $+/-V C F$ in people at high risk of recurrent PE, Outcome 2: Mortality

Analysis 1.3. Comparison 1: Anticoagulation +/-VCF in people at high risk of recurrent PE, Outcome 3: Lower limb thrombosis .

Analysis 1.4. Comparison 1: Anticoagulation +/- VCF in people at high risk of recurrent PE, Outcome 4: Major bleeding

Analysis 2.1. Comparison 2: Anticoagulation $+/-$ VCF in people after multiple trauma, Outcome 1: PE

Analysis 2.2. Comparison 2: Anticoagulation $+/-$ VCF in people after multiple trauma, Outcome 2: Mortality

Analysis 2.3. Comparison 2: Anticoagulation + - VCF in people after multiple trauma, Outcome 3: Lower limb thrombosis .......

Analysis 2.4. Comparison 2: Anticoagulation +/- VCF in people after multiple trauma, Outcome 4: Major bleeding

Analysis 2.5. Comparison 2: Anticoagulation +/-VCF in people after multiple trauma, Outcome 5: Non major bleeding ............ ADDITIONAL TABLES

APPENDICES

WHAT'S NEW

HISTORY

CONTRIBUTIONS OF AUTHORS

DECLARATIONS OF INTEREST

SOURCES OF SUPPORT

DIFFERENCES BETWEEN PROTOCOL AND REVIEW

INDEX TERMS 
[Intervention Review]

\section{Vena caval filters for the prevention of pulmonary embolism}

Tim Young1, Krishna Bajee Sriram²

1Department of Medicine, Gold Coast University Hospital, Southport, Australia. 2Department of Respiratory Medicine, Gold Coast

University Hospital, Southport, Australia

Contact address: Tim Young, timothy.young@health.qld.gov.au.

Editorial group: Cochrane Vascular Group.

Publication status and date: New search for studies and content updated (no change to conclusions), published in Issue 10, 2020.

Citation: Young T, Sriram KB. Vena caval filters for the prevention of pulmonary embolism. Cochrane Database of Systematic Reviews 2020, Issue 10. Art. No.: CD006212. DOI: 10.1002/14651858.CD006212.pub5.

Copyright @ 2020 The Cochrane Collaboration. Published by John Wiley \& Sons, Ltd.

\section{A B S T R A C T}

\section{Background}

Pulmonary emboli (PE), or blood clots in the lungs, can be potentially fatal. Anticoagulation is the first line therapy to prevent PE. In some instances anticoagulation fails to prevent more emboli, or cannot be given because the person has a high risk of bleeding. Inferior vena caval filters (VCFs) are metal alloy devices that mechanically trap fragmented emboli from the deep leg veins en route to the pulmonary circulation. Retrievable filters are designed to be introduced and removed percutaneously. Although their deployment seems of theoretical benefit, their clinical efficacy and adverse event profile is unclear. This is the third update of a Cochrane Review first published in 2007.

\section{Objectives}

To assess the evidence for the effectiveness and safety of vena caval filters (VCFs) in preventing pulmonary embolism (PE).

\section{Search methods}

For this review update, the Cochrane Vascular Information Specialist (CIS) searched the Specialised Register (last searched 10 September 2019) and the Cochrane Register of Controlled Trials (CENTRAL) (2019, Issue 8) via the Cochrane Register of Studies Online. The CIS also searched MEDLINE Ovid, EMBASE Ovid, CINAHL, and AMED (1 January 2017 to 10 September 2019) and trials registries to 10 September 2019.

\section{Selection criteria}

We included randomised controlled trials (RCTs) and controlled clinical trials (CCTs) that examined the efficacy of VCFs in preventing PE.

\section{Data collection and analysis}

For this update, studies were assessed and data extracted independently. We assessed study quality with Cochrane's 'Risk of bias' tool and used the GRADE approach to assess the overall certainty of the evidence. The outcomes of interest were PE, mortality, lower limb venous thrombosis, filter-related complications and major bleeding.

\section{Main results}

We identified four new studies for this update, bringing the total to six included studies involving 1388 participants. The six studies were clinically heterogeneous and we were unable to carry out meta-analysis. Only two studies were considered to be both applicable in current clinical settings and of good methodological quality.

One was a randomised open-label trial studying the effect of a retrievable inferior vena caval filter plus anticoagulation versus anticoagulation alone on risk of recurrent pulmonary embolism (PE) in 399 participants over three months. There was no evidence of a difference in the rates of PE, death, lower extremity deep vein thrombosis (DVT), or bleeding at three and six months after the 
intervention (moderate-certainty evidence). A filter was inserted in 193 people, but could only be successfully retrieved from 153. Minor filter complications were noted at six months.

The second clinically relevant study was a randomised open-label trial of 240 participants who had sustained multiple traumatic injuries, allocated to a filter or no filter, three days after injury, in conjunction with anticoagulation and intermittent pneumatic compression. Prophylactic anticoagulation was initiated in both groups when it was thought safe to do so. There was no evidence of a difference in symptomatic PE, death, or lower limb venous thrombosis rates (moderate-certainty evidence). The only major filter complication was that one person required surgical removal of the filter.

We are unable to draw any conclusions from the remaining four included studies. One study showed an increased incidence of long-term lower extremity DVT at eight years. Three studies are no longer clinically applicable because they utilised permanent filters which are seldom used now, or they did not use routine prophylactic anticoagulation which is current standard practice. The fourth study compared two filter types and was terminated prematurely as one filter group had a higher rate of thrombosis compared to the other filter type.

\section{Authors' conclusions}

Two of the six identified studies were relevant for current clinical settings. One showed no evidence of a benefit of retrievable filters in acute PE for the outcomes of PE, death, DVT and bleeding during the initial three months in people who can receive anticoagulation (moderatecertainty evidence). The other study did not show any benefit for prophylactic filter insertion in people who sustained multiple traumatic injuries, with respect to symptomatic PE, mortality, or lower extremity venous thrombosis (moderate-certainty evidence). We can draw no firm conclusions regarding filter efficacy in the prevention of PE from the remaining four RCTs identified in this review. Further trials are needed to assess vena caval filter effectiveness and safety, and clinical differences between various filter types.

\section{PLAIN LANGUAGE SUMMARY}

\section{Vena caval filters for the prevention of pulmonary embolism}

\section{Background}

Blood clots in the lungs are called pulmonary emboli. They commonly originate in the leg or pelvic veins, where they can fragment and travel to the lungs via the inferior vena cava (IVC, large vein which carries blood from the lower body to the heart). Further emboli are usually prevented by blood thinning medications (anticoagulants). In some instances (approximately $4 \%$ of cases), anticoagulation fails, or it is too dangerous to give anticoagulation.

Vena caval filters are metal alloy devices inserted within the IVC to trap blood clots. Modern filters are 'retrievable,' allowing their removal once they are no longer required. However, a number of retrievable filters are not removed. The long-term safety profile of these devices is not known. The aim of this review was to assess the effectiveness and safety of vena caval filters. The review authors looked for studies comparing filters with no filter, and studies comparing different filter designs.

\section{Study characteristics and key results}

We included six trials with a total of 1388 participants in the review (current until 10 September 2019). There were too many differences between these studies so we could not combine the results.

Two trials were applicable in current clinical settings. One trial showed there is no clear benefit in receiving a retrievable filter for the first three months after an acute PE, for those who can receive anticoagulation, in terms of recurrent pulmonary embolism (PE), deep vein thrombosis (DVT), death or bleeding. Not all filters could be removed. Only minor complications from the filters were noted at six months.

Another study of people who had sustained multiple traumatic injuries did not show any benefit of inserting a filter three days after injury to prevent PE, or reduce deaths. Preventive anticoagulation and calf compression devices were administered to participants when possible.

We are unable to draw any conclusions from the remaining four included studies. This is because three studies are no longer clinically relevant because they utilised permanent filters which are seldom used now, or they did not use routine preventative anticoagulation which is current standard practice. One study showed an increased rate of lower-extremity DVT in the permanent filter group. The fourth study compared two filter types and was stopped prematurely and thus did not generate sufficient data.

\section{Reliability of the evidence}

Two studies were relevant in current clinical contexts. The evidence presented by both of these studies is of moderate certainty. We reached this assessment because we were not able to combine the data from the studies, and because of the low numbers of participants and events involved. The studies differed in type of participants and clinical situations. There is a further need for trials evaluating the effectiveness of caval filters in people who cannot receive anticoagulation, or when PE occurs despite adequate anticoagulation. 
SUMMARY OF FINDINGS

\section{Summary of findings 1 . Retrievable vena caval filters with anticoagulation compared to anticoagulation for prevention of PE}

Does the use of vena caval filters prevent PE?

Patient or population: participants with unprovoked acute symptomatic PE and at high risk for recurrent PE $a$

\section{Settings: hospital}

Intervention: retrievable VCF (with anticoagulation)

Comparison: no VCF (anticoagulation alone)

\begin{tabular}{|c|c|c|c|c|c|c|}
\hline \multirow[t]{2}{*}{ Outcomes } & \multicolumn{2}{|c|}{$\begin{array}{l}\text { Anticipated absolute } \\
\text { effects }^{\star}(95 \% \mathrm{Cl})\end{array}$} & \multirow{2}{*}{$\begin{array}{l}\text { Relative } \\
\text { effect } \\
(95 \% \mathrm{CI})\end{array}$} & \multirow{2}{*}{$\begin{array}{l}\text { No of } \\
\text { Partici- } \\
\text { pants } \\
\text { (RCTs) }\end{array}$} & \multirow{2}{*}{$\begin{array}{l}\text { Certain- } \\
\text { ty of } \\
\text { the evi- } \\
\text { dence } \\
\text { (GRADE) }\end{array}$} & \multirow[t]{2}{*}{ Comments } \\
\hline & $\begin{array}{l}\text { Risk } \\
\text { with no } \\
\text { VCF and } \\
\text { antico- } \\
\text { agula- } \\
\text { tion }\end{array}$ & $\begin{array}{l}\text { Risk with } \\
\text { retrievable } \\
\text { VCF and an- } \\
\text { ticoagula- } \\
\text { tion }\end{array}$ & & & & \\
\hline $\begin{array}{l}\text { PE: recurrent fatal and non-fa- } \\
\text { tal PE, demonstrated by CT, pul- } \\
\text { monary angiography or ventila- } \\
\text { tion-perfusion lung scan } \\
\text { (up to } 6 \text { months) }\end{array}$ & $\begin{array}{l}20 \text { per } \\
1000\end{array}$ & $\begin{array}{l}35 \text { per } 1000 \\
(10 \text { to } 118)\end{array}$ & $\begin{array}{l}\text { RR } 1.74 \\
(0.52 \text { to } \\
5.86)\end{array}$ & $\begin{array}{l}399 \\
(1)\end{array}$ & $\begin{array}{l}\oplus \oplus \oplus \ominus \\
\text { moder- } \\
\text { ateb }^{b}\end{array}$ & $\begin{array}{l}\text { There was no clear difference between the VCF and no VCF group in } \\
\text { the number of recurrent PE detected; all participants received anti- } \\
\text { coagulation. }\end{array}$ \\
\hline $\begin{array}{l}\text { Mortality } \\
\text { (up to } 6 \text { months) }\end{array}$ & $\begin{array}{l}75 \text { per } \\
1000\end{array}$ & $\begin{array}{l}105 \text { per } 1000 \\
(56 \text { to } 197)\end{array}$ & $\begin{array}{l}\text { RR } 1.39 \\
(0.74 \text { to } \\
2.62)\end{array}$ & $\begin{array}{l}399 \\
(1)\end{array}$ & $\begin{array}{l}\oplus \oplus \oplus \ominus \\
\text { moder- } \\
\text { ateb }^{b}\end{array}$ & $\begin{array}{l}\text { There was no clear difference in mortality between the VCF and no } \\
\text { VCF group; all participants received anticoagulation. }\end{array}$ \\
\hline $\begin{array}{l}\text { Symtomatic lower extremity ve- } \\
\text { nous thrombosis } \\
\text { confirmed by Doppler ultrasound } \\
\text { or venography } \\
\text { (up to } 6 \text { months) }\end{array}$ & $\begin{array}{l}10 \text { per } \\
1000\end{array}$ & $\begin{array}{l}5 \text { per } 1000 \\
(1 \text { to } 55)\end{array}$ & $\begin{array}{l}\text { RR } 0.50 \\
(0.05 \text { to } \\
5.44)\end{array}$ & $\begin{array}{l}399 \\
(1)\end{array}$ & $\begin{array}{l}\oplus \oplus \oplus \ominus \\
\text { moder- } \\
\text { ateb }^{b}\end{array}$ & $\begin{array}{l}\text { There was no clear difference between the VCF and no VCF group in } \\
\text { the number of lower limb venous thrombosis detected; all partici- } \\
\text { pants received anticoagulation. }\end{array}$ \\
\hline
\end{tabular}

Filter-related complications

Filter-related complications were not assessed in PREPIC2. It was reported that only 153/193 VCF could be removed. 


\begin{tabular}{|c|c|c|c|c|c|c|}
\hline $\begin{array}{l}\text { Major bleedingc } \\
\text { (up to } 6 \text { months) }\end{array}$ & $\begin{array}{l}75 \text { per } \\
1000\end{array}$ & $\begin{array}{l}65 \text { per } 1000 \\
\text { (32 to } 133)\end{array}$ & $\begin{array}{l}\text { RR } 0.86 \\
(0.42 \text { to } \\
1.77)\end{array}$ & $\begin{array}{l}399 \\
(1)\end{array}$ & $\begin{array}{l}\oplus \oplus \oplus \ominus \\
\text { moder- } \\
\text { ate }^{b}\end{array}$ & $\begin{array}{l}\text { There was no clear difference in major bleeding between the VCF } \\
\text { and no VCF group; all participants received anticoagulation. }\end{array}$ \\
\hline
\end{tabular}

${ }^{*}$ The risk in the intervention group (and its $95 \%$ confidence interval) is based on the assumed risk in the comparison group and the relative effect of the intervention (and its $95 \% \mathrm{Cl})$.

Cl: confidence interval; $\mathbf{C T}$ : computer tomography; RCTs: randomised controlled trials; RR: risk ratio; VCF: vena caval filter

\section{GRADE Working Group grades of evidence}

High certainty: we are very confident that the true effect lies close to that of the estimate of the effect

Moderate certainty: we are moderately confident in the effect estimate: the true effect is likely to be close to the estimate of the effect, but there is a possibility that it is substantially different

Low certainty: our confidence in the effect estimate is limited: the true effect may be substantially different from the estimate of the effect

Very low certainty: we have very little confidence in the effect estimate: the true effect is likely to be substantially different from the estimate of effect

a This population was reported by PREPIC2. All participants also received anticoagulation.

b We downgraded certainty by one step due to some imprecision and risk of bias concerns (low numbers of events and open-label study design).

c Major bleeding was defined as bleeding that contributed to death; occurred at a critical site (e.g. intracranial, intraspinal, epidural, or lung haemorrhage); led to transfusion of 2 or more units of red cells, platelets, or fresh frozen plasma; or was associated with a decrease in the haemoglobin level of more than 2 grams per decilitre within any 24 hour period after injury (Schulman 2005).

\section{Summary of findings 2. Retrievable vena caval filters with anticoagulation compared to anticoagulation for prevention of PE following multiple} traumatic injuries

Does the use of vena caval filters prevent PE in people who have sustained multiple trauma?

Patient or population: participants who sustained multiple traumatic injuries ${ }^{a}$

\section{Settings: hospital}

Intervention: retrievable VCF (with anticoagulation and IPC) ${ }^{\mathrm{b}}$

Comparison: no VCF (with anticoagulation and IPC)

\begin{tabular}{|c|c|c|c|c|c|c|}
\hline \multirow[t]{2}{*}{ Outcomes } & \multicolumn{2}{|c|}{$\begin{array}{l}\text { Anticipated absolute } \\
\text { effects }^{\star}(95 \% \mathrm{CI})\end{array}$} & \multirow{2}{*}{$\begin{array}{l}\text { Relative } \\
\text { risk } \\
(95 \% \mathrm{CI})\end{array}$} & \multirow{2}{*}{$\begin{array}{l}\text { No of } \\
\text { Partici- } \\
\text { pants } \\
\text { (RCTs) }\end{array}$} & \multirow{2}{*}{$\begin{array}{l}\text { Certain- } \\
\text { ty of } \\
\text { the evi- } \\
\text { dence } \\
\text { (GRADE) }\end{array}$} & \multirow[t]{2}{*}{ Comments } \\
\hline & $\begin{array}{l}\text { Risk } \\
\text { with } \\
\text { no VCF, } \\
\text { with an- }\end{array}$ & $\begin{array}{l}\text { Risk with } \\
\text { VCF, with } \\
\text { anticoag- }\end{array}$ & & & & \\
\hline
\end{tabular}




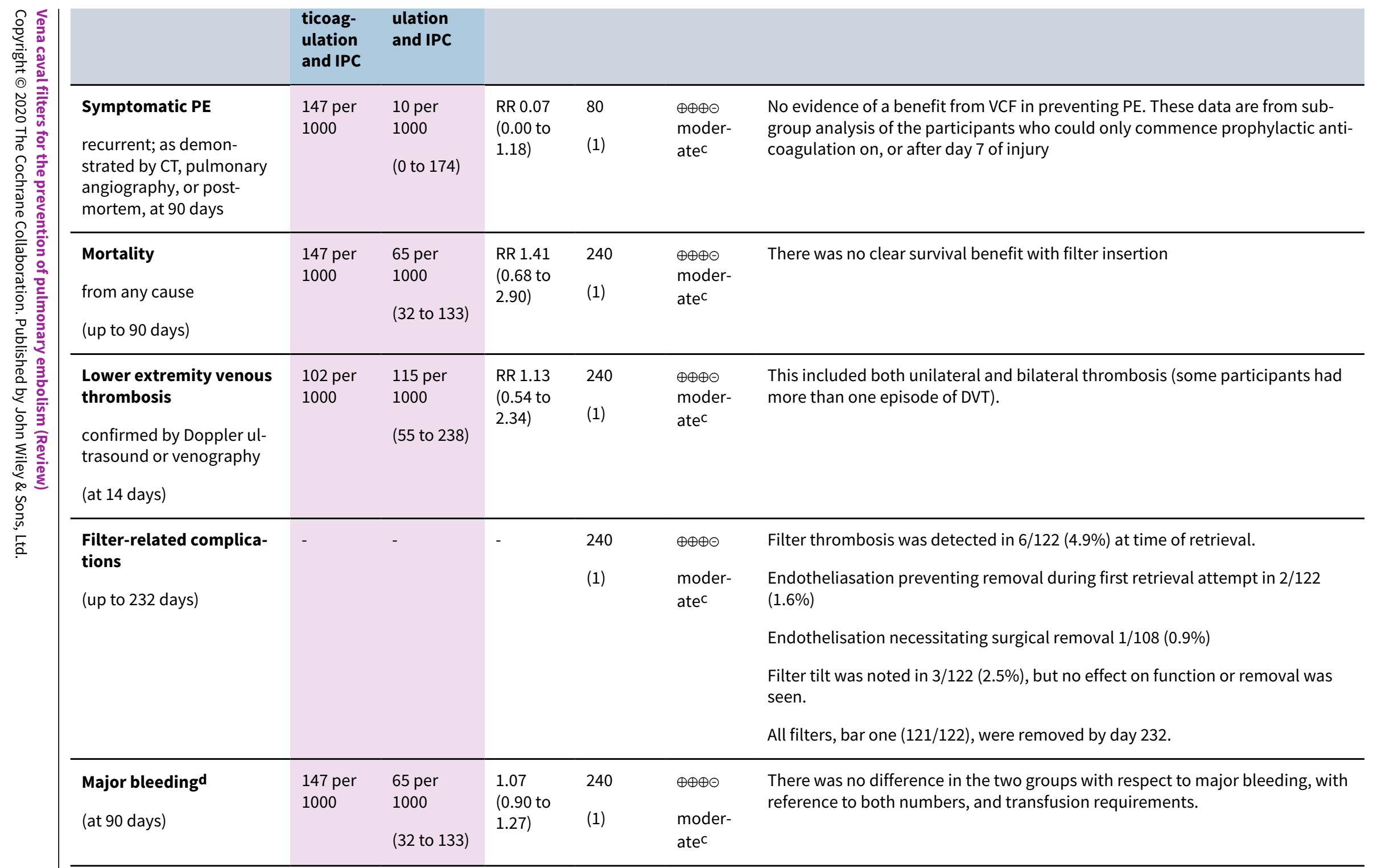

${ }^{\star}$ The risk in the intervention group (and its $95 \%$ confidence interval) is based on the assumed risk in the comparison group and the relative effect of the intervention (and its $95 \% \mathrm{Cl})$.

Cl: confidence interval; DVT: deep vein thrombosis; CT: computer tomography; IPC: intermittent pneumatic compression; RCTs: randomised controlled trials; RR: risk ratio; VCF: vena caval filter 
High certainty: we are very confident that the true effect lies close to that of the estimate of the effect

Moderate certainty: we are moderately confident in the effect estimate: the true effect is likely to be close to the estimate of the effect, but there is a possibility that it is substantially different

Low certainty: our confidence in the effect estimate is limited: the true effect may be substantially different from the estimate of the effect

Very low certainty: we have very little confidence in the effect estimate: the true effect is likely to be substantially different from the estimate of effect

a This population was investigated only by Ho 2019.

b Retrievable VCF were inserted between days 3 to 6 , or day 7+; all participants also received anticoagulation and IPC. The no VCF group received anticoagulation and IPC.

c We downgraded quality by one step due to some imprecision and risk of bias concerns (low numbers of events and open-label study design).

d Major bleeding was defined as bleeding that contributed to death; occurred at a critical site (e.g. intracranial, intraspinal, epidural, or lung haemorrhage); led to transfusion of

2 or more units of red cells, platelets, or fresh frozen plasma; or was associated with a decrease in the haemoglobin level of more than 2 grams per decilitre within any 24 hour period after injury (Schulman 2005). 


\section{B A C K G R O U N D}

\section{Description of the condition}

Blood clots can form anywhere in the venous circulation, but most commonly occur in the lower extremities (thigh) and pelvis. Blood clots or deep venous thrombosis (DVT) can occur under a number of different circumstances. Prolonged immobility, recent surgery, trauma, pregnancy, and oestrogen therapy are some of the temporary circumstances that make people vulnerable to blood clots or DVT. Having cancer (early or advanced stages) or an inherited hypercoagulable tendency are two of the longer-term conditions that make people vulnerable.

Deep vein thrombi can fragment and travel through the venous system to the lungs, causing pulmonary embolism (PE). The major conduit of venous drainage from the lower half of the body is the inferior vena cava. The clot(s) can detach and migrate through the vena cavae, through the right side of the heart and into the lung circulation. Large clots may lodge in the bifurcation between the right and left pulmonary (lung) arteries, resulting in haemodynamic compromise or collapse, or even death. Smaller clots travel to the pulmonary arterial branches, and the person may experience chest pain and breathlessness, and cough up blood.

Deep vein thrombi that extend into the thigh or pelvis are more likely to embolise than those that do not extend beyond the calf. Case series data indicate a rate between $27 \%$ to $60 \%$ for the risk of embolism if the clot is situated either within the inferior vena cava or the thigh or pelvic veins (Norris 1985; Radomski 1987).

Deep vein thrombi can also occur in the upper extremity (arm) and neck. They can embolise to the heart and lungs via the superior vena cava.

The current treatment for pulmonary embolism is anticoagulation (heparin, vitamin $\mathrm{K}$ antagonists (warfarin, coumadin), as well as the newer direct oral anticoagulants (apixaban, dabigatran, edoxaban, rivoraxaban). Infrequently, recurrent pulmonary emboli can occur despite therapeutic levels of anticoagulation; Douketis suggested a rate of $3.8 \%$ in a systematic review of the literature (Douketis 1998).

\section{Description of the intervention}

The concept of caval interruption emerged as early as the 18th century. Physicians performed the first successful surgical vena caval ligation (complete occlusion of the vena cava with sutures or external clips) in 1893. It required general anaesthesia and abdominal surgery, and was associated with considerable mortality. Anticoagulation became the mainstay of treatment in the 1950 s. By the $1960 \mathrm{~s}$, vena caval ligation carried an operative mortality risk of $14 \%$, and pulmonary embolism still occurred at a rate of $6 \%$ (due to the development of a large collateral circulation), with fatal embolism occurring at a rate of $2 \%$ (Greenfield 1992). In the 1970s, developers produced the first filters which could be inserted percutaneously, and these have since been used in increasing numbers. The first generation of filters were permanent implants, with later generation filters 'retrievable' or 'optional'.

\section{How the intervention might work}

Vena caval filters may be placed in the inferior or superior vena cava to mechanically trap emboli, interrupting their course before reaching the heart and lungs (Owens 2010). These self-expanding devices most commonly resemble an umbrella in appearance. They are made from metal alloys. They can be inserted percutaneously (inserted through the skin into a large vein in the groin (femoral approach) or neck (jugular approach). Inferior vena caval filters are usually deployed below the level of the renal veins, but also have been inserted supra-renally (Kalva 2008).

Once deployed, permanent filters are left in situ; they become endothelialised, meaning they are eventually incorporated within the blood vessel wall. Retrievable (also known as optional) filters can be removed. Advances in percutaneous retrieval techniques mean that some retrievable and permanent filters can successfully be removed after a prolonged dwell period (Lessne 2015). There are currently approximately 15 filter designs, a number of which are retrievable (Rajeshekar 2013). Retrievable filters have potential advantages over permanent filters; one is the opportunity for subsequent removal if no longer needed, thus avoiding longer term sequelae of DVT. They can also be repositioned within the vena cava if significant endothelialisation has not occurred. Despite being called 'retrievable', these filters can become permanent implants if their subsequent removal becomes complicated due to endothelialisation, or if there is a significant amount of trapped thrombus within the filter such that the filter cannot be retracted or snared back into its sheath, thus preventing percutaneous removal. Convertible filters are a relatively recent conical filter design, in which the filtering struts can be 'deactivated', or opened, percutaneously when the filter is no longer required. This results in the filtering struts lying flat against the caval vessel wall and anchoring struts, with no impedence to blood flow, and no filtering capability. Whether this mitigates the long-term rate of venous thrombosis noted with permanent filters, remains to be seen. Temporary filters are permanently attached to the end of a catheter, and no barbs or hooks are required to hold it in place (Tapson 2017). These temporary filters must be removed when the catheter is removed.

Filters do not prevent or treat pulmonary emboli; they avert major sequelae by intercepting larger clots before they reach the heart and lungs. The first line treatment for, and prevention of, venous thromboembolism (VTE) remains anticoagulation (ACCP 2012).

Filters can only be useful if placed downstream from the clot. Filters themselves are not fail-safe in preventing PE. Given their design, small emboli can still pass through the struts of a filter. The presence of clot(s) downstream may cause collaterals (circulation bypasses) to open up, thus clots may travel to the lungs by another route. Filter thrombosis is also a documented complication, whether this is due to an in situ thrombus or an entrapped clot. Clot extension could still occur at the distal end of the clot, thus propagating 'through' the filter. Deploying a second filter above this has been suggested, but there is no literature to support this practice.

\section{Why it is important to do this review}

Pulmonary embolism is a major cause of hospital morbidity and mortality. There is consensus that filters are strongly recommended for those who have a proximal DVT or PE, or both, where it is too dangerous for them to receive anticoagulation (ACCP 2012). However, there is controversy in the literature about whether other groups of people may potentially benefit from having a vena caval filter inserted (Hann 2005; Kinney 2003). These groups include: 
- people with extensive trauma without established venous thromboembolism (VTE);

- people with large free-floating ilio-femoral thrombosis who do or do not subsequently receive thrombolytic therapy for this;

- people with cancer and concurrent VTE;

- pregnant women who have VTE;

- prevention in high risk situations such as bariatric surgery or orthopaedic joint replacements;

- people with proven VTE who sustain recurrent PE despite adequate anticoagulation.

Most controversial of the indications is when filters are placed for prevention, or prophylaxis, in people who do not have an established diagnosis of VTE, but are considered high risk for such.

The studies and the interventions examined in this review were to assess the efficacy and safety of filters; whether efficacy and safety varied amongst the different filter designs, and with different concurrent antithrombotic drugs.

We intended the comparisons in this review to be as follows.

- Filters versus no filter in those people for whom anticoagulation is contraindicated.

- Filters and anticoagulants versus anticoagulants alone.

- Filters with anticoagulation versus filters with no anticoagulation, seeking to answer the question as to whether long-term anticoagulation is recommended with permanent filters in situ (there is considerable debate about this (Gomes 2003)).

- Trials of filters with newer antithrombotic or anticoagulant drugs, of interest as these newer agents may have greater antithrombotic action or less haemorrhagic complications. Both of these effects are relevant to current indications for filters.

- Direct comparison of filter brands, to see if any one filter is superior in terms of its filtering efficiency or low rate of complications.

Comparisons of filters versus no filters also examine the complications arising from, and adverse effects of, having filters in situ. Pooled case series data indicate a recurrent PE rate of $2 \%$ to $5 \%$ with a fatal PE rate of $0.7 \%$, despite the presence of a filter The mortality rate from complications related to filter insertion is $0.12 \%$. Filter migration has been estimated to occur at rates up to $69 \%$ and inferior vena caval perforation up to $24 \%$, though these figures reflect radiological findings and not necessarily clinical events. Kinney reports that DVT occurs at rates up to $45.7 \%$, and post-thrombotic syndrome up to 59\% (Kinney 2003); these problems were observed more frequently with longer durations of follow-up. Experts disagree about whether these lower limb complications are the result of having a filter in situ, or are part of the intrinsic prothrombotic tendency some people have.

\section{O B JECT IVES}

To assess the evidence for the effectiveness and safety of vena caval filters (VCFs) in preventing pulmonary embolism (PE).

\section{METHODS}

\section{Criteria for considering studies for this review}

\section{Types of studies}

We included randomised controlled trials (RCTs) and controlled clinical trials (CCTs) that studied the effectiveness of vena caval filters (VCFs) in preventing pulmonary embolism (PE). We excluded trials from the review if the participants had a life expectancy of less than four weeks when given treatment or if they had previous permanent VCF placement.

\section{Types of participants}

We considered participants for inclusion in trials if they were aged 18 or older and:

- had radiologically confirmed proximal deep venous thrombosis (DVT) or pulmonary embolism (PE), or both

or

- were considered to be at high risk of DVT or PE.

\section{Types of interventions}

We considered studies for inclusion with the following interventions.

- VCF versus no filter in people for whom anticoagulation was contraindicated.

- VCF and anticoagulation (heparin, low molecular weight heparin (LMWH), and vitamin $\mathrm{K}$ antagonists) versus anticoagulation (and no filter).

- VCF and anticoagulation versus filter with no anticoagulation.

- Permanent VCF versus temporary VCF.

- Direct comparisons between filter brands.

- VCF with newer antithrombotic drugs versus newer antithrombotic drugs (without filter).

- VCF with mechanical prophylaxis versus no filter and mechanical prophylaxis (includes graded compression stockings, intermittent pneumatic compression, venous foot pump) in people for whom anticoagulation was contraindicated.

\section{Types of outcome measures}

\section{Primary outcomes}

- PE (fatal and non-fatal) as demonstrated by computer tomography (CT), pulmonary angiography or ventilationperfusion lung scan

- Mortality

\section{Secondary outcomes}

- Lower extremity venous thrombosis: distal (to filter) thrombosis, vena caval thrombosis as documented by ultrasonography

- Filter-related complications: mortality, embolisation, clinical perforation

- Major bleeding (as defined by the International Society of Thrombosis and Haemostasis (ISTH, Schulman 2005) 


\section{Search methods for identification of studies}

\section{Electronic searches}

For this update the Cochrane Vascular Information Specialist (CIS) searched the following databases for relevant trials.

- The Cochrane Vascular Specialised Register (23 October 2017)

- The Cochrane Central Register of Controlled Trials (CENTRAL (2017, Issue 9)) via the Cochrane Register of Studies Online

See Appendix 1 and Appendix 2 for details of the search strategy used to search CENTRAL.

The CIS also searched the following trial registries for details of ongoing and unpublished studies (23 October 2017) using the terms 'vena AND filter' (see Appendix 1 and Appendix 2).

- ClinicalTrials.gov (www.clinicaltrials.gov)

- World Health Organization International Clinical Trials Registry Platform (www.who.int/trialsearch)

- ISRCTN Register (www.isrctn.com/)

The CIS subsequently conducted systematic top-up searches of the following databases without language, publication year or publication status restrictions.

- The Cochrane Vascular Specialised Register via the Cochrane Register of Studies (CRS-Web) (searched from 1 January 2016 to 10 September 2019)

- The Cochrane Central Register of Controlled Trials (CENTRAL) Cochrane Register of Studies Online (CRSO 2019, issue 8)

- MEDLINE (Ovid MEDLINE ${ }^{\circledR}$ Epub Ahead of Print, In-Process \& Other Non-Indexed Citations, Ovid MEDLINE ${ }^{\circledR}$ Daily and Ovid MEDLINE ${ }^{\circledast}$ ) (searched from 1 January 2017 to 10 September 2019)

- Embase Ovid (searched from 1 January 2017 to 10 September 2019)

- CINAHL Ebsco (searched from 1 January 2017 to 10 September 2019)

- AMED Ovid (searched from 1 January 2017 to 10 September 2019)

The CIS modelled search strategies for the listed databases on the search strategy designed for CENTRAL. Where appropriate, they were combined with adaptations of the highly sensitive search strategy designed by the Cochrane Collaboration for identifying randomised controlled trials and controlled clinical trials (as described in the Cochrane Handbook for Systematic Reviews of Interventions Chapter 6, Lefebvre 2011). Search strategies for major databases are provided in Appendix 3.

The CIS also performed top-up searches of the following trials registries on 10 September 2019.

- The World Health Organization International Clinical Trials Registry Platform (who.int/trialsearch)

- ClinicalTrials.gov (clinicaltrials.gov)

\section{Searching other resources}

The review authors also checked citations within identified studies.

\section{Data collection and analysis}

\section{Selection of studies}

Two authors (TY and KBS) independently reviewed the references identified by the searches for inclusion in the review. we contacted trial authors for further information if required.

\section{Data extraction and management}

One author (TY) independently extracted data according to the data extraction form provided by Cochrane Vascular. This was confirmed by a second author (KBS). The data collected on each trial included information on the participants, the interventions, and incidence figures of desired outcomes (as specified in Criteria for considering studies for this review).

\section{Assessment of risk of bias in included studies}

Two authors (TY, KBS) assessed all included studies for risk of bias using the criteria described in the Cochrane Handbook for Systematic Reviews of Interventions (Higgins 2011). The following domains were assessed as 'Yes' (low risk of bias), 'Unclear' (uncertain risk of bias) or 'No' (high risk of bias).

- Randomisation sequence generation

- Concealment of allocation

- Blinding (of participants, personnel)

- Blinding (of outcome assessors)

- Incomplete outcome data

- Selective outcome reporting

- Other possible areas of bias

\section{Measures of treatment effect}

We reported the risk ratio (RR), with $95 \%$ confidence interval (CI) and hazard ratios (HR) with $95 \% \mathrm{Cls}$ for dichotomous data as presented in the individual studies.

\section{Unit of analysis issues}

The participant was the individual unit of analysis.

\section{Dealing with missing data}

We intended to use intention-to-treat analysis and contact the study authors for further information in the case of missing data. There were no concerns regarding missing data.

\section{Assessment of heterogeneity}

We visually assessed the studies for clinical heterogeneity especially in regards to the subset of participants. Each study included a selected subset of people thought to potentially benefit from filters and could not be grouped together for metaanalysis. We did not perform heterogeneity investigations. If sufficient trials are available for analysis in future updates, we will assess the degree of heterogeneity amongst trials by using the $I^{2}$ statistic according to the formula $I^{2}=100 \% \times(Q-$ degrees of freedom)/Q, where $Q$ is the Chi2 statistic (Higgins 2011). If significant heterogeneity is present, we will calculate a summary statistic for each outcome using a random-effects model. 


\section{Assessment of reporting biases}

There were insufficient studies identified to create a funnel plot to assess reporting bias.

\section{Data synthesis}

We were not able to carry out meta-analysis because of clinical differences between the studies and because individual study results were reported and described textually. Trial results will be pooled by meta-analysis if sufficient trials become available in the future. For studies which were to be presented in the 'Summary of findings' tables, we entered study data into RevMan analyses. This was to facilitate importing data to GRADEpro GDT.

\section{Subgroup analysis and investigation of heterogeneity}

Should sufficient information become available we intend to carry out subgroup analysis on:

- people who had a contraindication to anticoagulation;

- people who had another episode of PE despite being anticoagulated;

- people who had cancer and co-existing VTE;

- pregnant women who had VTE;

- people who had superior VCFs inserted for upper limb venous thrombosis;

- people who had supra-renal VCFs inserted;

- people who had filters inserted versus those receiving the newer antithrombotic drugs;

- permanent vs retrievable filters;

- comparisons between filter brands.

\section{Sensitivity analysis}

We intended to undertake sensitivity analyses to test the robustness of our results by removing studies at high risk of bias but, as no meta-analysis was possible, this was not done.

\section{Summary of findings and assessment of the certainty of the evidence}

For this update, we prepared 'Summary of findings' tables to present the main findings of our systematic review. We were unable to carry out any meta-analysis due to the clinical heterogeneity of the studies. We have therefore presented the results from the most clinically relevant studies in separate 'Summary of findings' tables. These are 'Retrievable vena caval filters with anticoagulation compared to anticoagulation for prevention of PE' (Summary of findings 1), and 'Retrievable vena caval filters with anticoagulation compared to anticoagulation for prevention of PE following multiple traumatic injury' (Summary of findings 2). We included the outcomes of PE, mortality, lower limb DVT, filter related complications, and major bleeding. We used GRADEprofiler software to create the tables (GRADEpro GDT). The GRADE criteria was then used to rank the certainty of the evidence for each outcome based on risk of bias, inconsistency, indirectness, imprecision and publication bias (Guyatt 2008). We provided reasons for downgrading the certainty of the evidence in the footnotes of the tables.

\section{RES U LTS}

\section{Description of studies}

Results of the search

See Figure 1 


\section{Figure 1. Study flow diagram.}

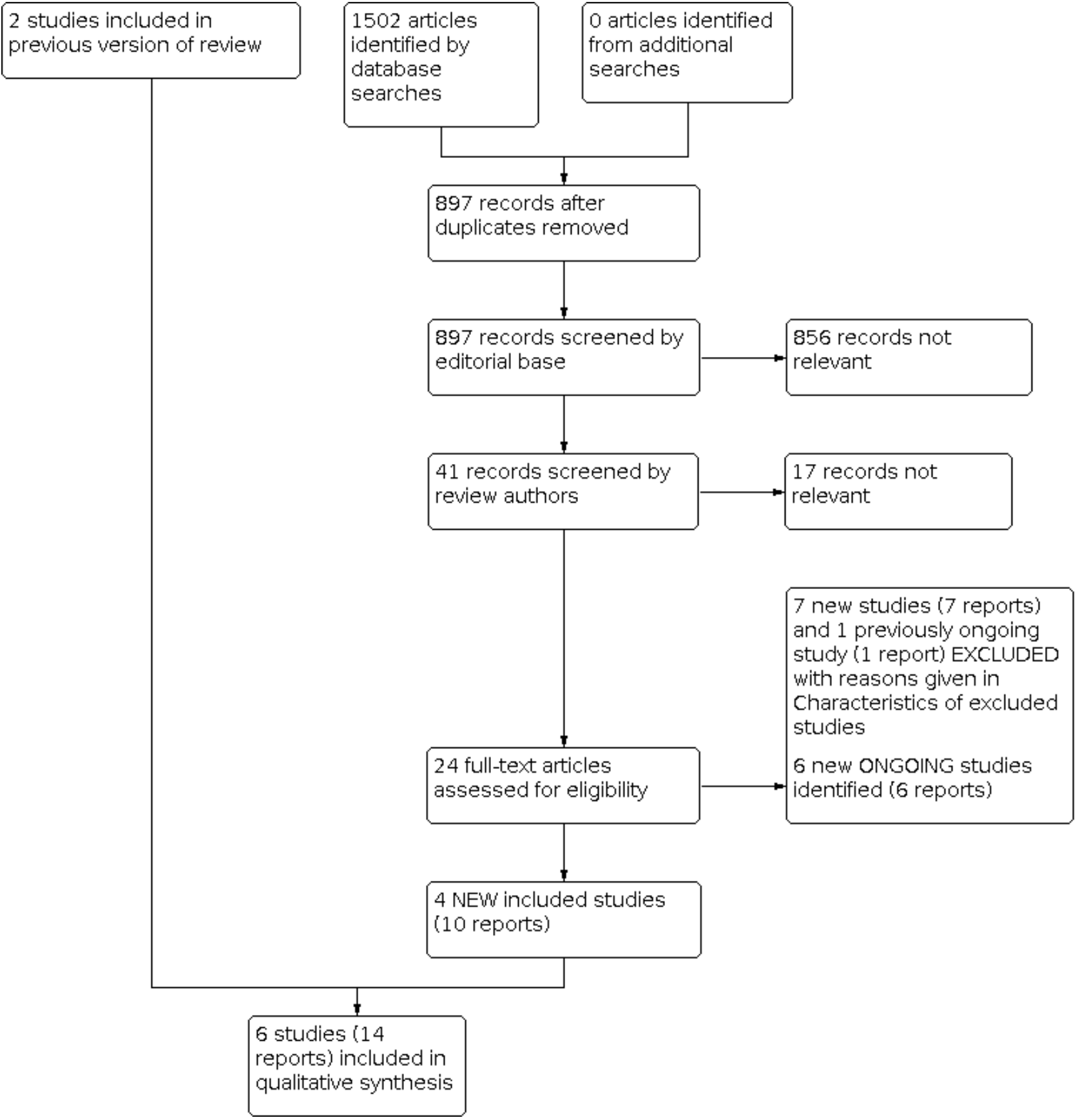

Four additional studies were included for this update (Barginear 2012; Ho 2019; PREPIC2; Usoh 2010), and six additional studies were excluded (Bocharov 2011; NCT02201277; Pan 2019; Rajasekhar 2011; Stavropoulos 2016; Sharifi 2012). One previously ongoing study was excluded as it was terminated due to poor recruitment (NCT00423683). In total, there are therefore six included studies (Barginear 2012; Ho 2019; Fullen 1973; PREPIC; PREPIC2; Usoh 2010); and 16 excluded studies (Bocharov 2011; Brasel 1997; Gosin 1997; Khansarinia 1995; Midy 1994; NCT00423683; NCT02201277; Pan 2019; Rajasekhar 2011; Rodriguez 1996; Rogers 1997; Rosenthal 1994; Rosner 2004; Sharifi 2012; Stavropoulos 2016; Webb 1992).

\section{Included studies}

The studies were heterogenous regarding both the participants they involved and in the interventions used.

- Anticoagulation with or without retrievable vena cava filter (VCF) in people at high risk of recurrent PE (PREPIC2).

- VCF in people who sustained multiple trauma, with delayed initiation of prophylactic anticoagulation (Ho 2019).

- Anticoagulation with or without permanent VCF in people at high risk of recurrent PE (PREPIC).

- VCF in people with traumatic hip fractures, who did not receive anticoagulation (Fullen 1973). 
- Anticoagulation with or without VCF in people who had cancer and with VTE (Barginear 2012).

- Comparison of two VCFs (Usoh 2010).

We have given summary details of the included studies in the Characteristics of included studies.

PREPIC2 was a multicentre prospective open-label randomised trial studying the effect of a retrievable inferior VCF (ALN Implants Chirurgicaux Ghisonaccia, France) plus anticoagulation versus anticoagulation alone on risk of recurrent PE in 399 participants. The filter was left in situ for three months and then retrieved. Participants included in the trial were considered to be at high risk of recurrent PE, i.e. those with coexisting lower limb thrombosis as well as being aged more than 75 years, right ventricular dysfunction, active cancer, bilateral or iliocaval DVT, or both, or cardiorespiratory compromise. Retrieval of all the in situ filters was intended to occur at three months. Both the filter and nonfilter group were then followed for another three months. The primary outcome was recurrent PE at three months. Secondary outcomes were symptomatic DVT at three months, VTE at six months, major bleeding, mortality at three and six months and filter-related complications. Two hundred people were randomised to receive a filter; 193 actually received a filter. All people received parenteral anticoagulation therapy (heparins $85 \%$, fondaparinux $15 \%)$ followed by vitamin $\mathrm{K}$ antagonists $(89 \%)$ or LMWH (11\%). Median age was 76 years. Thirty-five percent had a history of PE or DVT. Twenty-five percent had cancer.

The PREPIC study was a randomised controlled open-label trial with 400 participants from multiple (44) centres in France. Participants consisted of consecutive hospitalised people, made up of $64 \%$ males with an average age of 73 years, with documented proximal DVT or PE and considered by the referring physician to be at high risk of recurrent PE. There were numerous exclusion criteria; notably people were excluded if they failed or had contraindications to anticoagulation, or if they were pregnant. PREPIC had a $2 \times 2$ factorial design with interventions of (permanent) caval filter versus no filter, and low molecular weight heparin (LMWH) versus unfractionated heparin (UFH). Primary outcomes were: PE, mortality, and DVT. Secondary outcomes were: bleeding, post-thrombotic syndrome, and filter-related complications. Outcomes were assessed at 12 days, two years, and eight years. Both study groups received vitamin $\mathrm{K}$ antagonists for the first three months; at eight years, 35\% of people in both study groups were still receiving vitamin $\mathrm{K}$ antagonists. Similar proportions of people In both groups wore elastic stockings (45\% and $47 \%$ in the filter and no-filter group, respectively) at eight years. This study has limited generalisability as permanent filters have fallen out of favour.

Ho 2019 was an open-label randomised multicentre trial of 240 participants who sustained major trauma, with an Injury Severity Score of more than 15 and a median score of 27. Participants were allocated to filter or no filter within 72 hours of admission, as they could not receive immediate pharmacological VTE prophylaxis. Filters were subsequently inserted either at days 3 to 6 , or on or after day seven after injury. All participants received pharmacologic prophylactic anticoagulation as soon as it was deemed clinically safe, and intermittent pneumatic compression was applied to the uninjured lower limb/s. Follow-up was for 90 days. Primary outcomes were death or PE at any stage during the study; secondary endpoints were incidence of PE in those who could not commence pharmacological VTE prophylaxis within 7 days, versus those who could. Anticoagulation was initiated within seven days, in $67 \%$ of people enrolled; $33 \%$ had ongoing contraindications to anticoagulation. Two filters were used - Bard Denali-retrievable in 117 (95.9\%), and Cook-retrievable in 5 (4.1\%).

Fullen 1973 was a quasi-randomised open-label trial with 129 participants in a single centre in the US. All participants who had a traumatic hip fracture were asked to be involved in the study. The mean ages in the filter group and control group were 69 and 67 years, respectively. The gender distribution was not documented. There seemed to be a greater proportion of people with atherosclerotic heart disease and cardiac failure allocated to the filter group. Exclusion criteria was refusal to consent to participating in the trial. People included in the trial were randomised to receive a (Mobin-Uddin, first generation) caval filter. Primary outcomes were PE on a definite, probable or possible occurrence (based on clinical, imaging and post-mortem data), and mortality. Secondary outcomes were complications from surgery or the filter. Dates of outcome assessments were not stated; investigations for pulmonary embolic disease were performed when clinically suspected. The average length of stay was 33 and 34 days between the two groups; no range values were listed. Seven people could not have internal fixation, one in the filter group and six in the control group. Filters could not be inserted into seven people randomised to the filter group. A jugular approach was used. Filters could not be placed into these seven people due to narrow central veins or difficulty negotiating the filter through the right atrium in severe kyphosis. No anticoagulation was used by any participant. Small doses of aspirin may have been taken by a number of control participants (no figure given but described as "occasional"). This trial is no longer relevant as the peri-operative preventive and treatment for DVT and PE is anticoagulation such as LMWH or UFH.

Barginear 2012 was a randomised open-label study of 64 participants who had cancer and then subsequently developed VTE. It was conducted in a single centre in the US. The treatment groups had similar baseline characteristics. The predominant cancers were solid organ (lung, breast, pancreas) with only $7 \%$ to $12 \%$ being lymphomas; staging ranged from involving the nearby lymph nodes (stage II) to metastatic disease. A small number of participants had brain metastases (9\% to $15 \%)$. The majority were receiving chemotherapy (90\% to $94 \%$ ), and had ECOG performance scores of 0 to 3 (i.e. able to perform some self-care tasks, but not bed-bound). Both groups had DVT or PE confirmed by imaging following suspicious symptoms, and were commenced on fondaparinux (an anticoagulant). Participants were randomised to permanent filter insertion or control. Primary outcomes were filter complications, bleeding, and recurrent PEs. Outcomes were assessed by repeat imaging at days 14, 20 and 56, and clinical follow-up for up to three years.

Usoh 2010 was a randomised open-label study of 156 participants who had DVT or were at high risk of PE who received one of two currently available permanent filters. These were the Greenfield and TrapEase filters. The study was terminated early because it was apparent that there was a higher rate of symptomatic IVC/iliac vein thrombosis in participants with the TrapEase filter. The filter group was quasi-randomised. There were more participants who had malignancies and strokes in the Greenfileld filter group, whereas 
the TrapEase filter group had more participants who had recent surgery. Some participants could not receive anticoagulation.

\section{Excluded studies}

We identified six new studies for this update as excluded (Bocharov 2011; NCT02201277; Pan 2019; Rajasekhar 2011; Stavropoulos 2016; Sharifi 2012). A previously ongoing study was reassessed as excluded (NCT00423683). Sixteen studies in total were excluded and the reasons for exclusion included:

- studies designed to compare prospective interventional cohorts with historical controls (Khansarinia 1995; Rodriguez 1996; Rosner 2004)

- cost-effectiveness study (Brasel 1997)

- case series (Midy 1994; Rosenthal 1994)

- studies that did not have comparable prospective interventional and control groups; only selected high-risk people received filters, and prospective interventional cohorts were compared with historical controls (Gosin 1997; Rogers 1997)

- studies where only selected high-risk people received filters, and there were no data regarding baseline characteristics of the intervention and control groups. These people also received concurrent prophylactic anticoagulation in the setting of trauma (acetabular fracture) (Webb 1992)

- Rajasekhar 2011 was a pilot study about randomising filter placements in people who had been admitted following high- risk trauma. This was a feasibility study, and not designed to look for an outcome

- Sharifi 2012 was excluded as this was a randomised study concerning filters as an adjunct to percutaneous endovascular techniques for the treatment of lower extremity DVT. It showed an eight-fold reduction in PE (filter $1 / 14$ vs control $8 / 22, \mathrm{P}=$ 0.048). Five different endovascular techniques were utilised, and warrants further analysis; this is a highly specialised field, and considered outside the scope and expertise of the review

- study that was not randomised (Bocharov 2011)

- prospective cohort study of the Denali filter (Stavropoulos 2016)

- retrospective cohort analysis (Pan 2019)

- studies that were terminated early due to low recruitment (NCT00423683; NCT02201277)

Details of all excluded studies are given in the Characteristics of excluded studies.

\section{Ongoing studies}

Six studies have been identified as ongoing and are detailed within the Characteristics of ongoing studies table (ACTRN12612001071819; ChiCTR1900023485; NCT00588757; NCT03070834; NCT03691753; NCT03987321).

\section{Risk of bias in included studies}

See Figure 2 and Figure 3. 
Figure 2. Methodological quality summary: review authors' judgements about each methodological quality item for each included study.

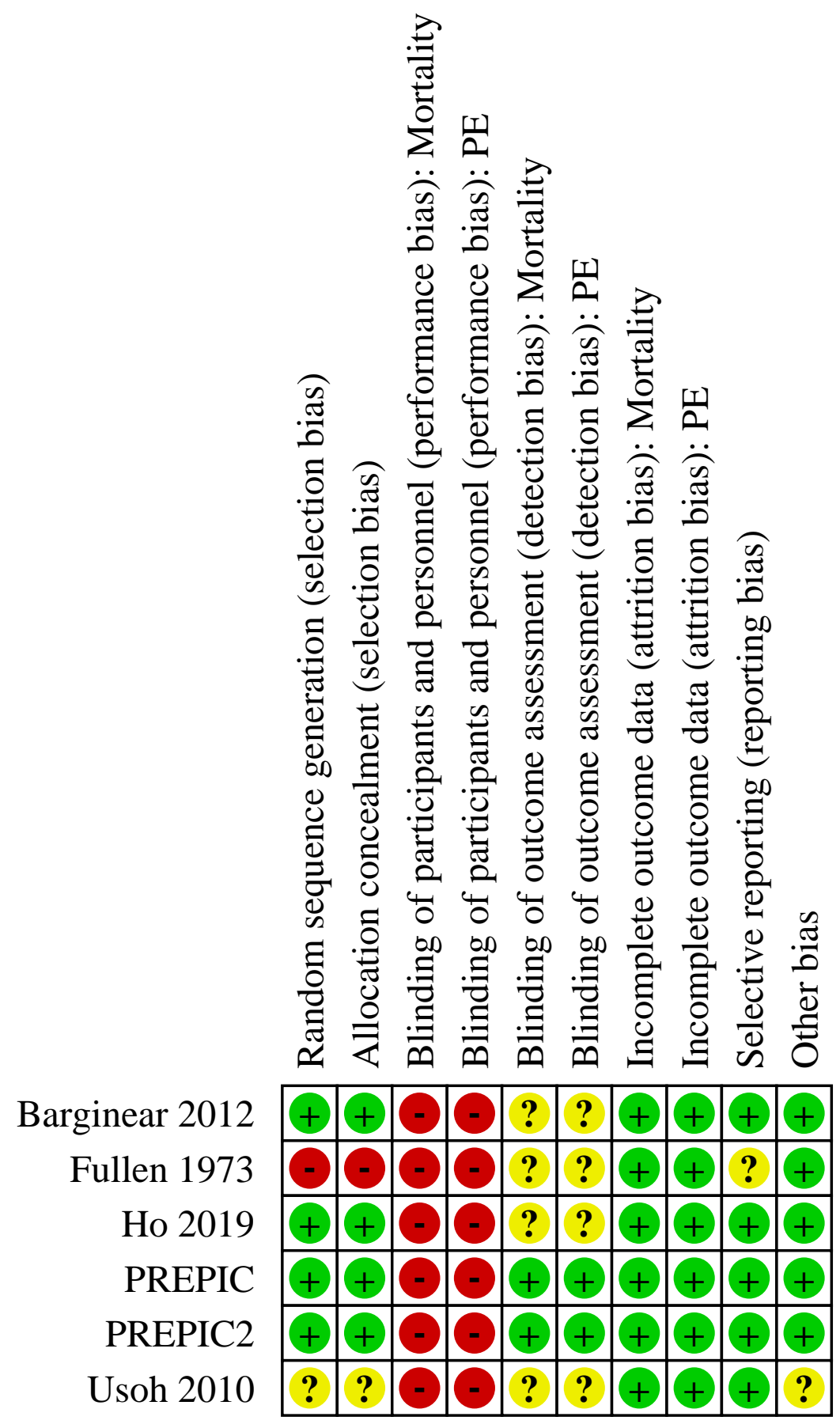




\title{
Figure 3. Methodological quality graph: review authors' judgements about each methodological quality item
} presented as percentages across all included studies.

\author{
Random sequence generation (selection bias)
}

Allocation concealment (selection bias)

Blinding of participants and personnel (performance bias): Mortality

Blinding of participants and personnel (performance bias): PE

Blinding of outcome assessment (detection bias): Mortality

Blinding of outcome assessment (detection bias): PE

Incomplete outcome data (attrition bias): Mortality

Incomplete outcome data (attrition bias): PE

Selective reporting (reporting bias)

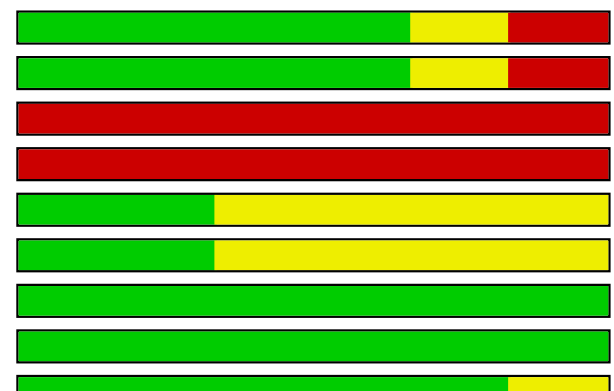

Other bias

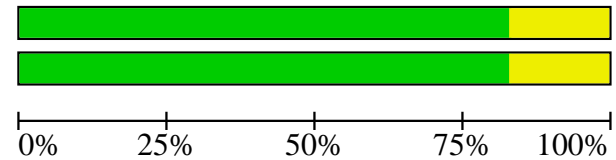

Low risk of bias

Unclear risk of bias

High risk of bias

PREPIC, PREPIC2 were at low risk of bias in all domains except for performance bias (they were open-label studies). Ho 2019 was at low risk of bias for all domains except performance and detection bias.

In PREPIC2, randomisation was via a central voice-activated system, in randomly permuted blocks of four or six; there was further stratification according to centre and the patient's creatinine clearance. It was an open-label study. The evaluation was blind, performed by a central adjudication committee. The inclusion criteria were stated, as were primary and secondary outcomes. The participants were followed for six months, and losses were minimal (two were lost to follow-up; both of these were in the filter group). The table of baseline characteristics showed matched intervention and control groups, as were the anticoagulation regimens between the two groups.

The PREPIC study was randomised by a centralised computer telephone system. The study was an open-label design. An independent adjudication committee who assessed all radiological and clinical outcomes was blinded to the treatment status of the participants. Baseline characteristics and co-interventions (including the proportion of people receiving vitamin $\mathrm{K}$ antagonists and wearing elastic stockings) were similar between the intervention and control groups. Withdrawals and dropouts were few and appropriately described in the manuscript. Participant cross-over was $10 \%$ (19 people initially assigned to the no-filter group subsequently received a filter). An intention-to-treat analysis was performed. Inclusion and exclusion criteria were clearly stated. Primary and secondary outcomes were reported.

Ho 2019 was randomised via permuted block scheme, stratified according to the trial centre. Four centres were involved. The trial was not blinded to either the participants nor the treating clinicians. A CTPA was required if certain criteria were met. Routine chest imaging for PE was not done in asymptomatic people. All participants underwent doppler ultrasonography of the legs at 2 weeks; this was not specified in the original protocol. All other prespecified primary and secondary outcomes were reported.
Fullen 1973 was at high risk of bias for randomisation, allocation and blinding (please also see comments within table) as it was randomised on the basis of hospital numbers (odd or even). The study was an open-label design. Participation in the filter group required consent and the insertion procedure. Baseline characteristics were scarce. A higher rate of atherosclerotic heart disease and cardiac failure was noted in the filter group. Cointerventions (usage of anticoagulation) was similar between the groups, as was time from admission-to-filter insertion and admission-to-fracture fixation. Seven people could not undergo fracture fixation - six of these were in the control group. It is not stated whether the outcome assessors were blinded or not. Diagnostic imaging for PE was not stated as being a routine part of the trial. The use of plain chest radiography for the diagnosis of PE is inaccurate. Follow-up was complete as this was an in-hospital population. Analysis was not by intention to treat. Inclusion and exclusion criteria were briefly stated. Primary outcomes of mortality and PE were given, as were details related to filter complications. No DVT rates were reported.

Barginear 2012 used a permuted block design to assign people to each treatment arm; the two groups did have similar baseline characteristics. It was an open-label study. Inclusion and exclusion criteria were clearly stated. Imaging was performed at baseline, at regular follow-up intervals, and if symptomatic of PE within 90 days of randomisation. Participants were followed for up to three years. It is not stated whether the radiologists and other assessors of outcome measures were blinded to the participant's filter status. Analysis was by intention to treat. All 64 participants were followed through to the study's end, with no loss of data. Both groups received anticoagulation with fondaparinux. Primary and secondary outcomes were reported.

Usoh 2010 recruited people who had lower extremity DVT, or were at high risk of this. People who consented to be in the trial were subsequently randomised - this involved a nurse or participant to randomly choose a prelabelled card in an envelope. Inclusion and exclusion criteria were clearly stated. The study was an openlabel design. Of 349 eligible people, 156 were randomised. The remainder became a prospective cohort, most declining to be in 
the trial or unable to meet follow-up requirements (303 people) but lack of an available filter was the reason in 21 people. Three people received an Optease filter as this was the choice of the proceduralist, or determined by filter availability. Participants had baseline imaging as warranted by their clinical situation, with planned routine imaging at follow-up over a period of two years. Further imaging was performed if clinically indicated. It is not stated whether the outcome assessors were blinded to the participants filter status. Primary and secondary outcomes were reported. There was no difference in rates of anticoagulation between the two filter groups.

\section{Allocation}

PREPIC, PREPIC2, Ho 2019, and Barginear 2012 used a central computer-generated randomisation method and were at low risk of selection bias. Usoh 2010 randomised people by a nurse or participant to select an envelope with a prelabelled card inside. This was judged to be at an unclear risk of bias as it was not apparent if the envelopes were opaque. Fullen 1973 was randomised on the basis of hospital numbers (odd or even) and was at high risk of selection bias.

\section{Blinding}

All studies were of an open-label design and so were judged to at a high risk of performance bias. Efforts were made to blind the assessors in PREPIC and PREPIC2 so these were at low risk of detection bias. Blinding of the assessors was not stated in the other four RCTs and these were assessed as being at unclear risk (Barginear 2012; Fullen 1973; Ho 2019, Usoh 2010). In Ho 2019, all thoracic radiology was confirmed by an independent consultant radiologist, but there is no reference as to whether this person was blinded to the filter status of the participant. In Ho 2019, all deaths underwent coronial investigation, with an external examination, post-mortem CT, or autopsy if the cause of death was not evident from the medical records. There is recognition that ante-mortem vascular thrombosis and embolism can be difficult to distinguish from post-mortem thrombosis within the heart and large vessels (Sutherland 2017).

\section{Incomplete outcome data}

All studies were assessed as being at low risk of attrition bias. There were no losses in Barginear 2012, Ho 2019 or PREPIC; and minimal losses to follow-up in PREPIC2 and Fullen 1973. Usoh 2010 was terminated early due to the interim results indicating a higher symptomatic IVC/IV thrombosis rate associated with the Trapease filter. Overall follow-up for both groups was 12 months, with a range of 0 to 33 months. Mortality rates were reported over the entire follow-up period. Serial lower limb doppler studies occurred in 121 participants (78.2\%) during the 28 month follow-up period.

\section{Selective reporting}

Barginear 2012; Ho 2019; PREPIC; PREPIC2; and Usoh 2010 were all at low risk of selective reporting bias as they reported all primary and secondary outcomes. Fullen 1973 reported mortality and rates of $\mathrm{PE}$.

\section{Other potential sources of bias}

We did not identify any other potential sources of bias in trial design or conduct in Barginear 2012; Ho 2019, PREPIC; or PREPIC2. Ho 2019 had similar rates of anticoagulation and use of intermittent pneumatic compression between the control and filter groups; both PREPIC and PREPIC2 had comparable rates of anticoagulation between the control and intervention groups.

Usoh 2010 was terminated early due to interim results and judged to be at unclear risk of other bias.

Fullen 1973 diagnosed PE based on chest X-ray (CXR), ventilation/ perfusion scans, and pulmonary angiography or autopsy if necessary. This was the available imaging technology at that time, and may have under-reported the rates of thromboembolism (as compared to modern CT pulmonary angiography). The rates of PE were classified into 'definite' (positive angiogram, positive lung scan and negative CXR, or post-mortem diagnosis), 'probable' (positive CXR for PE), or 'possible' (signs and symptoms consistent with $\mathrm{PE}$, but negative CXR, angiogram or lung scan not performed). It is beyond the scope of this review to discuss the sensitivity and specificities of a plain CXR and ventilation/perfusion scans in the detection of $\mathrm{PE}$, but the rates are poorer as compared to $C T$ pulmonary angiography. For further information, refer to the PIOPED and Greenspan 1982 reports. There was also a higher rate of ischaemic heart disease and cardiac failure in the filter group, but this did not affect the rates of death or PE in the overall outcomes.

\section{Effects of interventions}

See: Summary of findings 1 Retrievable vena caval filters with anticoagulation compared to anticoagulation for prevention of PE; Summary of findings 2 Retrievable vena caval filters with anticoagulation compared to anticoagulation for prevention of PE following multiple traumatic injuries

We were unable to pool results as the studies were too diverse in patient populations and clinical situations so we have reported the findings below.

In order to allow comparison between the studies, the results of the studies are presented by outcome. The studies are presented in the following order:

- Anticoagulation +/- retrievable VCF in people at high risk of recurrent $P E$

- VCF in people who sustained multiple trauma, who had delayed initiation of prophylactic anticoagulation as a result of their injuries

- Anticoagulation +/- permanent VCF in people at high risk of recurrent $\mathrm{PE}$

- VCF in people with traumatic hip fractures, who did not receive anticoagulation

- Anticoagulation +/- VCF in people who had cancer and VTE

- Comparison of two VCFs

Pulmonary embolus (demonstrated by computer tomography (CT), pulmonary angiography or ventilation-perfusion lung scan)

PREPIC2 reported no clear difference in recurrent PE (fatal and nonfatal) at three months (RR 1.99, 95\% $\mathrm{Cl} 0.5$ to $7.85 ; \mathrm{P}=0.33$; 1 study, 399 participants) and six months (RR $1.74,95 \% \mathrm{Cl} 0.52$ to 5.86 ; $\mathrm{P}=0.37$; 1 study, 399 participants; moderate-certainty evidence; Analysis 1.1). 
Ho 2019 reported no clear difference in PE at 90 days (RR 0.07, 95\% $\mathrm{Cl} 0.00$ to $1.18 ; \mathrm{P}=0.07 ; 1$ study, 80 participants; moderate-certainty evidence; Analysis 2.1). These data come from the subgroup analysis of the participants who could only commence prophylactic anticoagulation on, or after, day seven of injury. It is noted that six filters at initial retrieval had clot present within them, perhaps indicating they were indeed doing what they were intended to do.

The PREPIC study demonstrated the efficacy of caval filters in preventing PE in a group of people with proximal DVT or PE and receiving concurrent anticoagulation, at eight years (filter 9/200 versus control 24/200; hazard ratio (HR) $0.37,95 \% \mathrm{Cl} 0.17$ to 0.79 in favour of a filter) (see Figure 4). The PREPIC study included small subgroups of people with cancer, and used four permanent filter designs. It lacked statistical power to be able to draw any conclusions. The study authors reported that day $12 \mathrm{PE}$ rates did reach significance (filter $2 / 200$ versus no filter $9 / 200$; OR 0.22 , $95 \%$ $\mathrm{Cl} 0.05$ to $0.90, \mathrm{P}=0.03$ ); however, this trial utilised routine imaging for PE, which detected both symptomatic and asymptomatic PE. Symptomatic $P E$ rates were filter $2 / 200$ versus no filter $5 / 200$. Twoyear rates of symptomatic PE did not reach significance (filter $6 / 200$ versus $12 / 200$; OR $0.50,95 \% \mathrm{Cl} 0.19$ to $1.33, \mathrm{P}=0.16$ ). Treatment of asymptomatic incidental PE is subject to debate and controversy. This is discussed further under Overall completeness and applicability of evidence. Analysis of the rates of PE at eight years stated they were not statistically different between the LMWH and unfractionated heparin (UFH) groups, so they were considered to be equivalent treatments (LMWH 3.9\% versus UFH 5.7\%, OR 0.66, $95 \% \mathrm{Cl} 0.26$ to $1.70, \mathrm{P}=0.38$ ). Both arms received the same rate of anticoagulation.

Figure 4. PREPIC study: Kaplan-Meier analysis of time to pulmonary embolism (generated by Dr H Bartlett from data provided in publications from PREPIC)

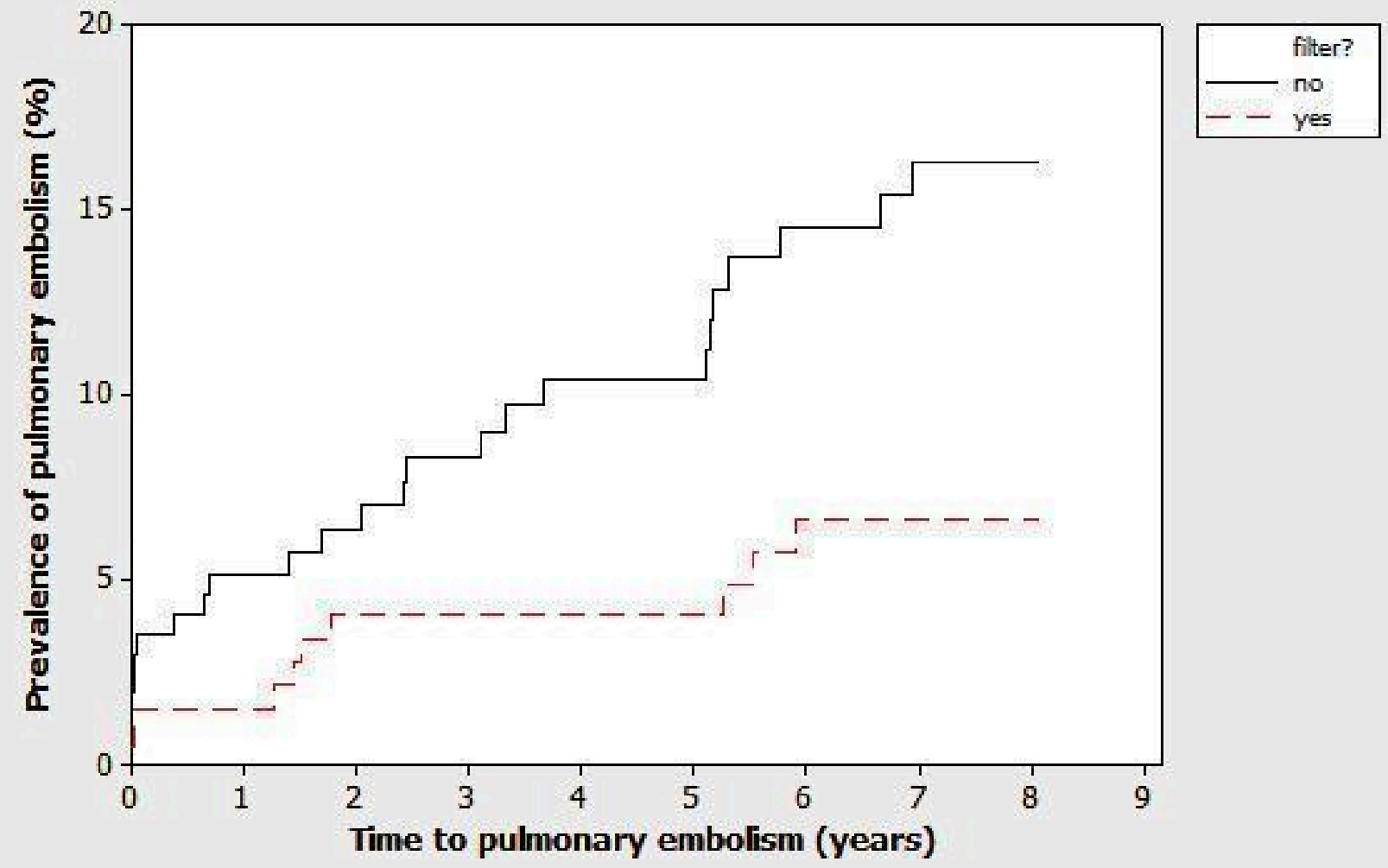

Fullen 1973 demonstrated caval filters were effective in reducing $\mathrm{PE}$ in a quasi-randomised trial of 129 participants with proximal femoral fractures, over a 33 to 34 day period. Anticoagulation was not given in either arm. Rates of PE were $4 / 41$ in the filter group, and $19 / 59$ in the control group.

Barginear 2012 showed no advantage or disadvantage for filter insertion in people who had cancer and concurrent venous thromboembolism who were anticoagulated. There was no difference in recurrence of PE between the two groups $(24.8 \%$ versus $24 \%$ ).
Usoh 2010 reported that there was no clear difference in recurrent $\mathrm{PE}$ rates with the TrapEase filter compared to the Greenfield filter (GF 18/84 versus TE 13/72, $\mathrm{P}=0.6$ ).

\section{Mortality}

PREPIC2 did not demonstrate any mortality or morbidity benefit in people with acute $\mathrm{PE}$ who were anticoagulated and who received a retrievable (ALN) filter in the first three months (RR 1.24, 95\% $\mathrm{Cl} 0.6$ to $2.59 ; \mathrm{P}=0.56 ; 1$ study, 399 participants), or six months (RR $1.39,95 \% \mathrm{Cl} 0.74$ to 2.62; $\mathrm{P}=0.3 ; 1$ study, 399 participants; moderate-certainty evidence; Analysis 1.2). People who had a contraindication to anticoagulation were not specifically studied. 
Ho 2019 did not demonstrate any clear difference in mortality from any cause at 90 days ( $R R 1.41,95 \% \mathrm{Cl} 0.68$ to $2.90 ; \mathrm{P}=0.36$; 1 study, 240 participants; moderate-certainty evidence; Analysis 2.2). The study authors reported no significant difference between the filter and control groups in terms of Injury Severity Scores, ventilation requirement, thoracic and/or abdominal visceral injuries, spinal cord injury with neurological sequelae, complex pelvic fractures, and (unilateral or bilateral) lower limb fractures.

PREPIC did not show any reduction in mortality at 12 days (filter $5 / 200$ versus no filter $5 / 200$ ), two years (filter $43 / 200$ versus no filter 40/200) and eight years (filter $98 / 200$ versus no filter 103/200) (HR $0.97,95 \% \mathrm{Cl} 0.74$ to $1.28, \mathrm{P}=0.83$ ).

Fullen 1973 reported caval filters were not effective in reducing mortality in a quasi-randomised trial of 129 patients with proximal femoral fractures over a 33 to 34 day period. Mortality was $4 / 41$ in the filter group and 14/59 in the control group. Rate of fatal PE in the filter group was $1 / 4$, and $8 / 14$ in the control group. There was a reduction in $\mathrm{PE}$ in the filter group, with the only case in the filter group occurring prior to filter insertion.

Barginear 2012 showed no advantage or disadvantage for filter insertion in people who had cancer and concurrent VTE who were anticoagulated. There was no difference in median survival between the two groups (anticoagulation only 493 days versus 266 days for anticoagulation with filter, $\mathrm{P}<0.57$ (data as per original study abstract)).

Usoh 2010 reported that there was no clear difference in mortality with the TrapEase (TE) filter compared to the Greenfield filter (GF) (GF 41/84 versus TE 25/72, $P=0.385$ ).

\section{Lower extremity venous thrombosis: distal (to filter) thrombosis, vena caval thrombosis (as documented by ultrasonography)}

PREPIC2 did not report any difference in rates of symptomatic DVT at three months (RR $0.99,95 \% \mathrm{Cl} 0.06$ to $15.8 ; \mathrm{P}=1 ; 1$ study, 399 participants), or six months (RR $0.5,95 \% \mathrm{Cl} 0.05$ to $5.44 ; \mathrm{P}=0.57 ; 1$ study; 399 participants; moderate-certainty evidence; Analysis 1.3).

Ho 2019 showed no clear difference in the incidence of overall lower extremity thrombosis between the filter and control groups (RR 1.13, 95\% Cl 0.54 to 2.34; $\mathrm{P}=0.75 ; 1$ study, 240 participants; moderate-certainty evidence; Analysis 2.3). Likewise, no clear differences were seen between the number of unilateral (RR 1.77, $95 \% \mathrm{Cl} 0.68$ to $4.64 ; \mathrm{P}=0.24$ ), or bilateral thrombosis ( $R R 0.55,95 \%$ $\mathrm{Cl} 0.17$ to $1.84 ; \mathrm{P}=0.33$ ). Some participants had more than one episode of DVT.

Intermittent pneumatic compression (IPC) was applied (for at least one day and post-surgical fixation) in both lower limbs in 103/122 (84\%) of the filter group compared to $101 / 118(86 \%)$ of the control group; unilateral IPC was employed in $14 / 122(12 \%)$ of the filter group, versus $18 / 118(15 \%)$ of the control group. No IPC could be used in $9 / 122(7 \%)$ of the filter group, and $2 / 118(2 \%)$ of the control group.

At eight years, PREPIC reported a significant increase in the rate of DVT and filter thrombosis in the filter group (one or more documented episodes of DVT occurred in 57 participants (35.7\%) in the filter group and $41(27.5 \%)$ in the control group, (HR 1.52, 95\% $\mathrm{Cl} 1.02$ to $2.27, \mathrm{P}=0.042)$ ), (see Figure 5). 
Figure 5. PREPIC study: Kaplan-Meier analysis of time to deep vein thrombosis (generated by Dr H Bartlett from data provided in publications from PREPIC)

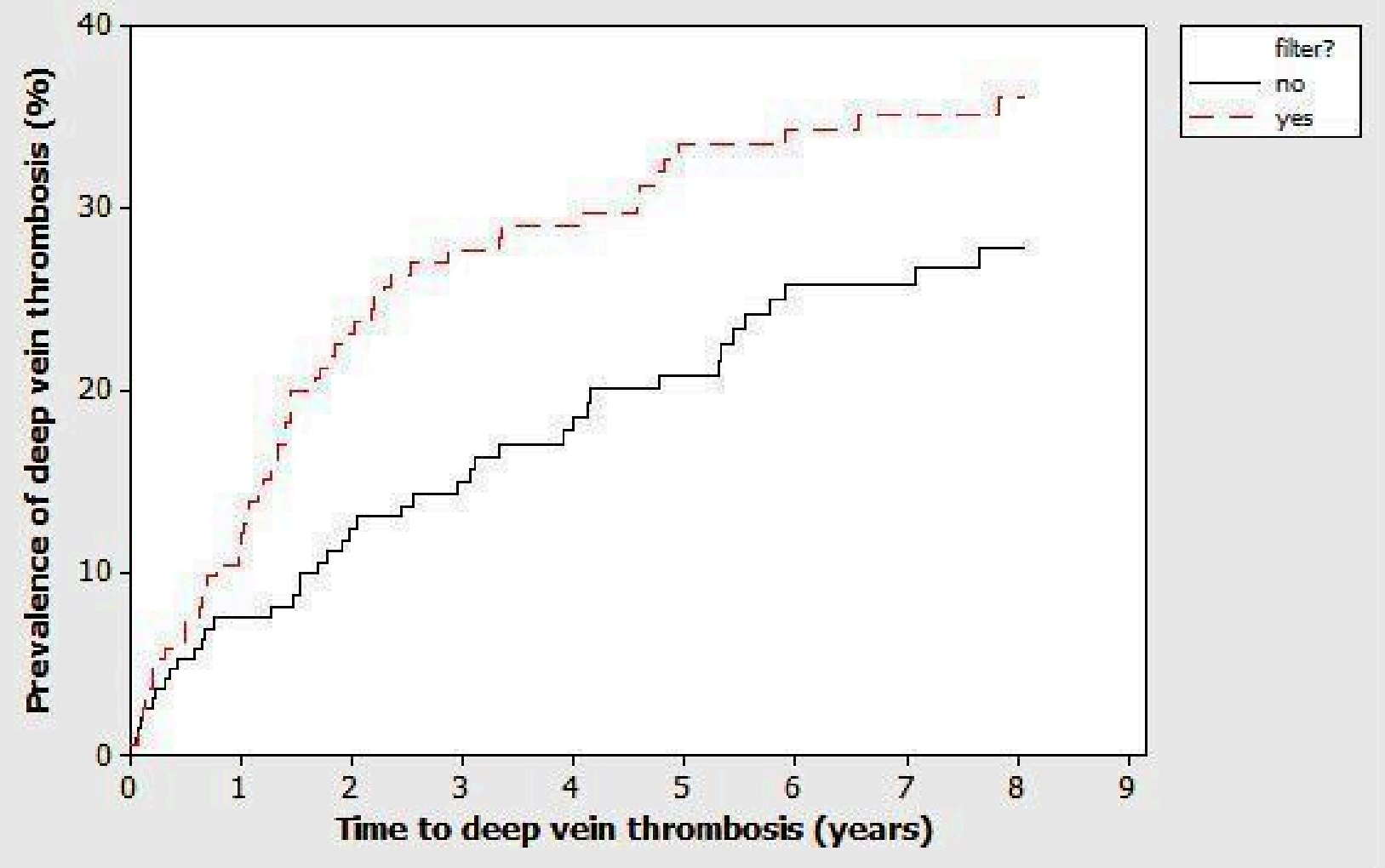

Thrombosis was not reported in Fullen 1973.

Barginear 2012 did not show any clear difference in DVT rates with or without filter (anticoagulation alone $58.4 \%$ versus $64 \%$ anticoagulation with filter).

Usoh 2010 suggested a higher rate of IVC or iliac vein thrombosis with the TrapEase filter compared to the Greenfield filter (TE 5/72 versus GF 0/84, P = 0.02).

\section{Filter-related complications: mortality, embolisation, clinical perforation}

PREPIC2 did not assess filter-related complications. However, it was noted that, of the 193 people who actually received a filter, it could only be successfully retrieved in 153 . There were only minor complications of the filter noted whilst in situ.

In Ho 2019, filter thrombosis was noted in 6/122 (4.9\%) at the time of first attempted retrieval. Endothelialisation was a factor in removing the filter $2 / 122(1.6 \%)$ and required surgical removal in $1 / 108(0.9 \%)$. Filter tilt was noted in 3/122 (2.5\%) but did not affect function or retrieval. In $7 / 122(5.7 \%)$, more than one attempt at removal was necessary. The filter could not be removed at 90 days in $36 / 108$ because of ongoing filter thrombosis ( 2 participants), difficulty gaining venous access for removal (27 participants) due to halo traction etc. One woman became pregnant and was the only loss to follow-up. Otherwise, all filters were removed by day 232 .
PREPIC reported that post-thrombotic syndrome was a common complication (defined as the appearance or worsening of oedema, varicose veins, trophic disorders, or ulcers) in both groups, affecting $68 \%$ to $70 \%$ of people in each study group. No data were collected on filter-related complications. However, the sample sizes were small for rare events and therefore unlikely to be powered to detect them. Anticoagulation rates were similar in both arms.

No details about long-term complication rates were given in Fullen 1973.

In Barginear 2012, two participants in the filter group (versus none in the anticoagulation group) developed filter-related complications, including thrombosis necessitating thrombectomy in one, and continued bleeding at the insertion site with a protracted hospital admission in the other.

Usoh 2010 suggested a higher rate of IVC or iliac vein thrombosis with the TrapEase filter as opposed to the Greenfield filter (TE 5/72 versus $\mathrm{GF} 0 / 84, \mathrm{P}=0.02$ ), but no difference in other complications.

\section{Major bleeding}

The ISTH definition of 'Major Bleeding' (Schulman 2005), which applies only to people who have not had recent surgery, is as follows:

1. Fatal bleeding; and/or 
2. Symptomatic bleeding in a critical area or organ, such as intracranial (within the skull cavity), intraspinal, intraocular (within the eye), retroperitoneal (a potential space behind the abdomen), intra-articular (occurring within a joint), pericardial (the thick membrane surrounding the heart), or intramuscular with compartment syndrome;

3. Bleeding causing a haemoglobin drop of $20 \mathrm{~g} / \mathrm{L}$ or more, and requiring transfusion of two or more units of whole blood, or red cells.

PREPIC2 reported no clear difference in major bleeding at three months (RR $0.80,95 \% \mathrm{Cl} 0.32$ to $1.98 ; \mathrm{P}=0.62 ; 1$ study, 399 participants) or six months (RR $0.86,95 \% \mathrm{Cl} 0.42$ to $1.77 ; \mathrm{P}=0.69 ; 1$ study, 399 participants; moderate-certainty evidence; Analysis 1.4).

Ho 2019 reported no differences between the filter and control groups with respect to blood product transfusion requirements. There was also no clear difference in major bleeding between the filter and control groups at 90 days (RR $1.07,95 \% \mathrm{Cl} 0.90$ to 1.27 ; $\mathrm{P}=0.47$; 1 study, 240 participants; moderate-certainty evidence; Analysis 2.4) or non-major bleeding (RR $1.34,95 \% \mathrm{Cl} 0.81$ to 2.21 , $\mathrm{P}=0.26 ; 1$ study, 240 participants; Analysis 2.5). Note: "major bleeding" was defined as bleeding that contributed to death; occurred at a critical site (e.g. intracranial, intraspinal, epidural, or lung haemorrhage); led to transfusion of two or more units of red cells, platelets, or fresh frozen plasma; or was associated with a decrease in the haemoglobin level of more than 2 grams per decilitre within any 24 hour period after injury. Non-major bleeding was defined as bleeding that led to new medical interventions (e.g. gastrointestinal endoscopy or local or systemic drugs to control bleeding). Minor bleeding that did not result in any medical intervention was not reported.

PREPIC reported no clear difference in bleeding at two-year followup results (filter $17 / 200$ versus no filter 22/200), reporting an odds ratio (OR) of $0.77,(95 \% \mathrm{Cl} 0.42$ to $1.41,400$ participants, $\mathrm{P}=0.41)$.

Fullen 1973 did not analyse this outcome, and it was not routine for the participants to receive anticoagulation.

Barginear 2012 suggested that there was no difference in bleeding (the study reported that one participant in the anticoagulation with filter group had significant bleeding, as opposed to two in the anticoagulation arm).

Usoh 2010 did not assess this outcome; some of the participants were enrolled because they had a problem with bleeding and therefore could not receive anticoagulation in the first instance.

\section{DISCUSSION}

\section{Summary of main results}

Six studies were included in this review but only two (PREPIC2; Ho 2019), were considered to be relevant to current clinical contexts.

PREPIC2 was a RCT of 399 participants, followed over six months, using retrievable filters in those at high risk of PE who could receive anticoagulation. This study showed no clear benefit in terms of PE, mortality, symptomatic lower extremity thrombosis (DVT), or bleeding (moderate-certainty evidence) in the initial three months. However, not all filters could be removed. Only minor complications from the filters were noted at six months but these people could be subject to the long-term problems associated with permanent filters.

Ho 2019 was a RCT of 240 participants who sustained multiple traumatic injuries and who had a retrievable filter inserted after three or seven days from injury, with delayed initiation of prophylactic anticoagulation. Follow-up was for 90 days. This study also did not show any evidence of a benefit in terms of symptomatic PE, mortality, lower extremity thrombosis or bleeding. One participant required surgery to remove the filter as it could not be done percutaneously.

The remaining four studies were deemed not relevant to current clinical practice because they used permanent filters which are seldom used now (Barginear 2012; PREPIC, Fullen 1973), they did not use routine prophylactic anticoagulation which is current standard practice (Fullen 1973), or compared two filter types and was stopped early as one filter group had a higher rate thrombosis compared to the other filter type.(Usoh 2010). Their results are summarised below:

PREPIC used permanent filter designs in a group of 400 participants who had DVT and/or at high risk of PE and who could also be anticoagulated. The PREPIC study showed permanent VCFs prevented PE at eight years and an increasing incidence of DVT that correlated to the length of time the filter was in situ.

Fullen 1973 showed a reduction in PE in 129 high risk participants following a traumatic hip fracture who did not receive DVT prophylaxis. However, it was inadequately randomised, had more people unable to have surgical fixation of their fracture in the control group, and the outcome assessors were not blinded. It also used a filter that was subsequently removed from clinical use because of its occasional fatal filter embolism risk and high late caval thrombosis rate (Greenfield 1992). It has limited generalisability as it is now considered standard practice for DVT prophylaxis to be administered in people with traumatic hip fractures. Fullen 1973 has problems with selection bias as well as poorer diagnostic methods for PE. The study was also done prior to routine anticoagulation post-traumatic femoral fractures, which is now the current standard practice.

Barginear 2012 was a modest, single-centre, high-quality RCT involving 64 participants, which suggested no benefit of a permanent filter over anticoagulation in people with cancer and VTE.

Usoh 2010 was a single-centre study of 156 participants at risk of $\mathrm{PE}$, who were randomised to one of two filter designs. The study was prematurely terminated when interim results indicated an increased rate of IVC/IV thrombosis with the Trapease filter group versus the Greenfield filter group over two years, but there were potential biases in participant selection.

Only preliminary conclusions regarding lack of filter efficacy in the prevention of PE can be drawn from these RCTs; further trial data would be desirable, but may be logistically challenging to achieve.

\section{Overall completeness and applicability of evidence}

PREPIC2, demonstrated there is no clear evidence of a benefit for routine retrievable filter insertion in people who are at high risk of PE, who can be anticoagulated. Ho 2019 showed no evidence of a benefit from prophylactic retrievable filter insertion in people 
with multiple traumatic injuries, deployed either after three or seven days (from insult), with concurrent but deferred initiation of pharmacological anticoagulation. As discussed above, only these two trials were considered relevant to current clinical settings. In PREPIC2, minor complications from the filters were noted at six months but these people could be subject to the long-term problems associated with permanent filters. Ho 2019 reported eventual percutaneous removal of all filters, except for two cases - one became pregnant and was lost to follow-up, and the other necessitated surgical removal. Retrievable filters have variable retrieval rates as reported in the literature, from 14\% (Brown 2017) to between $88 \%$ and $100 \%$ (Imberti 2005). The true rate of filter retrieval is not known as these figures are likely to reflect publication bias. Local rates of removal are influenced by the clinical situation, the experience of the individual interventionist, and institutional protocols. With increasing expertise, and the development of advanced retrieval techniques, allowing the extension of the (manufacturer's) recommended implantation period, this facilitated the scenario in which the filter was indicated to resolve or diminish; before this, their retrieval would be compromised. It is envisaged that retrievable filters may avoid the long-term thrombogenic problems seen with permanent filters but this remains to be seen.

In the PREPIC study, the group of people who received filters in the study varied significantly from the wider application in current clinical practice, notably those patients with DVT or PE, but excluded those in whom anticoagulation had failed or could not be administered. In addition, the PREPIC study used permanent filters. This limits the generalisability of the study's conclusion. There is an increasing trend towards the use of retrievable filters in practice, although it would seem many of these are left in situ (Karmy-Jones 2007). The PREPIC study also lacked statistical power to detect a reduction in the incidence of pulmonary embolism over shorter and more clinically significant time periods. The significance of the reported reduced PE at day 12 is contributed to in part by the rates of asymptomatic $\mathrm{PE}$. Incidental asymptomatic $\mathrm{PE}$ found on imaging for another indication is a management conundrum, with no evidence from either RCTs or large prospective trials showing a benefit from anticoagulation in people with no known VTE risk factor(s) (Chiu 2017). Filters are an adjunctive treatment with anticoagulation in patients with (or at high risk of) proximal DVT or $P E$. Anticoagulation remains the mainstay of treatment for venous thromboembolism (VTE) provided there are no contraindications to this.

Given the current lack of evidence in people who have a permanent filter inserted due to a perceived bleeding risk, observations from the PREPIC study suggest that consideration should be given to long-term anticoagulation when or if the risk of bleeding resolves. However, further data are required to confirm this observation. In PREPIC, caval filters were associated with an increased risk of DVT in the longer term and may be a consideration influencing the duration of anticoagulation (however, the ACCP VTE Guidelines ACCP 2016 stated the presence of a filter alone should not determine the use or duration of anticoagulation). Their use is recommended to be restricted to certain high-risk situations until more information becomes available.

No conclusions can be drawn for other subgroups of people who might benefit from filters as they have not been studied in this or any other RCT. There are several large case series reporting long-term experiences of filters for various indications but none of these studies fulfilled the inclusion criteria for this review. These groups of people include those with cancer and in pregnancy, with concurrent VTE; patients with proven DVT or PE in whom anticoagulation has failed; patients with upper extremity thrombosis and superior vena caval filters; and those with suprarenal caval filters.

The PREPIC study failed to demonstrate a survival advantage; it is noted that the majority of deaths were attributed to cancer or cardiovascular-related causes. Pulmonary embolism accounted for seven deaths, but the PREPIC study lacked statistical power to detect a difference in PE-related mortality.

Barginear 2012 showed no benefit from filter insertion in people who had cancer and acute VTE who also received anticoagulation. It was a modest trial of 64 participants, using permanent filters. Cancer staging ranged from locally advanced (stage II, involving immediately adjacent lymph node groups) to metastatic disease. To confound the current situation, the increasing use of targeted cancer immunotherapies has altered survival- and disease-free rates for certain malignancies (Carter 2020).

Fullen 1973 is no longer relevant as it is standard practice to use DVT prophylaxis to reduce PE rates in people who have sustained hip fractures.

Usoh 2010 demonstrated an increased filter thrombosis rate in the Trapease versus the Greenfield filter. There are many other filter designs available and no other trials have directly compared filters. It remains to be seen whether these double-basket filter designs have negative haemodynamics which promote filter thrombosis.

Superior vena caval filters are inserted for upper extremity thrombosis. Filters, being foreign objects within the body, potentially promote thrombosis. The superior vena cava is much shorter than the inferior vena cava, theoretically increasing the risk of clinically significant filter embolisation. Further information is needed before their placement in the superior vena cava is considered.

\section{Quality of the evidence}

Six RCTs with 1388 participants were included in this review. The studies were carried out in very different clinical situations and so were too heterogenous to pool together for meta-analyses. All were open-label studies (i.e. participants were not blinded) and were of variable methodological quality (see Figure 2 and Figure 3). Three studies were single-centre studies which were subject to significant selection, performance or detection bias (Barginear 2012; Fullen 1973; Usoh 2010). As all the caval filter trials discussed in this review had relatively low numbers of events from moderate numbers of participants, this introduces the possibility of imprecision.

PREPIC2 was a RCT of 399 participants, followed over six months, using retrievable filters in people with VTE at high risk of recurrent PE. They did not demonstrate any advantage of routine filter insertion for the first three or six months, in those who also received anticoagulation in terms of PE, symptomatic DVT, death or bleeding (moderate-certainty evidence). There was no difference in the rates of anticoagulation between the control and filter groups. This was a well-designed RCT. See Summary of findings 1 . We assessed this as moderate-certainty evidence and downgraded the certainty from 
high to moderate due to some concerns over imprecision and risk of bias (low numbers of events and open-label study design).

Ho 2019 was also a well-designed RCT involving 240 participants with sustained multiple traumatic injuries who received a filter early (day three to six) or later (after day seven) versus no filter, with delayed commencement of prophylactic VTE prophylaxis, over 90 days. There was no evidence of an advantage of filter insertion to symptomatic PE, mortality, or lower limb thrombosis rates (moderate-certainty evidence). There were similar rates of anticoagulation and intermittent pneumatic compression use between the filter and control groups. Only one filter could not be retrieved percutaneously, and warranted surgical removal. See Summary of findings 2 . We assessed this as moderate-certainty evidence and downgraded certainty from high to moderate due to some concerns over imprecision and risk of bias (low numbers of events and open-label study design).

We did not assess the remaining studies using GRADE criteria as they were not generally applicable to current clinical situations.

PREPIC lacked statistical power and used permanent filters that are now less frequently recommended. Fullen 1973 was of poor methodological quality and was published prior to routine prophylactic anticoagulation for post-traumatic femoral fractures, which is the current standard practice. Barginear 2012 also used permanent filters and was limited in its modest size and clinical applicability as it focussed on people with cancer and VTE. Usoh 2010 was terminated prematurely due to increased thrombosis in one filter group and compared only two of many available filters.

\section{Potential biases in the review process}

We applied no language restrictions on publications including ongoing trials. The Cochrane Vascular Information Specialist (CIS) carried out an extensive search for relevant studies. To further expand the search, we studied the reference lists of relevant articles retrieved by the above searches. Both authors identified and searched for the studies. The six included studies were clinically heterogeneous and therefore we did not pool the studies for analysis so there is limited evidence available for specific clinical situations.

\section{Agreements and disagreements with other studies or reviews}

There are reviews of filters in other circumstances such as obesity surgery but the evidence that filters may be beneficial, and without harm, is scarce (Rowland 2015). There is a paucity of RCT evidence for the effectiveness and indications for vena caval filters. Guidelines summarised in the table below are evidencebased, but the lack of RCT evidence limits the strength of their recommendations (Table 1 ).

The American College of Chest Physician's Antithrombotic Therapy and Prevention of Thrombosis Guidelines, was published in 2012 (ACCP 2012), with an update in 2016 (ACCP 2016). They state that in people with VTE who can be anticoagulated, there is no indication for the use of an IVC filter; the American Heart Association (AHA 2011) and the British Society of Haematology (BSH 2006) have made similar statements. There is not enough information to make any recommendations in the subgroup who have acute PE with hypotension, who subsequently go onto to receive thrombolysis and anticoagulation. Registry data support a reduction in mortality using caval filters in this group (ACCP 2012). In people with acute $\mathrm{PE}$, and a contraindication to anticoagulation, an IVC filter is recommended. In ACCP 2012, if a person has a PE, and an IVC filter is inserted, should the bleeding risk diminish, then anticoagulation should be given as if the filter was not in situ. They do not recommend continuing anticoagulation long term for a permanent filter. The ACCP guidelines (ACCP 2012; ACCP 2016), specifically do not make any recommendations regarding prophylactic indications of VCF insertion. The EAST 2002 guidelines suggest a retrievable filter be considered in people who have sustained trauma and are at high risk of VTE, including those with injuries which are a contraindication to anticoagulation, and/or injuries that result in prolonged immobility (such as significant head injuries, spinal cord injury with resultant paraplegia or quadriplegia, complex pelvic and/or long bone(s) fractures), but these have not been updated since the publication of Ho 2019.

\section{AUTHORS' CONCLUSIONS}

\section{Implications for practice}

Two of the six identified studies were relevant for current clinical settings. One showed no evidence of a difference with retrievable filters in acute PE for the outcomes of PE, death, symptomatic DVT and bleeding during the initial three months in people who could receive anticoagulation (moderate-certainty evidence). The other study did not show any evidence of a difference after prophylactic filter insertion in people who sustained multiple traumatic injuries with respect to symptomatic PE, mortality rates, or lower limb venous thrombosis (moderate-certainty evidence). No firm conclusions regarding filter efficacy in the prevention of PE can be drawn from the remaining four RCTs identified in this review.

With the paucity of evidence for groups of people for whom filters are potentially beneficial and for the use of retrievable filters, the American College of Chest Physician Guidelines (ACCP 2012) suggest the current accepted indication for filters is a contraindication to anticoagulation. Clinical judgement is required for other indications in which filters may be considered, such as for patients with VTE and diminished cardiopulmonary reserve, those undergoing high-risk surgery, or those who receive thrombolysis for a proximal DVT. It would appear to be prudent to scan the lower limbs to confirm the presence of residual thrombus before contemplating filter insertion.

\section{Implications for research}

Information regarding the indications is lacking, and short- and long-term complications of permanent and retrievable filters is incomplete (Brown 2017; Deso 2016). Large RCTs are desirable in groups of people who have failed, or have contraindications to anticoagulation, to confirm the efficacy of caval filters in this group; similarly, in people who have cancer and concurrent VTE, and in those with upper limb thrombosis and superior vena caval filters. Large RCTs to compare the various retrievable filter brands/ types would provide useful information about their efficacy and complication rates. However, relatively few filters are inserted and so the time to enroll sufficient numbers is considerable recruitment in PREPIC and PREPIC2 for 400 participants took four and six years respectively; Ho 2019 recruited 240 people over 2.5 years. Registry data may provide supplemental information. Outcomes should ideally include rates of PE and DVT, mortality, post-thrombotic syndrome and its effects on quality of life; filter- 
related complications: mortality from filter insertion, clinical filter embolism and perforation, and caval thrombosis. The duration of these trials should be at least two years to provide an indication of long-term complication rates.

\section{A C K N O WLEDGEMENTS}

Thanks to Cochrane Vascular for assisting with the search for relevant articles; Carmel Williams at the Buttfield library at the
NWRH and the University of Queensland Library for obtaining articles; and Dr Harry Bartlett (QUT) for statistical advice and input. The review authors would like to thank Rodney Hughes for his involvement in previous versions of the review.

The review authors and the Cochrane Vascular Editorial base thank the peer referees for their comments. 


\section{R E F E R E N C E S}

\section{References to studies included in this review}

Barginear 2012 \{published data only\}

Barginear MF, Gralla RJ, Akerman M, Lesser M, Bradley TP, Shapira I, et al. Is there an advantage to adding inferior vena cava filter (IVCF) placement to anticoagulation with fondaparinux in patients with cancer and venous thromboemboli (VTE): results of the Cancer and Thrombosis (CAT) prospective randomised clinical trial (RCT). Journal of Clinical Oncology 2011;29 (Suppl):abstr 9063.

* Barginear MF, Gralla RJ, Bradley TP, Ali SS, Shapira I, Greben C, et al. Investigating the benefit of adding a vena cava filter to anticoagulation with fondaparinux in patients with cancer and venous thromboembolism in a prospective randomised clinical trial. Supportive Care Cancer 2012;20(11):2865-72.

Gralla RJ, Barginear MF, Ackerman M, Lesser M, Bradley T, Shapira I, et al. Results of the CAT (Cancer And Thrombosis) prospective randomised clinical trial testing the addition of an IVC filter to fondaparinux. Supportive Care in Cancer 2011;19(2 Suppl):S192-3.

\section{Fullen 1973 \{published data only\}}

Fullen WD, Miller EH, Steele WF, McDonough JJ. Prophylactic vena caval interruption in hip fractures. Journal of Trauma 1973;13(5):403-10.

\section{Ho 2019 \{published data only\}}

* Ho KM, Rao S, Honeybul S, Zellweger R, Wibrow B, Lipman J, et al. A multicenter trial of vena cava filters in severely injured patients. New England Journal of Medicine 2019;381(4):328-37. [DOI: 10.1056/NEJMoa1806515] [PMID: 31259488]

Ho KM, Rao S, Honeybul S, Zellweger R, Wibrow B, Lipman J, et al. Detailed assessment of benefits and risks of retrievable inferior vena cava filters on patients with complicated injuries: the da Vinci multicentre randomised controlled trial study protocol. BMJ Open 2017;7(7):e016747. [DOI: 10.1136/ bmjopen-2017-016747] [PMID: 28706106]

\section{PREPIC \{published data only\}}

* Decousus H, Barral F, Buch-muller A, Charbonnier B, Girard P, Lamer $C$, et al. Eight-year follow-up of patients with permanent vena cava filter in the prevention of pulmonary embolism. Circulation 2005;112(3):416-22

Decousus H, Leizorovicz A, Parent F, Page Y, Tardy B, Girard $P$, et al. A clinical trial of vena caval filters in the prevention of pulmonary embolism in patients with proximal deep-vein thrombosis. New England Journal of Medicine 1998;338(7):409-15.

Decousus H. Eight-year follow-up of a randomized trial investigating vena cava filters in the prevention of $\mathrm{PE}$ in patients presenting a proximal DVT: the PREPIC trial. Journal of Thrombosis and Haemostasis 2003;1(Suppl 1):Abstract OC440. [MEDLINE: 6457]
PREPIC2 \{published data only\}

Mismetti P, Ennezat PV, Quéré I, Jeannot S, Barral FG, Couturaud $F$, et al. Prevention of pulmonary embolism recurrences by retrievable vena cava filter: results of the randomized multicenter trial PREPIC 2. Journal of Thrombosis and Haemostasis 2013;11 (Suppl 2):28.

* Mismetti P, Laporte S, Pellerin O, Ennezat P, Couturaud F, Elias A, et al. Effect of a retrievable inferior vena cava filter plus anticoagulation vs anticoagulation alone on risk of recurrent pulmonary embolism: a randomized clinical trial. Journal of the American Medical Association 2015;313(16):1627-35.

Mismetti P, Mottier D, Decousus H, Ennezat PV, Quere I, Schmidt J, et al. A randomized multicenter trial to assess the efficacy and safety of retrievable vena cava filter for the prevention of pulmonary embolism recurrences. Fundamental and Clinical Pharmacology 2014;28 (Suppl 1):25.

Mismetti P. Randomized trial assessing the efficacy of the partial interruption of the inferior vena cava by an optional vena caval filter in the prevention of the recurrence of pulmonary embolism. PREPIC 2 trial: prevention of embolic recurrences by caval interruption (prospective, multicentric, randomised, open trial). Revue de Pneumologie Clinique 2008;64(6):328-31.

NCT00457158. PREPIC 2: Prevention of recurrent pulmonary embolism by vena cava interruption (PREPIC2). clinicaltrials.gov/ct2/show/NCT00457158 (first posted 4 April 2007).

Pellerin O, Barral F, Sanchez O, Midulla M, Mismetti P, Sapoval M, et al. Optional vena cava filter placement and 3 months retrievability: results of the PREPIC 2 randomised multicenter trial. Journal of Vascular and Interventional Radiology 2014;25(3 (Suppl)):S84.

\section{Usoh 2010 \{published data only\}}

Usoh F, Hingorani A, Ascher E, Shiferson A, Patel N, Gopal K, et al. Prospective randomised study comparing the clinical outcomes between inferior vena cava Greenfield and TrapEase filters. Journal of Vascular Surgery 2010;52(2):394-9.

\section{References to studies excluded from this review}

\section{Bocharov 2011 \{published data only\}}

Bocharov AV, Cherenkov VG, Ukhanov AP, Chentsov VI. Potential endovascular prophylaxis for pulmonary thromboembolism in the combined treatment of cancer patients. Voprosy Onkologii 2011;57:513-6.

\section{Brasel 1997 \{published data only\}}

Brasel K, Borgstrom DC, Weigelt JA. Cost-effective prevention of pulmonary embolus in high-risk patients. Journal of Trauma, Injury, Infection and Critical Care 1997;42(3):456-62.

\section{Gosin 1997 \{published data only\}}

Gosin JS, Graham AM, Ciocca RG, Hammond JS. Efficacy of prophylactic vena caval filters in high-risk trauma patients. Annals of Vascular Surgery 1997;11:100-5. 
Khansarinia 1995 \{published data only\}

Khansarinia S, Dennis JW, Veldenz HC, Butcher LC, Hartland L. Prophylactic Greenfield filter placement in selected high-risk trauma patients. Journal of Vascular Surgery 1995;22:231-6.

\section{Midy 1994 \{published data only\}}

Midy D, Pheline P, Baste JC. Antheor percutaneous filter endocaval filter. Multicentre evaluation based on 300 cases [Filtre endocave percutane antheor. Evaluation multicentrique a propos de 300 cas]. Journal de Maladies Vasculaires 1994;19(4):308-13.

\section{NCT00423683 \{published data only\}}

NCT00423683. Anticoagulation and inferior vena cava filters in cancer patients with a venous thromboembolism. clinicaltrials.gov/ct2/show/NCT00423683 (first posted 18 January 2007).

\section{NCT02201277 \{published data only\}}

NCT02201277. ODEN Trial: Option vs. Denali IVC filters (ODEN). clinicaltrials.gov/ct2/show/NCT02201277 (first posted 23 July 2014).

\section{Pan 2019 \{published data only\}}

Pan Y, Mei J, Wang L, Shao M, Zhang J, Wu H, et al. Investigation of the incidence of periopeperative pulmonary embolism in patients with below-knee deep vein thrombosis after lower extremity fracture and evaluation of retrievable inferior vena cava filter deployment in these patients. Annals of Vascular Surgery 2019;60:45-51.

\section{Rajasekhar 2011 \{published data only\}}

Rajasekhar A, Lottenberg L, Lottenberg R. A pilot study on the randomisation of inferior vena cava filter placement for venous thromboembolism prophylaxis in high-risk trauma patients. Journal of Trauma, Injury, Infection and Critical Care 2011;71:323-8.

\section{Rodriguez 1996 \{published data only\}}

Rodriguez JL, Lopez JM, Proctor MC, Conley JL, Gerndt SJ, Marx VM, et al. Early placement of prophylactic vena caval filters in injured patients at high risk for pulmonary embolism. Journal of Trauma, Injury, Infection and Critical Care 1996;40(5):797-804.

\section{Rogers 1997 \{published data only\}}

Rogers FB, Shackford SR, Ricci MA, Huber BM, Atkins T. Prophylactic vena caval filter insertion in selected high-risk orthopaedic trauma patients. Journal of Orthopaedic Trauma 1997;11(4):267-72.

\section{Rosenthal 1994 \{published data only\}}

Rosenthal D, McKinsey JF, Levy AM, Lamis PA, Clark MD. Use of the Greenfield filter in patients with major trauma. Cardiovascular Surgery 1994;2(1):52-5.

\section{Rosner 2004 \{published data only\}}

Rosner MK, Kuklo TR, Tawk R, Moquin R, Ondra SL. Prophylactic placement of an inferior vena cava filter in high-risk patients undergoing spinal reconstruction. Neurosurgical Focus 2004;17(4):1-6

\section{Sharifi 2012 \{published data only\}}

Sharifi M, Bay C, Skrocki L, Lawson D, Mazdeh S. Role of IVC filters in endovenous therapy for deep venous thrombosis: the FILTER-PEVI (filter implantation to lower thromboembolic risk in percutaneous endovenous intervention) trial. Cardiovascular and Interventional Radiology 2012;35(6):1408-13.

Stavropoulos 2016 \{published data only\}

Stavropoulos SW, Chen JX, Sing RF, Elmasri F, Silver MJ, Powell A, et al. Analysis of the final DENALI trial data: a prospective, multicentre study of the Denali inferior vena cava filter. Journal of Vascular and Interventional Radiology 2016;27:1531-8.

Webb 1992 \{published data only\}

Webb LX, Rush PT, Fuller SB, Meredith WJ. Greenfield filter prophylaxis of pulmonary embolism in patients undergoing surgery for acetabular fracture. Journal of Orthopaedic Trauma 1992;6(2):139-45.

\section{References to ongoing studies \\ ACTRN12612001071819 \{published data only\}}

ACTRN12612001071819. A randomised study to compare the technical difficulty of retrieval between the Bard G2X and the Cook Celect Vena Cava Filter systems in patients at high risk for pulmonary embolism. anzctr.org.au/Trial/Registration/ TrialReview.aspx?id=336779 (first posted 8 October 2012).

\section{ChicTR1900023485 \{published data only\}}

ChiCTR1900023485. Prospective multi-center, randomized, controlled trial to assess the safety and performance of the ballet vena cava filter system for the precaution of pulmonary embolism. chictr.org.cn/showprojen.aspx?proj=38298 (first posted 31 May 2019).

\section{NCT00588757 \{published data only\}}

NCT00588757. Comparison between two optional IVC filters regarding ease of use, complications and outcome. clinicaltrials.gov/ct2/show/NCT00588757 (first posted 9 January 2008).

NCT03070834 \{published data only\}

NCT03070834. RIPT Feasibility Trial (RIPT). clinicaltrials.gov/ct2/ show/NCT03070834 (first posted 6 March 2017).

NCT03691753 \{published data only\}

NCT03691753. Safety and efficacy study of Fitaya vena cava filter. clinicaltrials.gov/ct2/show/NCT03691753 (first posted 2 October 2018)

NCT03987321 \{published data only\}

NCT03987321. Retrievability and incidence of complex retrieval in Celect versus Denali filter. clinicaltrials.gov/ct2/show/ NCT03987321 (first posted 17 June 2019). 


\section{Additional references}

\section{ACCP 2012}

Guyatt GH, Akl EA, Crowther M, Gutterman DD, Schunemann HJ, American College of Chest Physicians Antithrombotic Therapy and Prevention of Thrombosis Panel. Executive Summary. Antithrombotic Therapy and Prevention of Thrombosis 9th ed: American College of Chest Physicians Evidence-Based Clinical Practice Guidelines. Chest 2012;141(2):7S-47S.

\section{ACCP 2016}

Kearon C, Akl EA, Ornelas J, Blaivis A, Jimenez D, Bournameaux $\mathrm{H}$, et al. Antithrombotic therapy for VTE disease: CHEST guideline and expert panel report. Chest 2016;149(2):315-52.

\section{ACR-SIR Practice Parameter 2014}

American College of Radiology (ACR) and the Society of Interventional Radiology (SIR). ACR-SIR Practice parameter for the performance of inferior vena cava (IVC) filter placement for the prevention of pulmonary embolism. acr.org/QualitySafety/Standards-Guidelines/Practice-Guidelines-by-Modality/ Interventional (accessed 26 November 2015).

\section{AHA 2011}

Jaff MR, McMurtry MS, Archer SL, Cushman M, Goldenberg N, Goldhaber SZ, et al. Management of massive and submassive pulmonary embolism, iliofemoral deep vein thrombosis, and chronic thromboembolic pulmonary hypertension: a scientific statement from the American Heart Association. Circulation 2011;123:1788-1830.

\section{Brown 2017}

Brown JD, Raissi D, Han Q, Adams VR, Talbert JC. Vena cava filter retrieval rates and factors associated with retrieval in a large US cohort. Journal of American Heart Association 2017;6(9):e006708.

\section{BSH 2006}

Baglin TP, Brush J, Streiff M. Guidelines on use of vena cava filters: British Committee for Standards in Haematology. British Journal of Haematology 2006;134:590-5.

\section{Carter 2020}

Carter S, Thurston DE. Immuno-oncology agents for cancer therapy. Pharmaceutical Journal 2020;304(7937):S2-27. [DOI: 10.1211/PJ.2020.20207825]

\section{Chiu 2017}

Chiu V, O'Connell C. Management of the incidental pulmonary embolism. American Journal of Roentgenology 2017;208(3):485-8.

\section{Deso 2016}

Deso SE, Ibrahim Al, Kuo WT. Evidence-based evaluation of inferior vena cava filter complications based on filter type. Seminars in Interventional Radiology 2016;33(2):93-100.

\section{Douketis 1998}

Douketis JD, Kearon C, Bates S, Duku EK, Ginsberg JS. Risk of fatal pulmonary embolism in patients with treated venous thromboembolism. Journal of the American Medical Association 1998;279(6):458-62.

\section{EAST 2002}

Rogers FB, Cipolle MD, Velmahos G, Rozycki G, Luchette FA. Eastern Assocation for the Surgery of Trauma Practice Management Guidelines. Journal of Trauma 2002;53(1):142-64.

\section{ESC 2014}

Zamorano JL, Achenbach S, Baumgartner H, Bax JJ, Bueno H, Dean V, et al, the Task Force for the Diagnosis and Management of Acute Pulmonary Embolism of the European Society of Cardiology (ESC). 2014 ESC Guidelines on the diagnosis and management of acute pulmonary embolism. European Heart Journal 2014;35(43):3033-73.

\section{Gomes 2003}

Gomes MPV, Kaplan KL, Deitcher SR. Patients with inferior vena cava filters should receive chronic thromboprophylaxis. Medical Clinics of North America 2003;87:1189-203.

\section{GRADEpro GDT [Computer program]}

McMaster University (developed by Evidence Prime, Inc) GRADEpro Guideline Development Tool. Version accessed 23 January 2018. Hamilton (ON): McMaster University (developed by Evidence Prime, Inc), 2015. Available from gradepro.org.

\section{Greenfield 1992}

Greenfield LJ. Evolution of venous interruption for pulmonary thromboembolism. Archives of Surgery 1992;127(5):622-6. [MEDLINE: 1575633]

\section{Greenspan 1982}

Greenspan RH, Ravin CE, Polanksy SM, McLoud TC. Accuracy of the chest radiograph in diagnosis of pulmonary embolism. Investigative Radiology 1982;17(6):539-43.

\section{Guyatt 2008}

Guyatt GH, Oxman AD, Vist GE, Kunz R, Falck-Ytter Y, AlonsoCoello $P$, et al. GRADE: an emerging consensus on rating quality of evidence and strength of recommendations. $B M J$ 2008;336(7650):924-6.

\section{Hann 2005}

Hann CL, Streiff MB. The role of vena caval filters in the management of venous thromboembolism. Blood Reviews 2005;19:179-202.

\section{Higgins 2011}

Higgins JPT, Green S (editors). Cochrane Handbook for Systematic Reviews of Interventions Version 5.1.0 (updated March 2011). The Cochrane Collaboration, 2011. Available from handbook.cochrane.org.

\section{Imberti 2005}

Imberti D, Ageno W, Carpenedo M. Retrievable vena caval filters: a review. Current Opinion in Haematology 2006;13:351-6. 


\section{Jadad 1996}

Jadad AR, Moore RA, Carroll D, Jenkinson C, Reynolds JM, McQuay HJ. Clinical trials: is blinding necessary? Controlled Clinical Trials 1996;17:1-12.

\section{Kalva 2008}

Kalva SP, Chlapoutaki C, Wicky S, Greenfield AJ, Waltman AC, Athanasoulis A. Suprarenal inferior vena cava filters: a 20-year single-center experience. Journal of Interventional and Vascular Radiology 2008;19:1041-7.

\section{Karmy-Jones 2007}

Karmy-Jones R, Jurkovich GJ, Velmahos GC, Burdick T, Spaniolas K, Todd SR, et al. Practice patterns and outcomes of retrievable vena cava filters in trauma patients: an AAST multicenter study. Journal of Trauma Injury, Infection and Critical Care 2007;62:17-25.

\section{Kinney 2003}

Kinney TB. Update on inferior vena caval filters. Journal of Vascular and Interventional Radiology 2003;14:425-40.

\section{Lefebvre 2011}

Lefebvre C, Manheimer E, Glanville J. Chapter 6: Searching for studies. In: Higgins JP, Green S, editor(s). Cochrane Handbook for Systematic Reviews of Interventions Version 5.1.0 (updated March 2011). The Cochrane Collaboration, 2011. Available from handbook.cochrane.org.

\section{Lessne 2015}

Leesne ML, Holly B, Bhagat N, Tamrazi A. Percutaneous removal of permanent IVC filters: tips, tricks, and TrapEases. Journal of Vascular and Interventional Radiology 2015;26:S220-1.

\section{Norris 1985}

Norris CS, Greenfield LJ, Hermann JB. Free-floating iliofemoral thrombus: a risk of pulmonary embolism. Archives of Surgery 1985;120:806-8.

\section{Owens 2010}

Owens CA, Bui JT, Knuttinen G, Gaba RC, Carrillo TC. Pulmonary embolism from upper extremity deep vein thrombosis and the role of superior vena cava filters: a review of the literature. Journal of Vascular and Interventional Radiology 2010;21:779-87.

\section{PIOPED}

PIOPED investigators. Value of the ventilation/perfusion scan in pulmonary embolism. Results of the prospective investigation of pulmonary embolism diagnosis. Journal of the American Medical Association 1990;263(20):2753-9.

\section{Radomski 1987}

Radomski JS, Jarrell BE, Carabasi RA, Yang S-L, Koolpe H. Risk of pulmonary embolus with inferior vena caval thrombosis. American Surgeon 1987;53:97-101.

\section{Rajeshekar 2013}

Rajeshekar A, Streiff MB. Vena cava filters for managment of venous thromboembolism: a clinical review. Blood Reviews 2013;27(5):225-41.

\section{Rowland 2015}

Rowland SP, Dharmarajah B, Moore HM, Lane TR, Cousins J, Ahmed AR, et al. Inferior vena cava filters for prevention of venous thromboembolism in obese patients undergoing bariatric surgery: a systematic review. Annals of Surgery 2015;261(1):35-45.

\section{Schulman 2005}

Schulman S, Kearon C, Subcommittee on Control of Anticoagulation of the Scientific and Standardization Committee of the International Society on Thrombosis and Haemostasis. Definition of major bleeding in clinical investigations of anti-hemostatic medicinal products in nonsurgical patients. Journal of Thrombosis and Haemostasis 2005;3(4):692-4.

\section{Sutherland 2017}

Sutherland T, O'Donnell C. The artefacts of death: CT postmortem findings. Journal of Medical Imaging and Radiation Oncology 2017;62(2):203-10.

\section{Tapson 2017}

Tapson VF, Hazelton JP, Myers J, Roberson C, Gilani R, Dunn JA, et al. Evaluation of a device combining an inferior vena cava filter and a central venous catheter for preventing pulmonary embolism among critically ill trauma patients. Journal of Vascular and Interventional Radiology 2017;28(9):1248-54.

\section{References to other published versions of this review \\ Young 2006}

Young T, Aukes J, Hughes R, Tang H. Vena caval filters for prevention of pulmonary embolism. Cochrane Database of Systematic Reviews 2006, Issue 4. Art. No: CD006212. [DOI: 10.1002/14651858.CD006212]

\section{Young 2007a}

Young T, Aukes J, Hughes R, Tang H. Vena caval filters for the prevention of pulmonary embolism. Cochrane Database of Systematic Reviews 2007, Issue 3. Art. No: CD006212. [DOI: 10.1002/14651858.CD006212.pub2]

\section{Young 2007b}

Young T, Tang H, Aukes J, Hughes R. Vena caval filters for the prevention of pulmonary embolism. Cochrane Database of Systematic Reviews 2007, Issue 4. Art. No: CD006212. [DOI: 10.1002/14651858.CD006212.pub3]

\section{Young 2010}

Young T, Tang H, Hughes R. Vena caval filters for the prevention of pulmonary embolism. Cochrane Database of Systematic Reviews 2010, Issue 2. Art. No: CD006212. [DOI: 10.1002/14651858.CD006212.pub4]

* Indicates the major publication for the study 


\section{CHARACTERISTICS OF STUDIES}

Characteristics of included studies [ordered by study ID]

Barginear 2012

\section{Study characteristics}

\begin{tabular}{ll}
\hline Methods & Study design: randomised single-centre study \\
Country: United States \\
Follow-up: 3 years \\
\hline
\end{tabular}

Participants 64 people who had cancer and VTE
Age range: $51-81 \mathrm{yrs}$
40 of the 64 participants were female
Inclusion criteria: age $>18 \mathrm{yrs}$, with definite diagnosis of cancer, diagnosed with acute DVT or PE, who
were receiving anticoagulation
Exclusion criteria: previous filter in situ, renal impairment with creatinine clearance $<30 \mathrm{~mL} / \mathrm{min}$, in-
dication for thrombolysis, allergy to iodine, pregnancy, active bleeding requiring transfusion, platelet
count $<50$, hereditary thrombophilia, intracranial bleeding, brain metastases secondary to melanoma/
choriocarcinoma/renal cell carcinoma/or medullary thyroid carcinoma

\begin{tabular}{ll}
\hline Interventions & Vena Tech (permanent) filters were inserted within 3 days of randomisation \\
\hline Outcomes & Survival, recurrent PE, complications with filter insertion \\
\hline
\end{tabular}

Funding This study was supported in part by a grant from GlaxoSmithKline (Supportive Care in Cancer 20, 2865 $2872(2012))$.

Declarations of interest There were no financial disclosures from any authors (Supportive Care in Cancer 20, 2865 - 2872 (2012)).

Notes

The number of participants was small, and it was done at one centre.

The anticoagulant fondaparinux was given to both the intervention (filter) and control arm.

\section{Risk of bias}

\begin{tabular}{lll}
\hline Bias & Authors' judgement & Support for judgement \\
\hline $\begin{array}{l}\text { Random sequence genera- } \\
\text { tion (selection bias) }\end{array}$ & Low risk & Computer-generated permuted block design \\
\hline $\begin{array}{l}\text { Allocation concealment } \\
\text { (selection bias) }\end{array}$ & Low risk & Computer-generated permuted block design \\
\hline $\begin{array}{l}\text { Blinding of participants } \\
\text { and personnel (perfor- } \\
\text { mance bias) }\end{array}$ & High risk & Open-label study design \\
$\begin{array}{l}\text { Mortality } \\
\begin{array}{l}\text { Blinding of participants } \\
\text { and personnel (perfor- } \\
\text { mance bias) }\end{array}\end{array}$ & High risk & Open-label study design \\
\end{tabular}


Barginear 2012 (Continued)

PE

$\begin{array}{lll}\begin{array}{l}\text { Blinding of outcome as- } \\ \text { sessment (detection bias) }\end{array} & \text { Unclear risk } & \begin{array}{l}\text { Not stated if radiologists blinded to participants filter status; all 'events' were } \\ \text { evaluated by an Independent Safety Monitoring Board }\end{array}\end{array}$
Mortality

$\begin{array}{lll}\begin{array}{l}\text { Blinding of outcome as- } \\ \text { sessment (detection bias) }\end{array} & \text { Unclear risk } & \begin{array}{l}\text { Not stated if radiologists blinded to participants filter status, all 'events' were } \\ \text { evaluated by an Independent Safety Monitoring Board }\end{array}\end{array}$
PE

\begin{tabular}{lll}
\hline $\begin{array}{l}\text { Incomplete outcome data } \\
\text { (attrition bias) } \\
\text { Mortality }\end{array}$ & Low risk & Follow-up was adequate. No loss of data \\
\hline $\begin{array}{l}\text { Incomplete outcome data } \\
\begin{array}{l}\text { (attrition bias) } \\
\mathrm{PE}\end{array}\end{array}$ & Low risk & Follow-up was adequate. No loss of data \\
\hline $\begin{array}{l}\text { Selective reporting (re- } \\
\text { porting bias) }\end{array}$ & Low risk & Primary and secondary outcomes were reported \\
\hline Other bias & Low risk & None identified \\
\hline
\end{tabular}

Fullen 1973

\section{Study characteristics}

\begin{tabular}{ll}
\hline Methods & Study design: a single-centre study \\
Country: United States \\
Follow-up was an average of 33-34 days
\end{tabular}

Participants

Number: 129 participants with proximal femoral fractures

Age: average age 69 and 67 years (filter and control group, respectively)

Sex: gender distribution not stated

Inclusion criteria: proximal femoral fractures were invited to participate in the study.

Exclusion criteria: refusal to participate in the trial

\begin{tabular}{ll}
\hline Interventions & Treatment: permanent caval filter \\
& Control: no filter \\
\hline Outcomes & Primary outcomes: \\
& 1. Mortality \\
2. PE & Secondary outcomes: \\
& 1. Complications from filter insertion \\
Outcomes assessed when clinically indicated and at discharge
\end{tabular}


Fullen 1973 (Continued)

\begin{tabular}{ll} 
Funding & Not stated \\
\hline Declarations of interest & None declared \\
\hline Notes & Anticoagulation was not used in either the intervention (filter) or control arm. \\
& Not an intention-to-treat analysis \\
& A higher rate of atherosclerotic heart disease and cardiac failure was noted in the filter group.
\end{tabular}

\section{Risk of bias}

\begin{tabular}{|c|c|c|}
\hline Bias & Authors' judgement & Support for judgement \\
\hline $\begin{array}{l}\text { Random sequence genera- } \\
\text { tion (selection bias) }\end{array}$ & High risk & $\begin{array}{l}\text { Randomisation based on odd or even hospital numbers and a higher rate of } \\
\text { atherosclerotic heart disease and cardiac failure was noted in the filter group }\end{array}$ \\
\hline $\begin{array}{l}\text { Allocation concealment } \\
\text { (selection bias) }\end{array}$ & High risk & Participation in filter group based on consent \\
\hline $\begin{array}{l}\text { Blinding of participants } \\
\text { and personnel (perfor- } \\
\text { mance bias) } \\
\text { Mortality }\end{array}$ & High risk & Open-label study design \\
\hline $\begin{array}{l}\text { Blinding of participants } \\
\text { and personnel (perfor- } \\
\text { mance bias) } \\
\text { PE }\end{array}$ & High risk & Open-label study design \\
\hline $\begin{array}{l}\text { Blinding of outcome as- } \\
\text { sessment (detection bias) } \\
\text { Mortality }\end{array}$ & Unclear risk & Blinding of outcome assessors not stated \\
\hline $\begin{array}{l}\text { Blinding of outcome as- } \\
\text { sessment (detection bias) } \\
\text { PE }\end{array}$ & Unclear risk & $\begin{array}{l}\text { Blinding of outcome assessors not stated. Use of chest radiography and V/Q } \\
\text { scan in diagnosis of PE is inaccurate. Not stated whether all participants had } \\
\text { routine imaging, or only when clinically indicated }\end{array}$ \\
\hline $\begin{array}{l}\text { Incomplete outcome data } \\
\text { (attrition bias) } \\
\text { Mortality }\end{array}$ & Low risk & $\begin{array}{l}\text { Cause of death and numbers reported. Follow-up complete as in-hospital pop- } \\
\text { ulation }\end{array}$ \\
\hline $\begin{array}{l}\text { Incomplete outcome data } \\
\text { (attrition bias) } \\
\text { PE }\end{array}$ & Low risk & Definite, probable and possible pulmonary embolism rates reported \\
\hline $\begin{array}{l}\text { Selective reporting (re- } \\
\text { porting bias) }\end{array}$ & Unclear risk & $\begin{array}{l}\text { Protocol brief. Mortality, PE and filter complication outcomes documented. } \\
\text { Rates of DVT not reported }\end{array}$ \\
\hline Other bias & Low risk & $\begin{array}{l}\text { The imaging technology available at the time may have under-reported the } \\
\text { rates of pulmonary embolism. }\end{array}$ \\
\hline
\end{tabular}

\section{Study characteristics}


Ho 2019 (Continued)

Methods
Study design: multicentre, randomised open-label study

Country: Australia, majority of participants based in one major metropolitan city in Australia

Follow-up: 90 days

\section{Participants}

Number: 240 people who sustained multiple traumatic injuries

Age: $24-57$ years

Gender: male $81 \%$

Inclusion criteria:

1. Age $>18$ years

2. Injury Severity Score of 15 or more

3. Contraindication to anticoagulation within 72 hours after injury

Exclusion criteria:

1. Severe head or traumatic injury such that death was expected within $48-72$ hours

2. The treating clinicians judged that it was safe to commence prophylactic anticoagulation within 72 hours of injury

3. People who already had PE on CT pulmonary angiography at admission

4. People who were already on systemic anticoagulation for a pre-existing medical comorbidity (for example, atrial fibrillation, or previous DVT/PE)

5. Pregnancy

6. There would be a delay for IVC filter insertion for $>72$ hours from admission

7. Age $<18$ years

Early (days 3-6) vs delayed (on, or after day 7) retrievable filter insertion

Outcomes

Primary:

1. Composite of a) symptomatic PE or b) mortality

2. Cost-effectiveness of using VCFs to prevent PE after major trauma (inclusive of costs of the VCF, number of radiological scans, length of ICU and hospital stay, procedure and medications required to treat $\mathrm{PE}$ and/or complications from the filter itself

Secondary:

1. Symptomatic fatal and non-fatal PE between day 8 and 90 in people who could not receive prophylactic anticoagulation within 7 days of injury

2. Filter-related complications, including DVT within 90 days as detected by a screening ultrasound at 2 weeks; the latter was reported as a post hoc secondary outcome.

3. All cause mortality

4. Bleeding (note "major bleeding" was not designated as per the ISTH (Schulman 2005). In this trial, it was defined as bleeding that contributed to death; occurred at a critical site (e.g. intracranial, intraspinal, epidural, or lung haemorrhage); led to transfusion of 2 more units of red cells, platelets, or fresh frozen plasma; or was associated with a decrease in the haemoglobin level of more than 2 grams per decilitre within any 24-hour period after injury. Non-major bleeding was defined as bleeding that led to new medical interventions (e.g. gastrointestinal endoscopy or local or systemic drugs to control bleeding. Minor bleeding that did not result in any medical intervention was not reported). 
Ho 2019 (Continued)

A cost-effectiveness analysis was also one of the endpoints; these results will be reported in a subsequent publication of the study.

Funding

Supported by the Medical Research Foundation of Royal Perth Hospital and the Western Australia Department of Health. The funders provided financial support to employ the research coordinators and for the cost of ultrasonography for this trial. Dr Ho was funded by the Western Australia Department of Health and the Raine Medical Research Foundation through the Raine Clinical Research Fellowship to initiate and conduct this trial. No financial or nonfinancial (including in-kind) support has been received from any commercial entities.

Declarations of interest

Dr Ho reports serving on an advisory board for Medtronic and serving as an advisor for Cardinal Health; Dr Lipman reported that he received advisory board fees, paid to his institution, from Bayer and MSD, lecture fees from Pfizer South Africa and MSD South Africa, and honoraria from Pfizer. No other potential conflict of interest relevant to this article was reported.

Notes

The rates and commencement of prophylactic anticoagulation were recorded, as was the utility of intermittent pneumatic compression.

\section{Risk of bias}

\begin{tabular}{|c|c|c|}
\hline Bias & Authors' judgement & Support for judgement \\
\hline $\begin{array}{l}\text { Random sequence genera- } \\
\text { tion (selection bias) }\end{array}$ & Low risk & $\begin{array}{l}\text { Randomisation was done via permuted-block scheme, stratified according to } \\
\text { the trial centre. }\end{array}$ \\
\hline $\begin{array}{l}\text { Allocation concealment } \\
\text { (selection bias) }\end{array}$ & Low risk & Computer-generated permuted-block design \\
\hline $\begin{array}{l}\text { Blinding of participants } \\
\text { and personnel (perfor- } \\
\text { mance bias) } \\
\text { Mortality }\end{array}$ & High risk & Open-label study design \\
\hline $\begin{array}{l}\text { Blinding of participants } \\
\text { and personnel (perfor- } \\
\text { mance bias) } \\
\text { PE }\end{array}$ & High risk & Open-label study design \\
\hline $\begin{array}{l}\text { Blinding of outcome as- } \\
\text { sessment (detection bias) } \\
\text { Mortality }\end{array}$ & Unclear risk & $\begin{array}{l}\text { Blinding of assessors not stated; the coronial investigators would not have } \\
\text { been blinded to the filter status of the participant }\end{array}$ \\
\hline $\begin{array}{l}\text { Blinding of outcome as- } \\
\text { sessment (detection bias) } \\
\text { PE }\end{array}$ & Unclear risk & Blinding of the radiology outcome assessors not stated \\
\hline $\begin{array}{l}\text { Incomplete outcome data } \\
\text { (attrition bias) } \\
\text { Mortality }\end{array}$ & Low risk & Only one person lost to follow-up \\
\hline $\begin{array}{l}\text { Incomplete outcome data } \\
\text { (attrition bias) } \\
\text { PE }\end{array}$ & Low risk & Only one person lost to follow-up \\
\hline $\begin{array}{l}\text { Selective reporting (re- } \\
\text { porting bias) }\end{array}$ & Low risk & Primary and secondary outcomes reported \\
\hline Other bias & Low risk & None identified \\
\hline
\end{tabular}




\section{Study characteristics}

Study design: multicentre study; randomised controlled open-label trial using a $2 \times 2$ factorial design
Country: France
Follow-up: 8 yrs
Intention-to-treat analysis

Number: 400 participants
Age: $73+/-11$
Sex: $64 \%$ were male
Inclusion criteria: age $>18$ with documented proximal DVT or PE, and considered high risk for recurrent
PE
Exclusion criteria:
1. previous filter
2. contraindication or failure of anticoagulation
3. curative anticoagulation $>48$ hours duration
4. indication for thrombolysis
5. short life expectancy
6. allergy to iodine
7. hereditary thrombophilia
8. severe renal or hepatic failure
9. pregnancy
10.likely non-compliance

\section{Outcomes}

Primary outcomes
1. PE
2. Mortality
3. DVT

Secondary outcomes
1. Bleeding
2. PTS
3. Filter-related complications

Outcomes assessed at 12 days, two years, eight years

Funding This study was supported by grants from Ministère Français de la Santé (PHRC), Paris, France, and from
Fondation de l'Avenir.

Declarations of interest Jean-Yves Darmon and Yves Cadroy (MediBridge Clinical Research, Vélizy, France) provided editorial as-
sistance. No other disclosures were reported.

Notes Study had low power.


PREPIC (Continued)

Risk of bias

\begin{tabular}{|c|c|c|}
\hline Bias & Authors' judgement & Support for judgement \\
\hline $\begin{array}{l}\text { Random sequence genera- } \\
\text { tion (selection bias) }\end{array}$ & Low risk & Randomisation was based on a centralised computer system. \\
\hline $\begin{array}{l}\text { Allocation concealment } \\
\text { (selection bias) }\end{array}$ & Low risk & Centralised computer telephone system \\
\hline $\begin{array}{l}\text { Blinding of participants } \\
\text { and personnel (perfor- } \\
\text { mance bias) } \\
\text { Mortality }\end{array}$ & High risk & Open-label study design \\
\hline $\begin{array}{l}\text { Blinding of participants } \\
\text { and personnel (perfor- } \\
\text { mance bias) } \\
P E\end{array}$ & High risk & Open-label study design \\
\hline $\begin{array}{l}\text { Blinding of outcome as- } \\
\text { sessment (detection bias) } \\
\text { Mortality }\end{array}$ & Low risk & $\begin{array}{l}\text { An independent adjudication committee who assessed all radiological and } \\
\text { clinical outcomes was blinded to the treatment status of the participants. }\end{array}$ \\
\hline $\begin{array}{l}\text { Blinding of outcome as- } \\
\text { sessment (detection bias) } \\
\text { PE }\end{array}$ & Low risk & $\begin{array}{l}\text { An independent adjudication committee who assessed all radiological and } \\
\text { clinical outcomes was blinded to the treatment status of the participants. }\end{array}$ \\
\hline $\begin{array}{l}\text { Incomplete outcome data } \\
\text { (attrition bias) } \\
\text { Mortality }\end{array}$ & Low risk & $\begin{array}{l}\text { Negligible losses to follow-up (only } 4 \text { of } 400 \text { participants). No missing outcome } \\
\text { data. Causes of death reported. Mortality reported at } 12 \text { days, two years and } \\
\text { eight years }\end{array}$ \\
\hline $\begin{array}{l}\text { Incomplete outcome data } \\
\text { (attrition bias) } \\
\text { PE }\end{array}$ & Low risk & No missing outcome data. PE reported at 12 days, two years and eight years \\
\hline $\begin{array}{l}\text { Selective reporting (re- } \\
\text { porting bias) }\end{array}$ & Low risk & Primary and secondary outcomes were reported. \\
\hline Other bias & Low risk & None identified \\
\hline
\end{tabular}

\section{PREPIC2}

\section{Study characteristics}

\begin{tabular}{ll}
\hline Methods & Study design: prospective, multicentre, open-label \\
Country: France & \\
Follow-up: 6 months duration \\
\hline Participants & People (399) at high risk of recurrent PE, i.e. DVT of the lower limb with any of the following: \\
- age $>75$ & - presence of right ventricular dysfunction
\end{tabular}


PREPIC2 (Continued)

- active cancer

- bilateral DVT and/or ilio-caval thrombosis

- cardiorespiratory insufficiency

\begin{tabular}{ll}
\hline Interventions & Retrievable (ALN Implants Chir \\
\hline Outcomes & Primary outcome: \\
1. recurrent PE at 3 months \\
Secondary outcomes: \\
1. DVT at 3 months \\
2. VTE at 6 months \\
3. major bleeding \\
4. mortality at 3 months \\
5. mortality at 6 months \\
6. filter-related complications
\end{tabular}

Funding

The study was supported by grants from the Programme Hospitalier de Recherche Clinique (French Department of Health), Fondation de l'Avenir and Fondation de France. Filters were packaged and provided free of charge by ALN Implants Chirurgicaux. The study sponsor was the University Hospital of SaintEtienne. An academic steering committee assumed overall responsibility for all these steps. An independent data and safety monitoring committee periodically reviewed the main safety outcomes.

The sponsors had no role in the design and conduct of the study; collection, management, analysis, and interpretation of the data; preparation, review, or approval of the manuscript; and decision to submit the manuscript for publication. An academic steering committee assumed overall responsibility for all these steps.

Declarations of interest

'Dr Mismetti reports receiving research grants from Bayer and fees for board memberships from Bayer, Bristol-Myers Squibb/Pfizer, and Daiichi Sankyo, for lectures from Bayer, Boehringer Ingelheim, Bristol-Myers Squibb/Pfizer, Daiichi Sankyo, and Sanofi-aventis, and for development of educational presentations from Bayer, Bristol-Myers Squibb/Pfizer. Dr Laporte reports receiving fees for board memberships or consultancy from Bayer, Ferring, Leo Pharma, Pierre Fabre Santé, and Sanofi-aventis. Dr Pellerin reports receiving consultant fees from Perouse Medicale, Siemens Heath care, BTG International, Covidien, Merit Medical, b-Braun, and Boston Scientific. Dr Couturaud reports receiving research grant support from Bristol-Myers Squibb and Daiichi Sankyo. Dr Elias reports receiving research grant support and fees for board membership and consultancy activities from Bayer and Daiichi Sankyo. Dr Menneveau reports receiving research grant support from Boehringer Ingelheim and Bayer, and fees for consultancy from Bayer, Boehringer Ingelheim, and Bristol-Myers Squibb. Dr Roy reports receiving research grant support from Bayer and Sanofi-aventis, and fees for board membership and consultancy activities for Bayer, Boehringer Ingelheim, Bristol-Myers Squibb, Novartis, and Daiichi Sankyo. Dr Sanchez reports receiving research grant support from Bayer, Portola Pharmaceuticals, and Daiichi Sankyo, and fees or nonfinancial support for consultancy activities from Actelion, Boehringer Ingelheim, GlaxoSmithKline, and Chiesi. Dr Schmidt reports receiving fees for board membership from Bayer and Daiichi Sankyo and for symposia from Bayer. Dr Seinturier reports receiving fees for symposia from Bayer and Actelion and receiving travel support from Bayer, Pfizer, Leo Pharma, Actelion, ABS-Bolton Medical, and Sanofi-aventis. Dr Sevestre reports receiving fees for consultancy from Bayer, Leo Pharma, and GlaxoSmithKline. Dr Lacroix reports uncompensated board membership and consultancy activities for Bayer and Sanofi-aventis, and receiving travel support from Bayer and AstraZeneca. Dr Leizorovicz reports receiving research grant support from Bristol-Myers Squibb, GlaxoSmithKline, Portola Pharmaceuticals, and Sanofi-aventis, and fees for board memberships or consultancy from Bayer, Boehringer Ingelheim, and Sanofi-aventis. Dr Décousus reports receiving personal fees from ASPEN, Bristol-Myers Squibb/Pfizer, Daiichi Sankyo, and Bayer and grant funding from Bayer and Daiichi Sankyo. Dr Meyer reports receiving research grant support from Bayer, Boehringer Ingelheim, Leo Pharma, and Sanofi- 
PREPIC2 (Continued)

aventis; uncompensated board membership and consultancy activities for Bayer, Boehringer Ingelheim, Bristol-Myers Squibb, Leo Pharma, and Pfizer; and travel support from Bayer, Boehringer Ingelheim, Daiichi Sankyo, Leo Pharma, and Sanofi-aventis.

We thank Jean-Yves Darmon, MD (MediBridge SA, Velizy, France), for critically reviewing the manuscript during its development and providing editorial assistance funded by the Programme Hospitalier de Recherche Clinique. No member of the PREPIC2 Study Group received compensation for his or her role in the study.

No other disclosures were reported.'

\section{Notes}

\section{Risk of bias}

\begin{tabular}{lll}
\hline Bias & Authors' judgement & Support for judgement \\
\hline $\begin{array}{l}\text { Random sequence genera- } \\
\text { tion (selection bias) }\end{array}$ & Low risk & Centralised randomisation, computer-generated randomly permuted blocks \\
\hline $\begin{array}{l}\text { Allocation concealment } \\
\text { (selection bias) }\end{array}$ & Low risk & Central voice-activated system, in randomly permuted blocks \\
\hline $\begin{array}{l}\text { Blinding of participants } \\
\begin{array}{l}\text { and personnel (perfor- } \\
\text { mance bias) }\end{array}\end{array}$ & High risk \\
Mortality
\end{tabular}

Blinding of participants $\quad$ High risk
and personnel (perfor-
mance bias)
PE

Blinding of outcome as-
sessment (detection bias) $\quad$ Low risk $\quad$ The evaluation was blind, performed by a central adjudication committee.

\begin{tabular}{|c|c|c|}
\hline $\begin{array}{l}\text { Blinding of outcome as- } \\
\text { sessment (detection bias) } \\
\text { PE }\end{array}$ & Low risk & The evaluation was blind, performed by a central adjudication committee. \\
\hline $\begin{array}{l}\text { Incomplete outcome data } \\
\text { (attrition bias) } \\
\text { Mortality }\end{array}$ & Low risk & Only 2 people lost in follow-up \\
\hline $\begin{array}{l}\text { Incomplete outcome data } \\
\text { (attrition bias) } \\
\text { PE }\end{array}$ & Low risk & Only 2 people lost in follow-up \\
\hline $\begin{array}{l}\text { Selective reporting (re- } \\
\text { porting bias) }\end{array}$ & Low risk & Primary and secondary outcomes were reported. \\
\hline Other bias & Low risk & None identified \\
\hline
\end{tabular}


Usoh 2010

\section{Study characteristics}

\begin{tabular}{|c|c|}
\hline Methods & $\begin{array}{l}\text { Study design: single-centre study } \\
\text { Country: US } \\
\text { Follow-up: planned for } 2 \text { yrs but study terminated prematurely because of interim results }\end{array}$ \\
\hline Participants & $\begin{array}{l}\text { 156 people with lower limb DVT, or at high risk of PE } \\
\text { Age range: } 24-101 \text { yrs } \\
\text { Inclusion criteria: } \\
\text { - contraindication to anticoagulation with DVT/PE } \\
\text { - failed anticoagulation with DVT/PE } \\
\text { - trauma patient at high risk for DVT/PE } \\
\text { - high-risk procedure for thromboembolism with history of VTE } \\
\text { Exclusion criteria: } \\
\text { - age < } 18 \text { yrs } \\
\text { - pre-existing filter } \\
\text { - uncontrollable coagulopathy } \\
\text { - vena cava diameter }>30 \text { mm } \\
\text { - hypersensitivity to nickel, chromium, stainless steel } \\
\text { - pregnancy } \\
\text { - non-femoral access for IVC filter placement } \\
\text { - supra-renal IVC filter placement }\end{array}$ \\
\hline
\end{tabular}

\begin{tabular}{ll}
\hline Interventions & IVC filter: Greenfield (permanent) or TrapEase (permanent) \\
\hline Outcomes & Mortality \\
& Recurrent PE \\
& Iliac or IVC thrombosis \\
\hline Funding & Not stated \\
\hline Declarations of interest & None declared \\
\hline Notes & $\begin{array}{l}\text { The study group was randomised to one of two filters. The paper stated there was a non-randomised } \\
\text { group who also received filters based on the proceduralists choice, or filter availability (3 received a } \\
\text { different filter from the original options of a Greenfield or TrapEase filter; these people received an } \\
\text { Optease filter). This non-randomised group was not part of the study's analysis or conclusions, as they } \\
\text { were not followed up. However, it is noted that } 1 / 232 \text { people with the Greenfield filter in situ, 2/114 } \\
\text { people with the TrapEase filter in situ, and 0/3 people with the Optease filter in situ had IVCT/IVT }\end{array}$
\end{tabular}

\section{Risk of bias}

\begin{tabular}{lll}
\hline Bias & Authors' judgement & Support for judgement \\
\hline $\begin{array}{l}\text { Random sequence genera- } \\
\text { tion (selection bias) }\end{array}$ & Unclear risk & $\begin{array}{l}\text { A nurse or the patient randomly picked a prelabelled index card from an enve- } \\
\text { lope. }\end{array}$ \\
\hline $\begin{array}{l}\text { Allocation concealment } \\
\text { (selection bias) }\end{array}$ & Unclear risk & $\begin{array}{l}\text { '..prelabelled card in an envelope' - not stated if opaque envelope, randomly } \\
\text { ordered envelopes, card was concealed within a separate envelope }\end{array}$ \\
\hline
\end{tabular}


Usoh 2010 (Continued)

$\begin{array}{lll}\begin{array}{l}\text { Blinding of participants } \\ \text { and personnel (perfor- }\end{array} & \text { High risk } & \text { Open-label study design } \\ \text { mance bias) } \\ \text { Mortality }\end{array}$

\begin{tabular}{|c|c|c|}
\hline $\begin{array}{l}\text { Blinding of outcome as- } \\
\text { sessment (detection bias) } \\
\text { Mortality }\end{array}$ & Unclear risk & $\begin{array}{l}\text { Not stated whether the outcome assessors were blinded to the participants fil- } \\
\text { ter status }\end{array}$ \\
\hline
\end{tabular}

\begin{tabular}{|c|c|c|}
\hline $\begin{array}{l}\text { Blinding of outcome as- } \\
\text { sessment (detection bias) }\end{array}$ & Unclear risk & $\begin{array}{l}\text { Not stated whether the outcome assessors were blinded to the participants fil- } \\
\text { ter status }\end{array}$ \\
\hline
\end{tabular}

PE

\begin{tabular}{lll}
\hline $\begin{array}{l}\text { Incomplete outcome data } \\
\text { (attrition bias) } \\
\text { Mortality }\end{array}$ & Low risk & Follow-up adequate \\
\hline $\begin{array}{l}\text { Incomplete outcome data } \\
\text { (attrition bias) } \\
\text { PE }\end{array}$ & Low risk & Follow-up adequate \\
\hline $\begin{array}{l}\text { Selective reporting (re- } \\
\text { porting bias) }\end{array}$ & Low risk & Primary and secondary outcomes were reported. \\
\hline Other bias & Unclear risk & The study was terminated prematurely because of the interim results.
\end{tabular}

CT: computed tomography

DVT: deep vein thrombosis

LMWH: low molecular weight heparin

ICU: intensive care unit

ISTH: International Society on Thrombosis and Haemostasis

IVC: inferior vena cava

IVCT: inferior vena cava thrombosis

IVT: iliac vein thrombosis

PE: pulmonary embolism

PTS: post-thrombotic syndrome

VCF: vena caval filter

vs: versus

VTE: venous thromboembolism

Characteristics of excluded studies [ordered by study ID]

\begin{tabular}{ll}
\hline Study & Reason for exclusion \\
\hline Bocharov 2011 & Not a randomised controlled trial \\
\hline Brasel 1997 & Cost-effectiveness analysis \\
\hline Gosin 1997 & $\begin{array}{l}\text { Prospective interventional cohort with historical control; selected high-risk people received filters; } \\
\text { no data on baseline characteristics of the interventional cohort and the control group }\end{array}$ \\
\hline
\end{tabular}




\begin{tabular}{|c|c|}
\hline Study & Reason for exclusion \\
\hline Khansarinia 1995 & Prospective interventional cohort with historical control \\
\hline Midy 1994 & Case series \\
\hline NCT00423683 & Study terminated early \\
\hline NCT02201277 & Study terminated early \\
\hline Pan 2019 & A retrospective cohort analysis \\
\hline Rajasekhar 2011 & Feasability study of vena cava insertion into people with trauma \\
\hline Rodriguez 1996 & Prospective interventional cohort with historical control \\
\hline Rogers 1997 & $\begin{array}{l}\text { Prospective interventional cohort with historical control; selected high-risk people received filters } \\
\text { interventional and cohort groups unmatched according to baseline characteristics }\end{array}$ \\
\hline Rosenthal 1994 & Case series \\
\hline Rosner 2004 & Prospective interventional cohort with historical control \\
\hline Sharifi 2012 & $\begin{array}{l}\text { Participants randomised filters as an adjunct to percutaneous endovascular techniques for the } \\
\text { treatment of lower limb DVT }\end{array}$ \\
\hline Stavropoulos 2016 & A prospective single-arm cohort analysis \\
\hline Webb 1992 & $\begin{array}{l}\text { Selected high-risk patients received filters; no data on baseline characteristics of interventional } \\
\text { and control groups; people received concurrent DVT prophylaxis }\end{array}$ \\
\hline
\end{tabular}

DVT: deep vein thrombosis

Characteristics of ongoing studies [ordered by study ID]

\section{ACTRN12612001071819}

Study name
Cook randomised study to compare the technical difficulty of retrieval between the Bard G2X and the

Methods Prospective randomised open-label

Participants Key inclusion criteria:

1. Any patient considered at high risk for pulmonary embolism and is under consideration for placement of a short-term VCF. The patient should have at least one of the following 7 indications:

a. Patients with evidence of PE embolus or IVC, iliac, or femoral-popliteal DVT and a contraindication, complication, or failure of anticoagulation

b. Massive PE with residual DVT in a patient at risk for further PE

c. Free-floating iliofemoral or IVC thrombus

d. Severe cardiopulmonary disease and DVT (e.g. cor pulmonale with pulmonary hypertension)

e. Poor compliance with anticoagulant medications

f. Severe trauma without documented PE or DVT in patient with a closed head injury, spinal cord injury, or multiple long bone or pelvic fractures

g. High-risk patients (e.g. immobilised, intensive care patients, prophylactic pre-operative placement in patients with multiple risk factors for VTE)

2. Patient must have patent internal jugular vein 
3. Age: greater than or equal to 18 years

4. Patient or person responsible must have signed the informed consent form

Age: $18-80$ yrs

Gender: both males and females

Key exclusion criteria:

1. Age $<18$ yrs

2. Pregnancy

3. Uncontrollable coagulopathy

4. Vena cava diameter over $30 \mathrm{~mm}$, measured by vena cava sizing catheters

5. Vena cava diameter less than $15 \mathrm{~mm}$, measured by vena cava sizing catheters

6. Contrast allergy that cannot be adequately pre-medicated

7. Simultaneously participating in another investigative drug or device trial, or have a previous IVC filter

Interventions Comparator/control treatment:

Comparing the retrievability of 2 TGA-approved IVC filters

One group will be randomised to receiving the Cook Filter and the other group will be randomised to the Bard filter. We will then determine which of the two filters is easier to remove.

\section{Outcomes}

Primary outcome: technical difficulty of retrieval will be assessed by the radiologist using a 5-point numerical scale. The time point of the outcome, retrieving the filter, will vary based on the clinical need of the patient. The filter will be removed when the patient is no longer at risk of developing a PE.

Secondary outcome: composite serious adverse events

Examples of expected adverse events include:

10 in 100 chance of haemorrhage (bleeding) and perforation (tearing) of the blood vessel

4 in 100 chance of PE (blood clot in the lung)

10 in 100 chance of occlusion (blockage) of the blood vessel

Less than 16 in 100 chance of significant filter migration (shifting in position)

10 in 100 chance of fracture of the filter

$<1$ in 100 chance of procedure-related death

Time points: procedure; 1, 3, 612 months; time of retrieval

\begin{tabular}{ll}
\hline Starting date & $15 / 04 / 2010$ \\
\hline Contact information & Name: Helen Kavnoudias \\
& Address: Radiology Department \\
& The Alfred Hospital \\
& Commercial Road \\
& Melbourne, Vic 3004 Country Australia \\
\hline
\end{tabular}

Notes

\section{ChicTR1900023485}

Prospective, multicentre, randomised controlled trial to assess the safety and performance of the
Ballet vena cava filter system for the prevention of pulmonary embolism

Ballet vena cava filter system for the prevention of pulmonary embolism

Methods Randomised parallel group




\section{ChiCTR1900023485 (Continued)}

Participants
144 participants, age $>18$ years

Inclusion criteria:

1. People who agreed to participate with voluntary written consent

2. People who were at high risk of PE meeting one of the following:

a. People with PE or inferior or femoral condyle vein thrombosis and:

i. contraindication to anticoagulation or;

ii. complications from anticoagulation such as bleeding, or;

iii. recurrent PE despite anticoagulation.

b. There are free thrombi or massive thrombi in the iliac crest, femoral vein or IVC

c. People with thrombophilia and recurrent PE

d. People with acute lower limb DVT requiring catheter thrombolysis and thrombectomy

Exclusion criteria:

1. Pregnancy or lactation

2. Participant is actively involved in another drug or medical device clinical trial

3. People with chronic IVC thrombosis or severe IVC stenosis

4. The person has massive, life-threatening PE

5. Allergy to contrast and anaesthetics

6. Other situations in which the investigator determines it is not appropriate for endovascular treatment

\begin{tabular}{|c|c|}
\hline Interventions & Ballet vena cava filter vs a Lifetech Medical Technology VCF \\
\hline \multirow[t]{7}{*}{ Outcomes } & Primary: Incidence of PE with VCF in situ \\
\hline & Secondary: \\
\hline & 1. Successful filter insertion rate \\
\hline & 2. Successful filter retrieval rate \\
\hline & 3. Incidence of PE within 30 days of VCF retrieval \\
\hline & 4. Incidence of adverse events \\
\hline & $\begin{array}{l}\text { 5. Filter-related complications - caval obstruction, filter breakage, IVC perforation, filter tilt }(>15 \\
\text { degrees) and displacement }(>2 \mathrm{~cm})\end{array}$ \\
\hline
\end{tabular}

Address: Hangzhou Weiquang Medical Technology Co, Ltd, Room 318, Building 2, Wantan Science Park, 88 Jiangling Road, Binjiang District, Hagzhou, Zhejiang, China

\section{Notes}

\section{NCT00588757}

\begin{tabular}{ll} 
Study name & Complications between two optional IVC filters regarding ease of use, complications and outcome \\
\hline Methods & Randomised parallel group assignment \\
\hline Participants & 100 participants, age $>18$ years \\
& Inclusion criteria: all people referred for filter insertion
\end{tabular}


NCT00588757 (Continued)

$$
\text { Exclusion criteria: young people }<18 \text { years }
$$

\begin{tabular}{ll}
\hline Interventions & Optease vs Gunther-Tulip Filter \\
\hline Outcomes & Primary: comparing the filters at 1 year \\
\hline Starting date & Jan 2008 \\
\hline Contact information & Name: Uri Ramon \\
& Address: Sheba Medical Centre, Tel hashomer, Israel 52621 \\
\hline Notes & No updates recorded on clinicaltrials.gov since 2009 \\
\hline
\end{tabular}

\section{NCT03070834}

\begin{tabular}{ll}
\hline Study name & Retrievable Inferior vena caval filter for primary PE prophylaxis in at-risk Trauma patients (RIPT) \\
\hline Methods & Randomised parallel group assignment \\
\hline Participants & 42 people, age > 18 years with trauma who are: \\
1. deemed unable to receive medical VTE prophylaxis within 72 hours post-injury based on trauma- & tologists' suspicion of increased bleeding risk, per-spinal cord bleeding risk, or need for multiple \\
surgical interventions; and & 2. have at-least one of the following high-risk VTE injuries as per the EAST Guidelines: \\
a. severe closed head injury (GCS 8 or less upon presentation) & b. incomplete spinal cord injury with para- or quadriplegia \\
c. complex pelvic fracture with associated long bone fracture(s) \\
d. multiple long bone fractures. \\
Exclusion criteria: \\
1. people who were not expected to survive for at least 72 hours post-trauma \\
2. people with known uncorrectable coagulopathy \\
3. people known to be unable to receive a retrievable VCF as part of this trial (for anatomical reasons \\
or standard contraindication for device insertion) \\
4. known active VTE \\
5. pregnancy
\end{tabular}

Interventions

Cook 'Celect' Filter and pharmacologic anticoagulation commenced when safe, vs no filter and pharmacologic anticoagulation when safe

Primary: time left unprotected to PE
Secondary:
1. Symptomatic VTE
2. Mortality
3. Time to filter insertion
4. Time and rates to/of filter retrieval
5. Rates of worsening intracranial bleed

\begin{tabular}{ll}
\hline Starting date & March 2017 \\
\hline Contact information & Name: lan Ball \\
\hline
\end{tabular}


Notes

NCT03691753

Study name

Safety and efficacy of Fitaya vena cava filter for deep vein thrombosis: a multicentre, randomized controlled trial

Methods

Randomised parallel assignment

Participants

186 participants, age $>18$ years
Inclusion criteria:

1. People who agreed to participate with voluntary written consent, and agreement for follow-up

2. People with inferior DVT (IVC, iliac, femoral or popliteal DVT) or PE and concomitant with one or more of the following situations:

a. contraindication to pharmacological anticoagulation

b. bleeding complications during anticoagulation therapy

c. recurrent PE despite adequate anticoagulation therapy

d. unable to achieve adequate anticoagulation

e. PE with coexistent inferior DVT

f. free thrombosis or large amounts of thrombosis are found in the iliac, femoral, popliteal, or inferior vena cava

g. people who have acute risk factors of DVT and PE needing to undergo abdominal, pelvic or lower limb surgery simultaneously

h. people with acute DVT, prior to catheter-directed thrombolysis (CDT), percutaneous mechanical thrombectomy (PMT), or surgical thrombectomy

3. The investigator determined the participant had appropriate femoral or jugular access for filter insertion

4. The diameter of the IVC for proposed filter implantation is between $18 \mathrm{~mm}$ and $29 \mathrm{~mm}$

Exclusion criteria:

1. People with a previous IVC filter

2. Thombosis of the femoral or jugular vein preventing filter insertion

3. Permanent filter indicated

4. Severe spinal deformity affecting either filter insertion or retrieval

5. Renal vein thrombosis, or IVC thrombosis involving the renal vein

6. Congenital malformation of the IVC

7. Uncontrolled sepsis or severe infection

8. Active malignancy, with metastatic disease

9. Allergy to filter components

10.People who have contraindication to $x$-rays

11.Liver or renal dysfunction - defined as transaminases 2.5 times the upper limit of normal (ULN), or serum creatinine two times higher the ULN

12.Pre-existing abnormal coagulation - defined as activated partial thrombin time (APTT) 10 seconds above ULN

13.People whose life expectancy was less than 12 months

14.People who had severe heart or lung disease

15.Pregnant or lactating women, or women trying to conceive 
NCT03691753 (Continued)

16.People who were actively participating in other clinical trials involving other drugs or medical devices, who did not withdraw within the first 3 months of the screening period in this trial

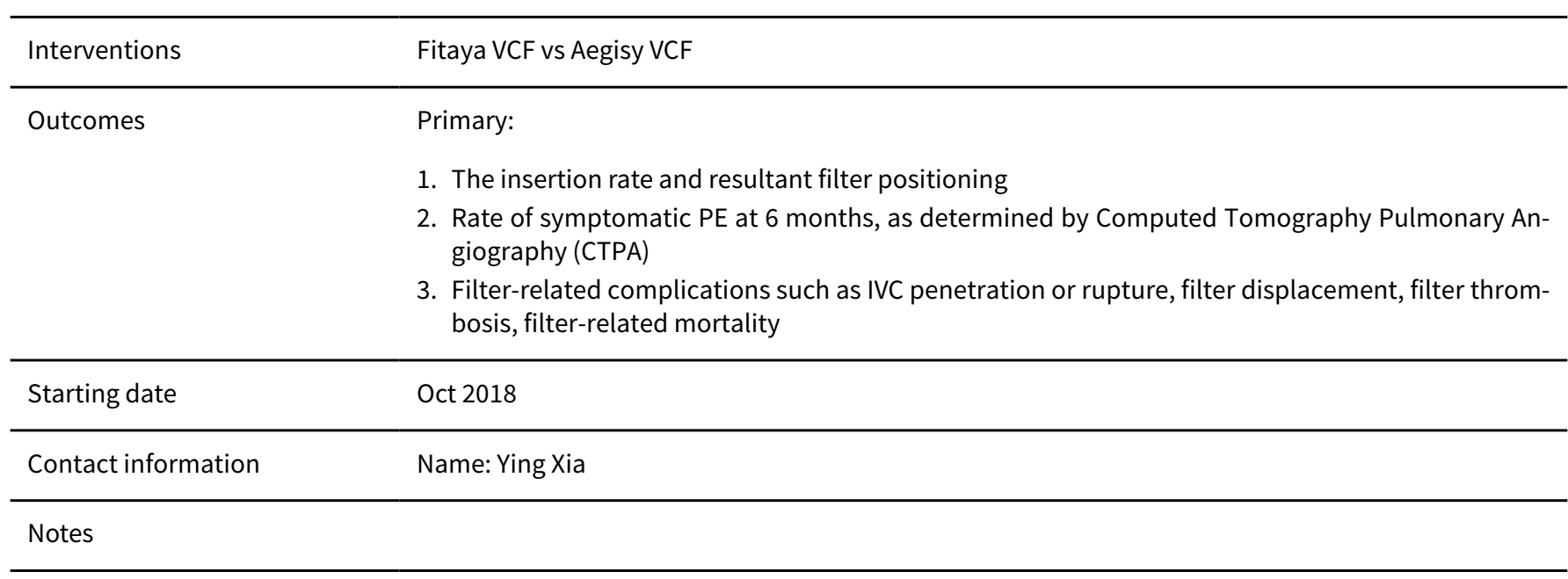

\section{NCT03987321}

$\begin{array}{ll}\text { Study name } & \begin{array}{l}\text { Retrievability and incidence of complex retrieval in Celect vs Denali Filter: a prospective, random- } \\ \text { ized comparative study }\end{array}\end{array}$

\begin{tabular}{ll}
\hline Methods & Randomised parallel group assignment \\
\hline Participants & 174 participants, age > 18 years with either: \\
1. DVT and/or PE, who are commenced on anticoagulation, or & 2. prior to mechanical thrombectomy for DVT, or \\
& 3. prophylactic prior to trauma or major surgery. \\
& People who were septic or needed a permanent filter were exclu \\
\hline Interventions & Denali or Celect Filter \\
\hline Outcomes & Primary: incidence of complicated filter retrieval at 2 months \\
& Secondary: \\
1. incidence of penetration at 2 months \\
2. tilt angle at 2 months \\
3. filter migration/fracture at 2 months \\
4. signs of inferior vena caval occlusio/stenosis at 2 months
\end{tabular}

\section{July 2019}

Name: Man-Deuk Kim

Address: Department of Radiology, Severance Hospital, Yonsei College of Mediclne, Seoul, Republic of Korea

\section{Notes}

APTT: activated partial thrombin time CDT: catheter-directed thrombolysis 
CT: computed tomography

CTPA: computed tomography pulmonary angiography

DVT: deep vein thrombosis

EAST: Eastern Association for the Surgery of Trauma

GCS: Glasgow Coma Scale

IVC: inferior vena caval

LMWH: low molecular weight heparin

MRI: magnetic resonance imaging scan

PE: pulmonary embolism

PI: principal investigator

PMT: percutaneous mechanical thrombectomy

TGA: Therapeutic Goods Administration (Department of Health, Australia)

UCSF: University of California San Francisco

UFH: unfractionated heparin

ULN: upper limit of normal

VCF: vena caval filter

vs: versus

VTE: venous thromboembolism

yrs: years

\section{DATA AND ANALYSES}

\section{Comparison 1. Anticoagulation +/- VCF in people at high risk of recurrent PE}

\begin{tabular}{|c|c|c|c|c|}
\hline $\begin{array}{l}\text { Outcome or subgroup ti- } \\
\text { tle }\end{array}$ & $\begin{array}{l}\text { No. of } \\
\text { studies }\end{array}$ & $\begin{array}{l}\text { No. of } \\
\text { partici- } \\
\text { pants }\end{array}$ & Statistical method & Effect size \\
\hline 1.1 PE & 1 & & Risk Ratio (M-H, Fixed, 95\% Cl) & Totals not selected \\
\hline 1.1.13 months & 1 & & Risk Ratio (M-H, Fixed, 95\% Cl) & Totals not selected \\
\hline 1.1.2 6 months & 1 & & Risk Ratio (M-H, Fixed, 95\% Cl) & Totals not selected \\
\hline 1.2 Mortality & 1 & & Risk Ratio (M-H, Fixed, 95\% Cl) & Totals not selected \\
\hline 1.2.13 months & 1 & & Risk Ratio (M-H, Fixed, 95\% CI) & Totals not selected \\
\hline 1.2.2 6 months & 1 & & Risk Ratio (M-H, Fixed, 95\% CI) & Totals not selected \\
\hline 1.3 Lower limb thrombosis & 1 & & Risk Ratio (M-H, Fixed, 95\% CI) & Totals not selected \\
\hline 1.3.13 months & 1 & & Risk Ratio (M-H, Fixed, 95\% CI) & Totals not selected \\
\hline 1.3.2 6 months & 1 & & Risk Ratio (M-H, Fixed, 95\% CI) & Totals not selected \\
\hline 1.4 Major bleeding & 1 & & Risk Ratio (M-H, Fixed, 95\% CI) & Totals not selected \\
\hline 1.4.13 months & 1 & & Risk Ratio (M-H, Fixed, 95\% Cl) & Totals not selected \\
\hline 1.4.2 6 months & 1 & & Risk Ratio (M-H, Fixed, 95\% CI) & Totals not selected \\
\hline
\end{tabular}


Analysis 1.1. Comparison 1: Anticoagulation +/- VCF in people at high risk of recurrent PE, Outcome 1: PE

\begin{tabular}{ccccccc} 
& \multicolumn{2}{c}{ VCF +/- anticoagulation } & Anticoagulation & \multicolumn{2}{c}{ Risk Ratio } & Risk Ratio \\
Study or Subgroup & Events & Total & Events & Total & M-H, Fixed, 95\% CI & M-H, Fixed, 95\% CI
\end{tabular}

1.1.1 3 months
PREPIC2

1.1.2 6 months PREPIC2

$\begin{array}{lllll}7 & 200 & 4 & 199 & 1.74[0.52,5.86]\end{array}$

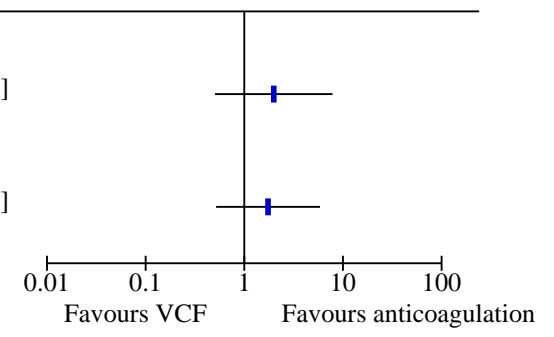

Analysis 1.2. Comparison 1: Anticoagulation +/- VCF in people at high risk of recurrent PE, Outcome 2: Mortality

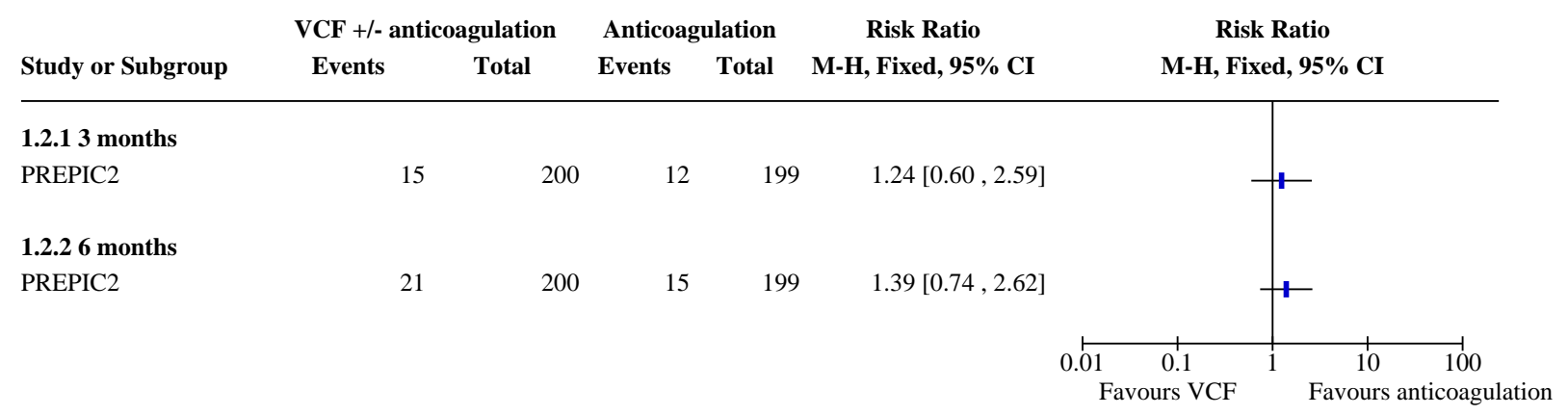

Analysis 1.3. Comparison 1: Anticoagulation $+/$ - VCF in people at high risk of recurrent $\mathrm{PE}$, Outcome 3: Lower limb thrombosis

\begin{tabular}{ccccccc} 
& VCF +/- anticoagulation & \multicolumn{2}{c}{ Anticoagulation } & \multicolumn{2}{c}{ Risk Ratio } & Risk Ratio \\
Study or Subgroup & Events & Total & Events & Total & M-H, Fixed, 95\% CI & M-H, Fixed, 95\% CI
\end{tabular}

1.3.1 3 months PREPIC2

1.3.2 6 months PREPIC2

1

1

200

1

199

$0.99[0.06,15.80]$

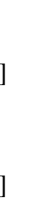

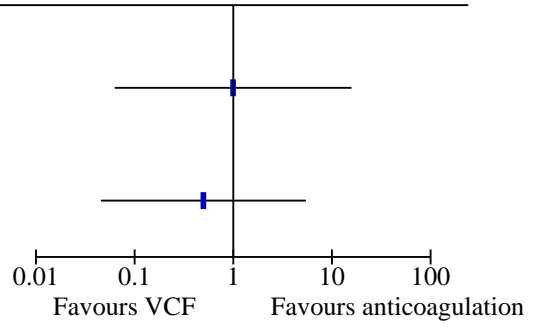




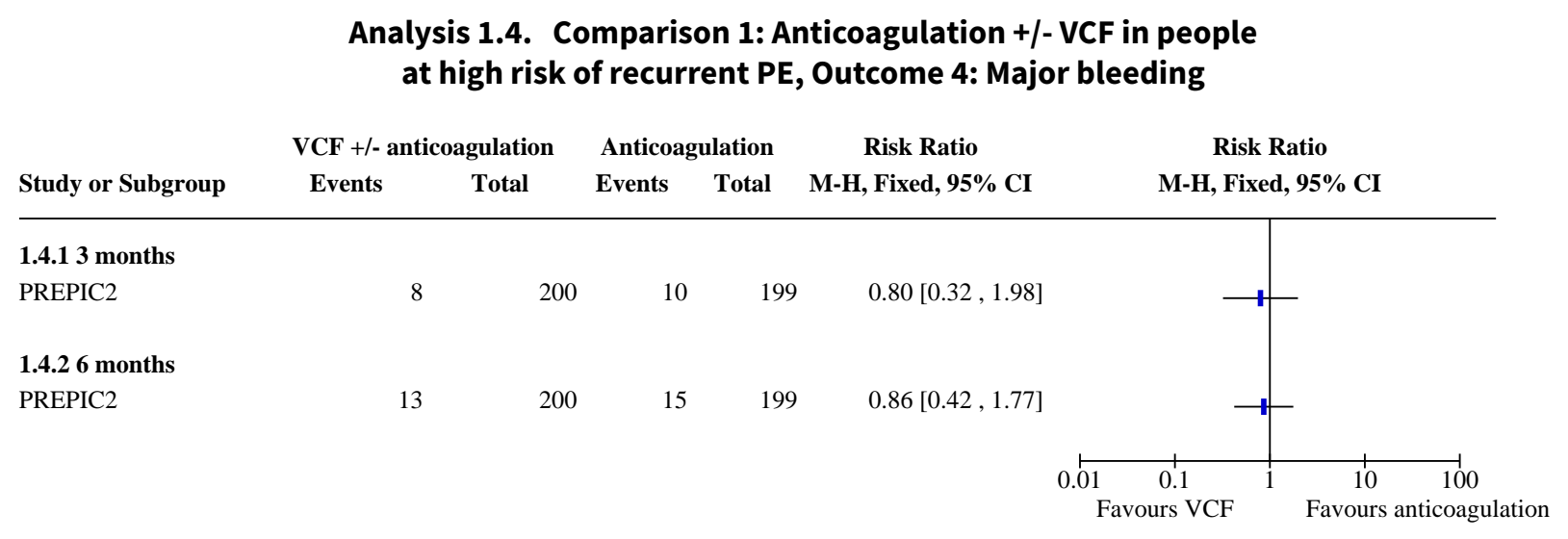

\section{Comparison 2. Anticoagulation +/- VCF in people after multiple trauma}

\begin{tabular}{|c|c|c|c|c|}
\hline Outcome or subgroup title & $\begin{array}{l}\text { No. of } \\
\text { studies }\end{array}$ & $\begin{array}{l}\text { No. of } \\
\text { partici- } \\
\text { pants }\end{array}$ & Statistical method & Effect size \\
\hline 2.1 PE & 1 & & Risk Ratio (M-H, Fixed, 95\% Cl) & Totals not selected \\
\hline 2.2 Mortality & 1 & & Risk Ratio (M-H, Fixed, 95\% Cl) & Totals not selected \\
\hline 2.3 Lower limb thrombosis & 1 & & Risk Ratio (M-H, Fixed, 95\% Cl) & Totals not selected \\
\hline 2.3.1 All & 1 & & Risk Ratio (M-H, Fixed, 95\% Cl) & Totals not selected \\
\hline 2.3.2 Unilateral & 1 & & Risk Ratio (M-H, Fixed, 95\% Cl) & Totals not selected \\
\hline 2.3.3 Bilateral & 1 & & Risk Ratio (M-H, Fixed, 95\% Cl) & Totals not selected \\
\hline 2.4 Major bleeding & 1 & & Risk Ratio (M-H, Fixed, 95\% Cl) & Totals not selected \\
\hline 2.5 Non major bleeding & 1 & & Risk Ratio (M-H, Fixed, 95\% Cl) & Totals not selected \\
\hline
\end{tabular}

Analysis 2.1. Comparison 2: Anticoagulation +/- VCF in people after multiple trauma, Outcome 1: PE

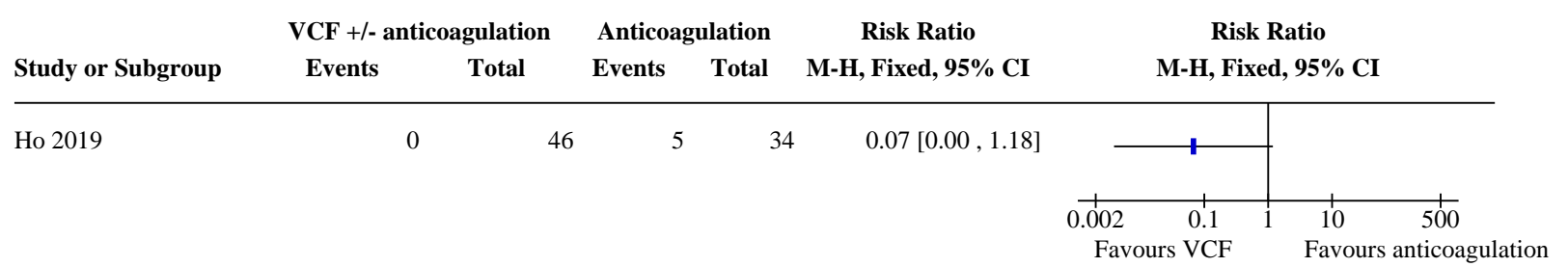


Analysis 2.2. Comparison 2: Anticoagulation +/- VCF in people after multiple trauma, Outcome 2: Mortality

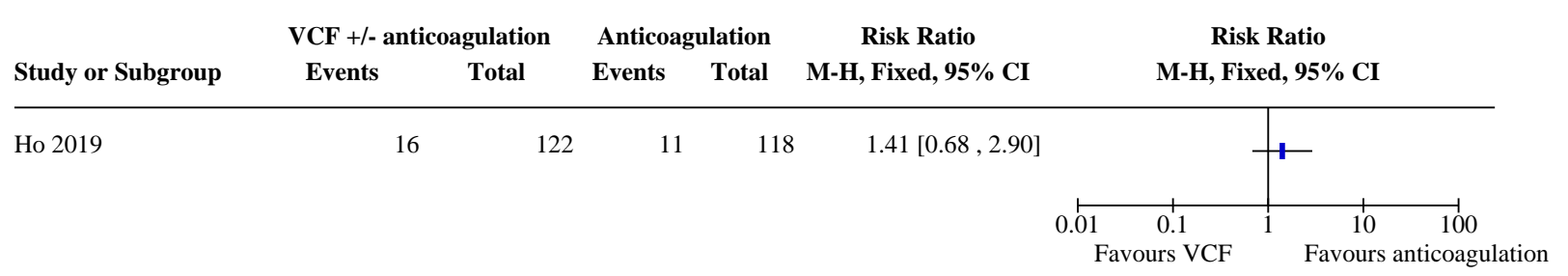

Analysis 2.3. Comparison 2: Anticoagulation $+/$ - VCF in people after multiple trauma, Outcome 3: Lower limb thrombosis

\begin{tabular}{ccccccc} 
& VCF +/- anticoagulation & Anticoagulation & \multicolumn{2}{c}{ Risk Ratio } & Risk Ratio \\
Study or Subgroup & Events & Total & Events & Total & M-H, Fixed, 95\% CI & M-H, Fixed, 95\% CI
\end{tabular}

\begin{tabular}{lccccc}
\hline $\begin{array}{l}\text { 2.3.1 All } \\
\text { Ho } 2019(1)\end{array}$ & 14 & 122 & 12 & 118 & $1.13[0.54,2.34]$ \\
$\begin{array}{l}\text { 2.3.2 Unilateral } \\
\text { Ho } 2019\end{array}$ & 11 & 122 & 6 & 118 & $1.77[0.68,4.64]$ \\
$\begin{array}{l}\text { 2.3.3 Bilateral } \\
\text { Ho } 2019\end{array}$ & 4 & 122 & 7 & 118 & $0.55[0.17,1.84]$
\end{tabular}

Footnotes

(1) Some participants had more than one episode of thrombosis

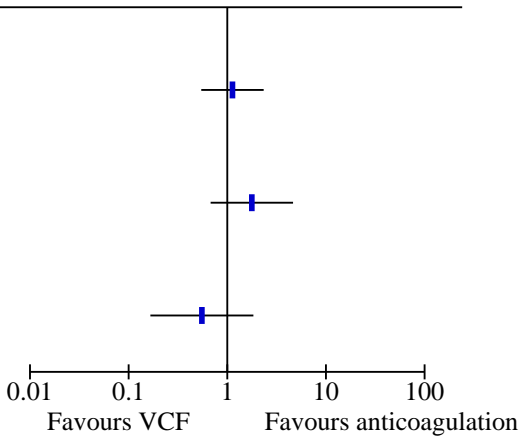

Analysis 2.4. Comparison 2: Anticoagulation +/- VCF in people after multiple trauma, Outcome 4: Major bleeding

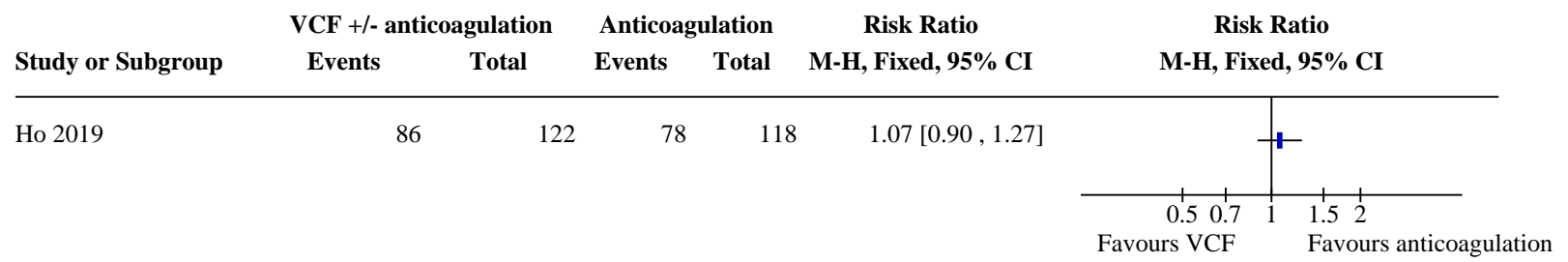

Analysis 2.5. Comparison 2: Anticoagulation +/- VCF in people after multiple trauma, Outcome 5: Non major bleeding

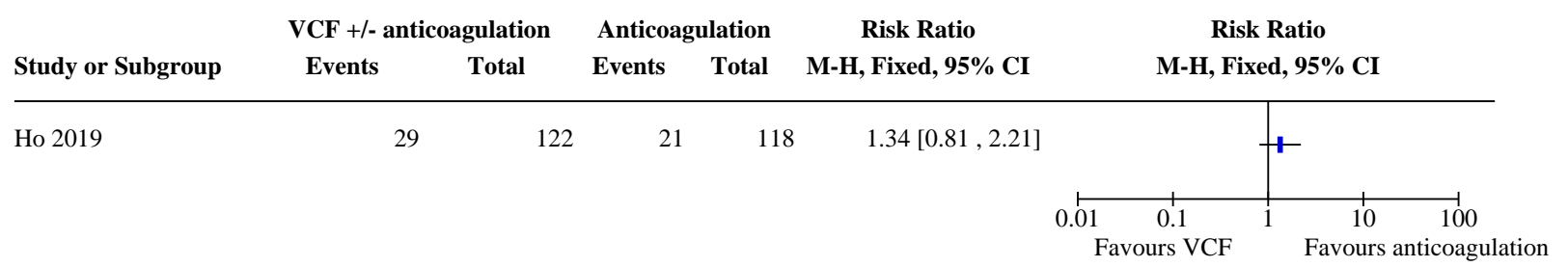

ADDITIONAL TABLES 
Table 1. Inferior vena cava filter insertion guidelines*

\begin{tabular}{|c|c|c|c|}
\hline Situation & $\begin{array}{l}\text { Organisation } \\
\text { CEP recom- } \\
\text { mends }\end{array}$ & $\begin{array}{l}\text { Organisation } \\
\text { CEP counsels } \\
\text { 'consider' }\end{array}$ & $\begin{array}{l}\text { Organisation } \\
\text { CEP disap- } \\
\text { proves }\end{array}$ \\
\hline Documented VTE with contraindication to anticoagulation & $\begin{array}{l}\text { ACCP, AHA, } \\
\text { ACR-SIR, BSH, } \\
\text { ESC }\end{array}$ & - & - \\
\hline Recurrent PE despite therapeutic anticoagulation & ACR-SIR, ESC & $\mathrm{AHA}$ & - \\
\hline $\begin{array}{l}\text { Massive PE treated with or without thrombolysis, surgical thrombectomy, } \\
\text { or adjunct to surgical thrombo-endarterectomy }\end{array}$ & ACR-SIR & $\mathrm{AHA}$ & $\mathrm{BSH}, \mathrm{ESC}$ \\
\hline 'Free-floating' proximal thrombus & ACR-SIR & - & $\mathrm{BSH}, \mathrm{ESC}$ \\
\hline Iliocaval DVT & ACR-SIR, EAST & - & AHA, BSH, ESC \\
\hline $\begin{array}{l}\text { Documented VTE in a person with co-existing severe cardiac and/or lung } \\
\text { disease }\end{array}$ & ACR-SIR & $\mathrm{BSH}, \mathrm{AHA}$ & - \\
\hline Documented VTE in people with cancer & - & - & - \\
\hline Documented VTE in pregnancy & - & - & - \\
\hline People with CTEPH undergoing pulmonary thromboembolectomy & - & ACCP & ESC \\
\hline $\begin{array}{l}\text { People requiring urgent surgery, recent diagnosis of VTE (one month) - re- } \\
\text { trievable filter }\end{array}$ & - & - & $\mathrm{BSH}$ \\
\hline $\begin{array}{l}\text { Continued anticoagulation with filter in situ, without persistent and concur- } \\
\text { rent VTE risk factors; acute VTE episode resolved }\end{array}$ & - & - & ACCP \\
\hline
\end{tabular}

Prophylaxis in high-risk populations (no concurrent diagnosis of VTE), such

as:

- severe trauma with contraindication to anticoagulation - and/or significant head or spinal cord injury, or multiple long-bone and/or pelvic frac-

tures

- perioperative phase for bariatric surgery

- perioperative phase for orthopaedic joint replacement

*Author's (TY) interpretation of each Organisation CEP Guidelines ACCP: American College of Chest Physicians (ACCP 2012; ACCP 2016)

AHA: American Heart Association (AHA 2011)

ACR- SIR: American College of Radiology- Society for Interventional Radiology (ACR-SIR Practice Parameter 2014)

BSH: British Committee for Standards in Haematology IVC Filter Guidelines (BSH 2006)

CEP: Consensus Expert Panel

CTEPH: chronic thromboembolic pulmonary hypertension

DVT: deep vein thrombosis

EAST: Eastern Association for the Surgery of Trauma (EAST 2002)

ESC: European Society of Cardiology (ESC 2014)

PE: pulmonary embolism

VTE: venous thromboembolism 


\section{APPENDICES}

\section{Appendix 1. Search strategies 3 October 2016}

\begin{tabular}{|c|c|c|}
\hline Source & Search strategies & Hits retrieved \\
\hline \multirow{28}{*}{$\begin{array}{l}\text { CENTRAL (The } \\
\text { Cochrane Library) } \\
\text { via The Cochrane } \\
\text { Register of Studies } \\
\text { Online }\end{array}$} & \#1 MESH DESCRIPTOR Thrombosis 1233 & 141 \\
\hline & \#2 MESH DESCRIPTOR Thromboembolism 893 & \\
\hline & \#3 MESH DESCRIPTOR Venous Thromboembolism 234 & \\
\hline & \#4 MESH DESCRIPTOR Venous Thrombosis EXPLODE ALL TREES 1998 & \\
\hline & $\begin{array}{l}\text { \#5 (thrombus }{ }^{\star} \text { or thrombotic* or thrombolic }{ }^{\star} \text { or thromboemboli* or thrombos }{ }^{\star} \text { or } \\
\text { embol*):TI,AB,KY } 16851\end{array}$ & \\
\hline & \#6 MESH DESCRIPTOR Pulmonary Embolism EXPLODE ALL TREES 731 & \\
\hline & \#7 (PE or DVT or VTE):TI,AB,KY 4482 & \\
\hline & \#8 ((vein* or ven*) near thromb*):TI,AB,KY 6116 & \\
\hline & \#9 (blood near3 clot*):TI,AB,KY 2561 & \\
\hline & $\# 10$ (pulmonary near3 clot*):TI,AB,KY 5 & \\
\hline & $\# 11$ (lung near3 clot*):TI,AB,KY 4 & \\
\hline & \#12 \#1 OR \#2 OR \#3 OR \#4 OR \#5 OR \#6 OR \#7 OR \#8 OR \#9 OR \#10 OR \#11 21948 & \\
\hline & \#13 MESH DESCRIPTOR Embolic Protection Devices EXPLODE ALL TREES 40 & \\
\hline & $\# 14$ (ven* near cav*):TI,AB,KY 597 & \\
\hline & \#15 Tempofilter:TI,AB,KY 0 & \\
\hline & \#16 VenaTech:TI,AB,KY 0 & \\
\hline & \#17 (Bard near G2):TI,AB,KY 0 & \\
\hline & \#18 (Bard near Recovery):TI,AB,KY 0 & \\
\hline & \#19 (Boston near Greenfield):TI,AB,KY 0 & \\
\hline & \#20 ("Birds Nest"):TI,AB,KY 0 & \\
\hline & \#21 (Celect near3 filter):TI,AB,KY 0 & \\
\hline & \#22 (Tulip near3 filter):TI,AB,KY 1 & \\
\hline & \#23 OptEase:TI,AB,KY 0 & \\
\hline & \#24 TrapEase:TI,AB,KY 1 & \\
\hline & \#25 Mobin-Uddin:TI,AB,KY 1 & \\
\hline & \#26 ((option or ALN) near3 filter):TI,AB,KY 1 & \\
\hline & \#27 (Rex Medical Option):TI,AB,KY 0 & \\
\hline & \#28 (Simon near Nitinol):TI,AB,KY 0 & \\
\hline
\end{tabular}


(Continued)

\#29 IVC:TI,AB,KY159

\#30 \#13 OR \#14 OR \#15 OR \#16 OR \#17 OR \#18 OR \#19 OR \#20 OR \#21 OR \#22 OR \#23

OR \#24 OR \#25 OR \#26 OR \#27 OR \#28 OR \#29 706

\#31 \#12 AND \#30 142

\begin{tabular}{llc}
\hline Clinical.trials.gov & vena AND filter & 78 \\
\hline $\begin{array}{l}\text { World Health Orga- } \\
\text { nization Internation- } \\
\begin{array}{l}\text { al Clinical Trials Reg- } \\
\text { istry Platform }\end{array}\end{array}$ & vena AND filter & 37 \\
\hline ISRCTN Register & vena AND filter & 5 \\
\hline $\begin{array}{l}\text { Cochrane Vascular } \\
\text { Specialised Register }\end{array}$ & 16 \\
\hline
\end{tabular}

Appendix 2. Search strategies 23 October 2017

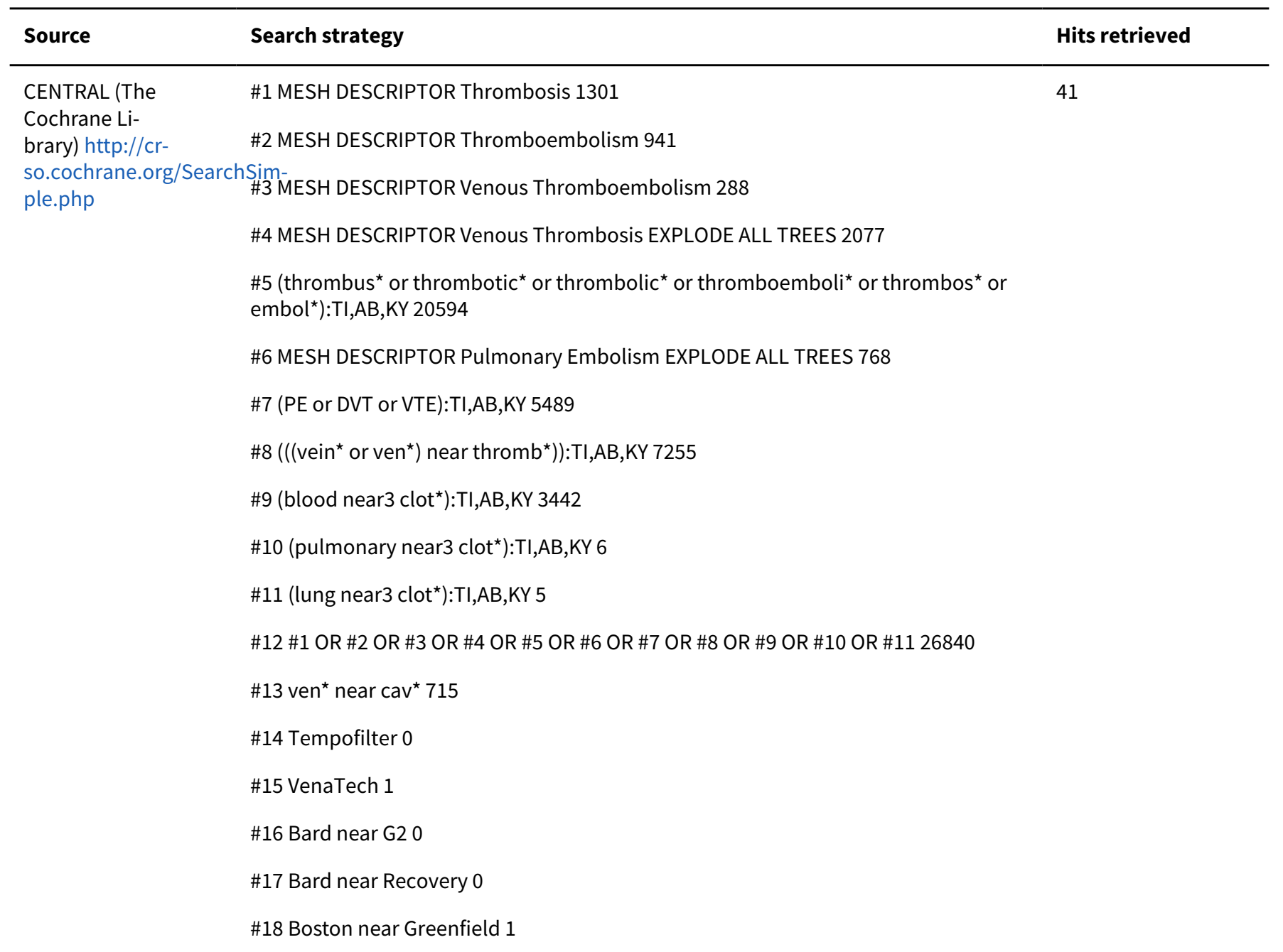


(Continued)

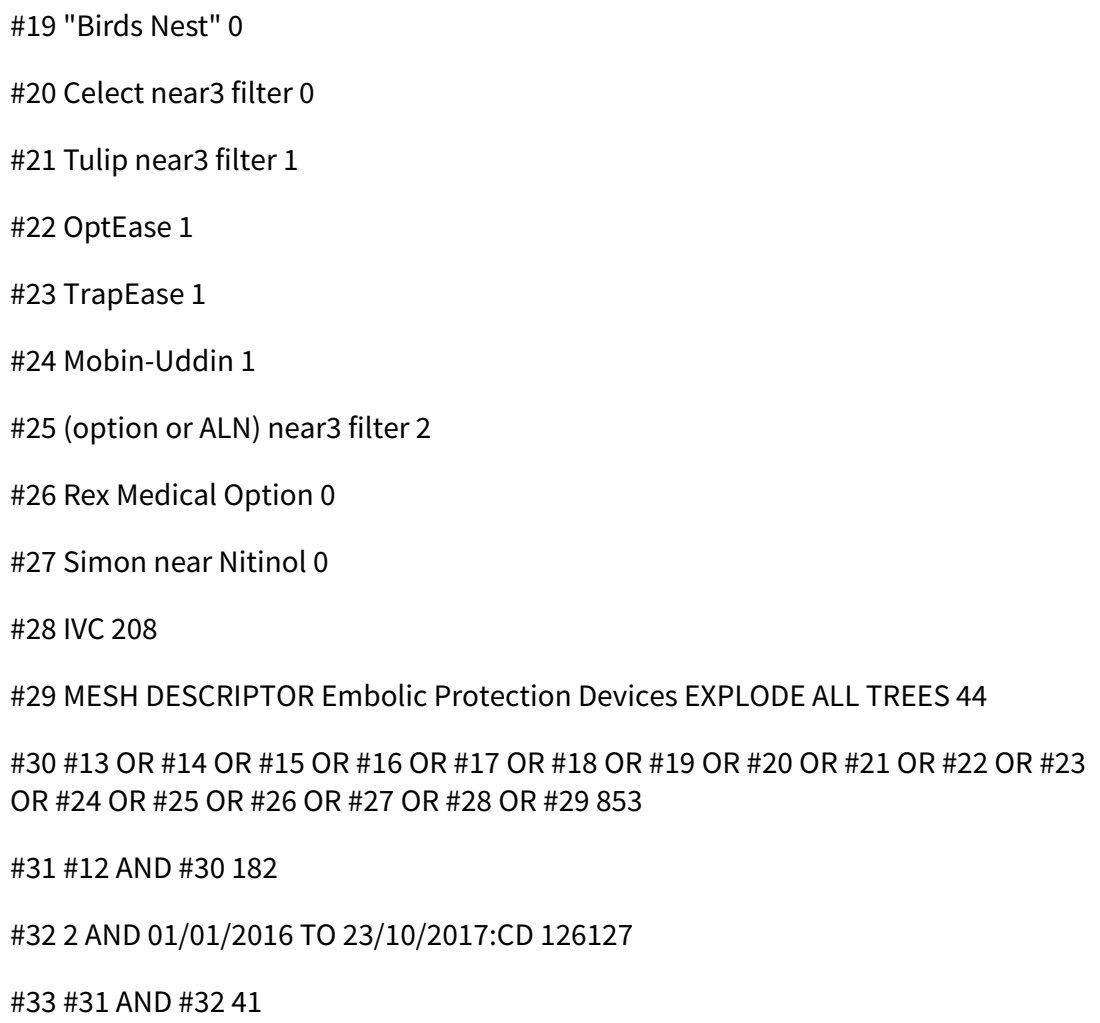

2 *Thromboembolism/ 14919

3 *Venous Thromboembolism/ 7237

4 exp Venous Thrombosis/ 53408

5 (thrombus ${ }^{\star}$ or thrombotic ${ }^{\star}$ or thrombolic ${ }^{\star}$ or thromboemboli* or thrombos ${ }^{*}$ or embol*).ti,ab. 309171

6 exp Pulmonary Embolism/ 37732

7 (PE or DVT or VTE).ti,ab. 47021

8 ((vein* or ven*) adj thromb*).ti,ab. 62549

9 (blood adj3 clot ${ }^{\star}$ ).ti,ab. 10323

10 (pulmonary adj3 clot*).ti,ab. 194

11 (lung adj3 clot*).ti,ab. 45

12 or/1-11 385423

13 exp Embolic Protection Devices/ 3144

$14\left(\right.$ ven $^{\star}$ adj $\left.\operatorname{cav}^{\star}\right) \cdot$ ti,ab. 38025

15 Tempofilter.ti,ab. 15

16 VenaTech.ti,ab. 23

17 Bard near G2.ti,ab. 0

18 (Bard adj Recovery).ti,ab. 19 
19 (Boston adj Greenfield).ti,ab. 0

20 "Birds Nest".ti,ab. 211

21 (Celect adj3 filter).ti,ab. 26

22 (Tulip adj3 filter).ti,ab. 84

23 OptEase.ti,ab. 70

24 TrapEase.ti,ab. 58

25 Mobin-Uddin.ti,ab. 83

26 ((option or ALN) adj3 filter).ti,ab. 38

27 Rex Medical Option.ti,ab. 0

28 Simon near Nitinol.ti,ab. 0

29 IVC.ti,ab. 6485

30 or/13-26 39267

3112 and 3012034

32 randomized controlled trial.pt. 497429

33 controlled clinical trial.pt. 99269

34 randomized.ab. 434012

35 placebo.ab. 202938

36 drug therapy.fs. 2116475

37 randomly.ab. 299126

38 trial.ab. 457784

39 groups.ab. 1847670

40 or/32-39 4373745

4131 and 401939

$422017^{\star}$.dc. 1013696

4341 and 4243

Embase

1974 to present
1 *Thrombosis/ 35969

2 *Thromboembolism/ 10153

3 *Venous Thromboembolism/ 12916

4 exp Venous Thrombosis/ 92212

5 (thrombus $^{\star}$ or thrombotic ${ }^{*}$ or thrombolic* or thromboemboli* or thrombos* or embol*).ti,ab. 327639

6 exp Pulmonary Embolism/ 65195

7 (PE or DVT or VTE).ti,ab. 64224

8 ((vein* or ven $\left.{ }^{\star}\right)$ adj thromb*).ti,ab. 72863 
9 (blood adj3 clot*).ti,ab. 8974

10 (pulmonary adj3 clot $^{\star}$ ).ti,ab. 216

11 (lung adj3 clot $^{\star}$ ).ti,ab. 50

12 or/1-11 429010

13 exp Embolic Protection Devices/ 5782

$14\left(\right.$ ven $^{\star}$ adj $\left.\operatorname{cav}^{\star}\right) . t i, a b .31153$

15 Tempofilter.ti,ab. 16

16 VenaTech.ti,ab. 33

17 Bard near G2.ti,ab. 0

18 (Bard adj Recovery).ti,ab. 26

19 (Boston adj Greenfield).ti,ab. 0

20 "Birds Nest".ti,ab. 161

21 (Celect adj3 filter).ti,ab. 43

22 (Tulip adj3 filter).ti,ab. 113

23 OptEase.ti,ab. 122

24 TrapEase.ti,ab. 84

25 Mobin-Uddin.ti,ab. 10

26 ((option or ALN) adj3 filter).ti,ab. 64

27 Rex Medical Option.ti,ab. 0

28 Simon near Nitinol.ti,ab. 0

29 IVC.ti,ab. 9521

30 or/13-26 34232

3112 and 3012765

32 randomized controlled trial/ 430404

33 controlled clinical trial/ 405597

34 random\$.ti,ab. 1116788

35 randomization/ 67742

36 intermethod comparison/ 221687

37 placebo.ti,ab. 212361

38 (compare or compared or comparison).ti. 322661

39 ((evaluated or evaluate or evaluating or assessed or assess) and (compare or compared or comparing or comparison)).ab. 1536790

40 (open adj label).ti,ab. 59046

41 ((double or single or doubly or singly) adj (blind or blinded or blindly)).ti,ab. 151544 
42 double blind procedure/ 117639

43 parallel group\$1.ti,ab. 18719

44 (crossover or cross over).ti,ab. 69322

45 ((assign\$ or match or matched or allocation) adj5 (alternate or group $\$ 1$ or intervention $\$ 1$ or patient $\$ 1$ or subject $\$ 1$ or participant $\$ 1)$ ).ti,ab. 237683

46 (assigned or allocated).ti,ab. 278807

47 (controlled adj7 (study or design or trial)).ti,ab. 249300

48 (volunteer or volunteers).ti,ab. 166367

49 trial.ti. 202856

50 or/32-49 3326430

$512017^{\star}$. dc. 1500421

5231 and 50 and 51157

2 exp Pulmonary Embolism/ 53

3 (PE or DVT or VTE).ti,ab. 240

4 ((vein ${ }^{\star}$ or ven $\left.{ }^{\star}\right)$ adj thromb*).ti,ab. 305

5 (blood adj3 clot*).ti,ab. 34

6 (pulmonary adj3 clot ${ }^{\star}$ ).ti,ab. 0

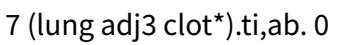

8 or/1-7 805

$9\left(\right.$ ven $^{\star}$ adj cav*).ti,ab. 47

10 Tempofilter.ti,ab. 0

11 VenaTech.ti,ab. 0

12 Bard near G2.ti,ab. 0

1 (Bard adj Recovery).ti,ab. 0

3 (Boston adj Greenfield).ti,ab. 0

14 "Birds Nest".ti,ab. 4

15 (Celect adj3 filter).ti,ab. 0

16 (Tulip adj3 filter).ti,ab. 0

17 OptEase.ti,ab. 0

18 TrapEase.ti,ab. 0

19 Mobin-Uddin.ti,ab. 0

20 ((option or ALN) adj3 filter).ti,ab. 1

21 Rex Medical Option.ti,ab. 0 
(Continued)

22 Simon near Nitinol.ti,ab. 0

23 IVC.ti,ab. 11

24 or/9-23 51

258 and 2417

26 "2017".af. 66

2724 and 260

\section{S39 S33 OR S34 OR S35 OR S36 OR S37 OR S38}

S38 TX randomly

S37 TX "treatment as usual"

S36 TX "double-blind*"

S35 TX "single-blind*"

S34 TX trial

S33 MH "Clinical Trials"

S32 EM 2017

S31 S12 AND S30 755

S30 S13 OR S14 OR S15 OR S16 OR S17 OR S 18 OR S19 OR S20 OR S21 OR S22 OR S23 OR S24 OR S25 OR S26 OR S27 OR S28 OR S29 2,731

\section{S29 Simon N1 Nitinol 1}

S28 Rex Medical Option 5

S27 Rex Medical Option 0

S26 ((option or ALN) N3 filter) 8

S25 Mobin-Uddin 0

S24 TrapEase 2

S23 OptEase 2

S22 Tulip N3 filter 5

S21 Celect N3 filter 1

S20 ("Birds Nest") 1

S19 Boston N1 Greenfield 1

S18 Bard N1 Recovery 9

S17 Bard N1 Recovery 0

S16 Bard N1 G2 8

S15 Tempofilter 0

S14 Tempofilter 0 
(Continued)

\author{
S13 ven* N1 cav $^{\star} 2,624$ \\ S12 S1 OR S2 OR S3 OR S4 OR S5 OR S6 OR S7 OR S8 OR S9 OR S10 OR S11 36,406 \\ S11 (lung N3 clot $\left.^{\star}\right) 11$ \\ S10 (pulmonary N3 clot*) 19 \\ S9 (blood N3 clot*) 694 \\ S8 ((vein* or ven*) N1 thromb*) 10,416 \\ S7 PE or DVT or VTE 4,855 \\ S6 (MH "Pulmonary Embolism") 4,572 \\ S5 thrombus* or thrombotic ${ }^{\star}$ or thrombolic ${ }^{\star}$ or thromboemboli* or thrombos* or \\ embol* 33,702 \\ S4 (MH "Venous Thrombosis+") 6,123 \\ S3 (MH "Venous Thromboembolism") 2,876 \\ S2 (MH "Thromboembolism") 3,164 \\ S1 (MH "Thrombosis") 4,466
}

ClinicalTrials.gov "pulmonary embolism" OR Thrombosis OR Thromboembolism OR embolism OR

"pulmonary embolism" OR Thrombosis OR Thromboembolism OR embolism OR

5 thrombus OR thrombotic | filter OR filters OR "Embolic Protection" | First posted

(www.clinicaltrialfrom $01 / 01 / 2016$ to $10 / 23 / 2017$ | Last update posted from $01 / 01 / 2016$ to $10 / 23 / 2017$

s.gov)

ICTRP

pulmonary embolism OR Thrombosis OR Thromboembolism OR embolism OR

thrombus OR thrombotic | filter OR filters OR Embolic Protection

Appendix 3. Database searches

\begin{tabular}{llll}
\hline Source & $\begin{array}{l}\text { Version/Plat- } \\
\text { form/url }\end{array}$ & Date of Search & $\begin{array}{l}\text { Records re- } \\
\text { trieved }\end{array}$ \\
\hline $\begin{array}{l}\text { Ovid MEDLINE(R) Epub Ahead of Print, In- } \\
\begin{array}{l}\text { Process \& Other Non-Indexed Citations, Ovid } \\
\text { MEDLINE(R) Daily and Ovid MEDLINE(R) 1946 }\end{array}\end{array}$ & (Ovid SP) & 23.10 .2017 & 43 \\
$\begin{array}{l}\text { to Present } \\
\text { Embase }\end{array}$ & (Ovid SP) & 14.11 .18 & 161 \\
1972- & & 10.9 .19 & 138 \\
& & 14.11 .18 & 157 \\
\hline AMED & (Ovid SP) & 23.10 .2017 & 441 \\
& & 14.11 .18 & 316 \\
\hline
\end{tabular}


(Continued)
10.9.19
0

\begin{tabular}{|c|c|c|c|}
\hline \multirow[t]{3}{*}{ CENTRAL } & CRSO & 23.10 .2017 & 41 \\
\hline & & 14.11 .18 & 37 \\
\hline & & 10.9.19 & 92 \\
\hline \multirow[t]{3}{*}{ CINAHL } & EBSCO & 23.10 .2017 & 15 \\
\hline & & 14.11 .18 & 22 \\
\hline & & 10.9.19 & 1 \\
\hline \multirow{3}{*}{$\begin{array}{l}\text { ClinicalTrials.gov } \\
\text { (www.clinicaltrials.gov) }\end{array}$} & & 23.10 .2017 & 5 \\
\hline & & 14.11 .18 & 6 \\
\hline & & 10.9.19 & 6 \\
\hline \multirow[t]{3}{*}{ ICTRP } & & 23.10 .2017 & 2 \\
\hline & & 14.11 .18 & 3 \\
\hline & & 10.9 .19 & 5 \\
\hline \multirow[t]{3}{*}{ Register } & & 23.10 .2017 & 0 \\
\hline & & 14.11 .18 & 3 \\
\hline & & 10.9.19 & 8 \\
\hline
\end{tabular}

\section{WHAT'S NEW}

\begin{tabular}{lll}
\hline Date & Event & Description \\
\hline 10 July 2020 & New search has been performed & $\begin{array}{l}\text { Searches re-run. Four new studies were included and seven new } \\
\text { studies excluded. We identified six new ongoing studies. }\end{array}$ \\
\hline 10 July 2020 & $\begin{array}{l}\text { New citation required but conclusions } \\
\text { have not changed }\end{array}$ & $\begin{array}{l}\text { Searches re-run. Four new studies were included and seven new } \\
\text { studies excluded. We identified six new ongoing studies. Review } \\
\text { text was updated and 'Summary of findings' tables added to re- } \\
\text { flect current Cochrane standards. Conclusions not changed. }\end{array}$ \\
\hline
\end{tabular}

\section{H I S T O R Y}

Protocol first published: Issue 4, 2006

Review first published: Issue 3, 2007

\begin{tabular}{lll}
\hline Date & Event & Description \\
\hline 22 October 2009 & $\begin{array}{l}\text { New citation required but conclusions } \\
\text { have not changed }\end{array}$ & John Aukes removed as author from the updated review. \\
\hline
\end{tabular}




\begin{tabular}{lll}
\hline Date & Event & Description \\
\hline 22 October 2009 & New search has been performed & $\begin{array}{l}\text { Searches updated and one additional RCT included. Conclusions } \\
\text { remain unchanged. }\end{array}$ \\
\hline 21 April 2008 & Amended & Converted to new review format. \\
\hline 9 November 2007 & New search has been performed & $\begin{array}{l}\text { One additional reference (conference abstract) added to the in- } \\
\text { cluded study (PREPIC). No change to conclusions. }\end{array}$ \\
\hline 22 August 2007 & $\begin{array}{l}\text { New citation required but conclusions } \\
\text { have not changed }\end{array}$ & Citation order revised on request of review author. \\
\hline
\end{tabular}

\section{CONTRIBUTIONS OF AUTHORS}

TY: wrote the protocol, review and update, searched for trials, contacted relevant biomedical companies and clinicians involved with filters, and obtained full-text articles, independently selected and assessed trials for inclusion and risk of bias, and assessed the certainty of the evidence using GRADE.

KBS: independently searched for trials, independently selected and assessed trials for inclusion and risk of bias, independently extracted data, and assisted in writing the review update.

\section{DECLARATIONS OF INTEREST}

TY: none known

KBS: none known

\section{SOURCES OF SUPPORT}

\section{Internal sources}

- No sources of support supplied

\section{External sources}

- Chief Scientist Office, Scottish Government Health Directorates, Scottish Government, UK

The editorial base of Cochrane Vascular is supported by the Chief Scientist Office.

\section{DIFFERENCES BETWEEN PROTOCOL AND REVIEW}

For the original review, each trial was evaluated for quality according to the Jadad scale (Jadad 1996). For this update, we used Cochrane's 'Risk of bias' tool and presented the results in a 'Summary of findings' table.

We have added 'major bleeding' as an outcome, as this is a clinically relevant potential adverse effect due to the use of anticoagulation in these patients more so than the presence, or absence, of a filter.

\section{INDEX TERMS}

\section{Medical Subject Headings (MeSH)}

Pulmonary Embolism [mortality] [ ${ }^{*}$ prevention \& control]; Randomized Controlled Trials as Topic; *Vena Cava Filters [adverse effects]; Vena Cava, Inferior; Venous Thrombosis [complications]

\section{MeSH check words}

Humans 